\title{
C. Iulius Caesar und Hyrkanus II. Überlegungen Zur Chronologischen AbFolge Der Dokumente Bei Flavius Josephus aNT. 14,10,2-10 (190-222) UND ANT. 14,8,5 (145-148) ${ }^{1}$
}

\author{
Andreas Zack
}

Heinrich-Heine-Universität Düsseldorf

\begin{abstract}
The key thesis of this essay is that, in the documentary excursus of the $14^{\text {th }}$ book, Josephus took the official titles of Caesar from the text of his sources. The titles of Caesar were perfectly understandable to the contemporaries of the original documents in respect of their chronological statement. If one approaches the texts of Josephus with this perspective, then the documents can be put into a chronological order that gives a conclusive historical and political sense. Only from the backward point of view of Josephus (and also of today reader) the titles of Caesar confusing. As a result, Josephus presented the documents in a chronological, confused order because he had the documents as a loose collection of deeds, and because he did not understand their datings. But this was negligible with regard to Josephus' apologetic intention, as he was concerned not with a historically accurate arrangement of the documents in their correct chronological order, but with proof that the Romans had in the past repeatedly granted the Jews special privileges. For this purpose, Josephus' chosen manner of presenting the documents was perfectly adequate. With this result, a further argument for the latest interpretation - elaborated by Miriam Pucci Ben Zeev (1998) - is now obtained, that Josephus' direct or indirect sources for the documents in the $14^{\text {th }}$ book of the antiquitates Iudaicae were authentic documents. A systematic overview of the reconstructed chronology and sequence of documents and the individual titles of Caesar 48-44 $\mathrm{BCE}$ can be found in the chronological table at the end of the article.
\end{abstract}

${ }^{1}$ Bei der folgenden Untersuchung handelt sich um ein weiteres Ergebnis eines Forschungsprojektes, das unter dem Titel „Die rechtlichen Grundlagen der römischen Außenbeziehungen und ihre historische Entwicklung (6.-1. Jh. v.Chr.)“ mit einer Sachbeihilfe von der Deutschen Forschungsgemeinschaft 02.2014 bis 02.2016 gefördert wurde (ZA808/1-1). Die Texte des Josephus erschienen dem Autor des Beitrages auf den ersten Blick als der am besten dokumentierte Fall der Vereinbarung einer amicitia et societas Roms mit einem fremden Gemeinwesen, deshalb wandte er sich ihnen zu. Es stellte sich zwangsläufig die Frage nach der chronologischen Abfolge der Texte, die im Folgenden erörtert wird. Zu Dank verpflichtet bin ich den Professoren Alexandru Avram, Bruno Bleckmann, Altay Cosskun, Martin Jehne, Jan Radicke und den Doktoren Mehran Nickbakht, Johannes Wienand und Linda Zollschan, die das Manuskript gelesen haben. Danken möchte ich ferner Mejra Reichert für die Korrekturlesung des Manuskriptes und Benjamin Nagel für die Hilfe bei der Besorgung der Sekundärliteratur. Die Thesen und alle möglichen Unzulänglichkeiten des Textes möge der Leser allein meiner Person zurechnen. Den Beitrag widme ich Katja Schmal (Bönen). 
Key words: C. Iulius Caesar, Hyrcanus II, Flavius Josephus, titles (dictator, imperator) of Caesar 49-44 v.Chr., Roman-Jewish relations in the times of Caesar, documents in the $14^{\text {th }}$ Book of the antiquitates Iudaicae of Flavius Josephus.

\section{Der Kontext, das Thema, die These und der methodische Ansatz}

Im zehnten Kapitel des vierzehnten Buches der Antiquitates Iudaicae unterbricht Flavius Josephus die fortlaufende Erzählung der jüdischen Geschichte in der Zeit C. Iulius Caesars und legt einen Exkurs ein, in dem er Dokumente teils wörtlich zitiert, teils in einem Referat wiedergibt, wobei er an den Wortlaut der referierten Dokumente anknüpft. $^{2}$ Es sind dies senatus consulta aus der Zeit Caesars und Edikte Caesars (Josephus, ant. 14,10,2-10 (190-222)), Edikte römischer Statthalter und deren Reskripte auf Wünsche und Forderungen der Juden (Josephus, ant. 14,10,11-21 (223-246)) ${ }^{3}$ sowie Beschlüsse griechischer Städte des Imperium Romanum in Hinsicht auf die dort ansässigen Juden (Josephus, ant. 14,10,22-25 (247-264)). ${ }^{4}$ Die senatus consulta aus der Zeit Caesars und die Edikte Caesars (Josephus, ant. 14,10,2-10 (190-222)) bieten den in der antiken Überlieferung überaus seltenen Fall einer über einen längeren Zeitraum (49-44 v.Chr.) sich erstreckenden zusammenhängenden „urkundlichen“ Dokumentation eines diplomatischen Kontaktes Roms mit einem Gemeinwesen der Außenwelt. An ihrem Beispiel lässt sich das Wechselspiel der militärtaktischen und politischen Außenaktivitäten Caesars mit den Gegenheiten der rechtlichen und politischen Ordnung des römischen Gemeinwesens unter den Bedingungen des Bürgerkrieges für die Jahre 49 bis 44 v.Chr. im Detail beobachten. Voraussetzung einer solchen Betrachtung ist aber die Rekonstruktion der Chronologie der Dokumente, die Josephus in einer heilosen Verwirrung präsentiert. Dieses viel besprochene Problem einer neuen Lösung zuzuführen ist das Anliegen des folgenden Beitrags.

${ }^{2}$ Es gibt noch weitere Dokumentenexkurse in den Antiquitates Iudaicae des Josephus, womit das $\mathrm{Zu}-$ rückgreifen auf Dokumente als ein charakteristisches Mittel seiner Darstellungskunst fassbar wird: 1) Josephus, ant. 14,12,2-13 (301-323): Dokumente der Zeit von 42-37 v.Chr. 2) Josephus, ant. 16,6,1-7,1 (160178): Dokumente der Zeit von 31 v.Chr. 2/3 n.Chr. 3) Josephus, ant. 19,5,2-3 (280-291): Edikt des Claudius aus dem Jahr 41 n.Chr. 4) Josephus, ant. 19,6,3 (303-311): Dokument aus dem Jahr 41/42 n.Chr.). Vgl. weiterhin die vollständige Liste aller Dokumentenzitate bei Josephus in Hinsicht auf das römisch-jüdische Verhältnis bei Juster 1914, 158-159, A. 1.

3 Josephus, ant. 14,10,14 (231-232) ist ein Psephisma aus Delos, das auf ein Edikt des Statthalters L. Cornelius Lentulus Bezug nimmt, und Josephus, ant. 14,10,20 (241-243) ist eine Empfangsbescheinigung und Antwort des Archonten von Laodikeia auf ein Edikt des Statthalters C. Rabilius, so dass diese Dokumente von Josephus wegen ihres Kontextes in den Abschnitt der Edikte römischer Statthalter aufgenommen wurden; vgl. Judeich 1885, 121.

${ }^{4}$ In dieser Reihenfolge. Dieses Anordnungsprinzip für den Exkurs formuliert Josephus an dessen Ende (Josephus, ant. 14,10,26 (265)), so dass es als das von Josephus intendierte Ordnungsschema für die Anordnung der Dokumente gelten darf, wobei in der Reihenfolge der Dokumentenanordnung aber die Beschlüsse der Städte den Platz mit den Edikten römischer Statthalter wechselten; vgl. Judeich 1885, 120-121 und Täubler 1913, 161. 
Am Anfang des Exkurses erläutert Josephus, mit welcher Absicht er den Exkurs in die Schilderung der Ereignisse einlegt. ${ }^{5}$

Josephus, ant. 14,10,1 (186-189): [186] Ich habe es nun für notwendig gehalten, hier einmal alle Ehrenbezeugungen, die unserem Volke von den Römern und deren Imperatoren erwiesen worden sind, sowie die Bündnisse aufzuzählen, damit es allgemein bekannt werde, dass die Herrscher in Asien und Europa aus Achtung vor unserer Tapferkeit und Treue uns ausgezeichnet haben. Denn viele wollen aus Abneigung gegen uns das nicht glauben, [187] was die Perser und Makedonier über uns geschrieben haben, weil die Werke dieser Geschichtsschreiber nicht überall zu haben sind und an den öffentlichen Orten (i.e. Archiven) sich nicht vorfinden, sondern nur bei uns und einigen wenigen fremden Völkern aufbewahrt werden. [188] Doch wagen sie nichts gegen die Beschlüsse der Römer einzuwenden. Denn diese sind sowohl an den öffentlichen Orten der Städte (i.e. Archive) und auf dem Kapitol niedergelegt, als auch jetzt noch auf bronzenen Tafeln eingraviert. So hat zum Beispiel Iulius Caesar die zu Alexandria wohnenden Juden durch eine auf einer bronzenen Tafel eingravierte Inschrift öffentlich für alexandrinische Bürger erklärt. [189] Aus diesen Quellen will ich also den Beweis führen und die Beschlüsse des Senates sowie des Iulius Caesar, die sich auf Hyrkanus und unser Volk beziehen, beifügen. (Die Übersetzung in Anlehnung an diejenige von Heinrich Clementz). ${ }^{6}$

Die schriftstellerische Absicht des Josephus ist demnach nicht narrativer, sondern apologetischer Natur. Er will nicht historische Ereignisse anhand von Dokumenten darstellen, sondern es geht ihm mit dem Exkurs um eine Verteidigung des jüdischen Volkes gegenüber denjenigen unter seinen Zeitgenossen, die wegen ihrer Feindseligkeit

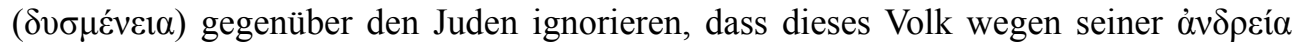

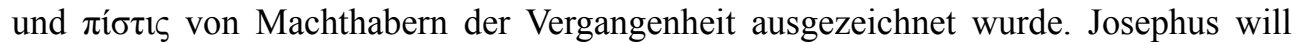
die Glaubwürdigkeit seiner Darstellung mit dem Hinweis unterstreichen, dass jeder die Richtigkeit der von ihm wiedergegebenen Beweismittel anhand von Urkunden, die in den Stadtarchiven der griechischen und jüdischen Regionen des Imperium Romanum aufbewahrt sind und auch in der Hauptstadt Rom - frei zugänglich - veröffentlicht sind, selbst überprüfen könne.

${ }^{5}$ Zu den Intentionen des Josephus, vgl. Pucci Ben Zeev 1998, 2-6; Schuol 2007, 67-68. (mit weiterer Literatur) und zum Aussagewert der Dokumente bzgl. der römisch-jüdischen Beziehungen im Imperium Romanum: Pucci Ben Zeev 1998, 2-5; Rajak 1978, 19-35; 2001, 301-332.

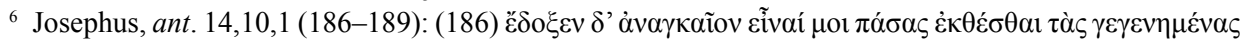

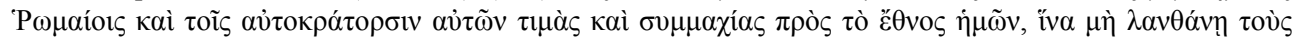

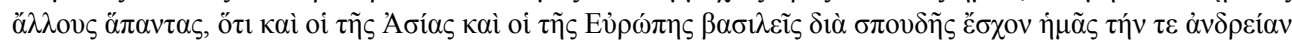

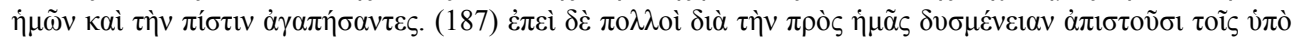

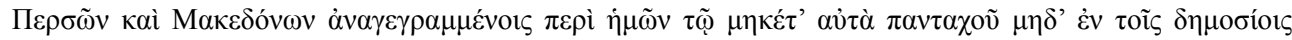

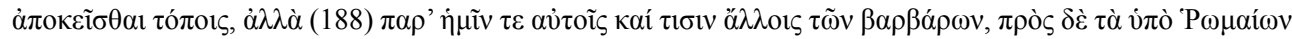

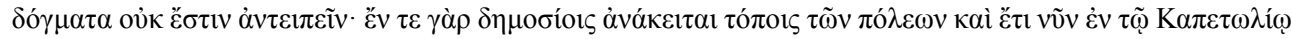

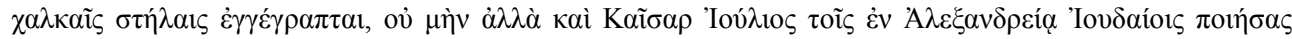

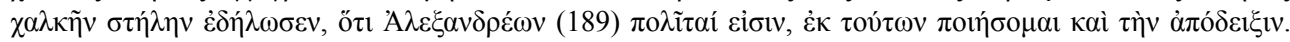

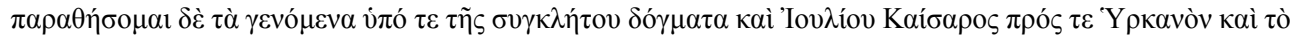

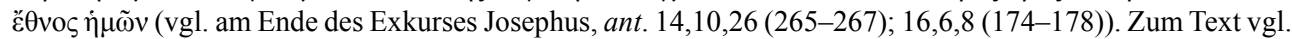
den Kommentar bei Pucci Ben Zeev 1998, 25-31. 
Mit den im Folgenden von Josephus zitierten bzw. referierten Schriftsücken verbinden sich für den modernen Interpreten zahlreiche Fragen: ${ }^{7}$ Was waren die Vorlagen des Josephus für den Exkurs und woher bezog er sie? Können die Texte des Josephus als Wiedergabe authentischer Dokumente gelten und sind sie also als historische Quellen verwertbar oder sind sie mit Absicht angefertigte Fälschungen? Mit der zuletzt genannten Frage ist unmittelbar eine andere Frage verbunden: Wie ist die absolute Chronologie und die relative chronologische Abfolge der Dokumentenzitate bzw. Dokumentenreferate zu rekonstruieren? Denn ließe sich eine historisch-politisch sinnvolle Abfolge der Dokumente erweisen, wäre dies zugleich zumindest ein Indiz für deren Authentizität.

Die folgende Abhandlung hat die zuletzt genannte Fragestellung im Augenmerk. Es soll die absolute und relative Chronologie und der historisch-politische Zusammenhang der mit der Person Caesars verbundenen Zitate bzw. Referate rekonstruiert werden, die am Anfang des Exkurses stehen (Josephus, ant. 14,10,2-10 (190-222) und außerdem ant. 14,8,5 (145-148)). ${ }^{8}$

Die Kernthese dieses Aufsatzes ist, dass Josephus die in den Dokumenten bzw. Dokumentenreferaten begegnenden Titulaturen Caesars dem Text seiner Vorlagen entnahm und dass diese Titulaturen Caesars für die Adressaten der ursprünglichen Schriftstücke in ihrer chronologischen Aussage verständlich waren. ${ }^{9}$ Mit dieser These bricht der Autor dieses Beitrages mit sämtlichen Interpretationen seit Johann Tobias Krebs (1718-1782), die stets annahmen, dass der Text der Handschriften in den entsprechenden Partien verderbt sei und deshalb konjiziert werden müsse. ${ }^{10}$ Nähert man sich den Texten aber mit

${ }^{7} \mathrm{Zu}$ den Fragen der Glaubwürdigkeit des Josephus, der Authentizität der von ihm dargebotenen Dokumente, der Herkunft der Vorlagen für die Dokumentenexkurse, vgl. den Überblick über die aktuelle Forschungsmeinung bei Freber 1993, 52-54, 62-63; Schuol 2007, 66-75 (mit weiterer Literatur) und ausführlicher Pucci Ben Zeev 1998, 6-10 (Authentizität), 388-408 (Quellen des Josephus, mit ausführlichem Referat der diesbezüglichen Forschungsmeinungen).

${ }^{8}$ Eine nützliche Übersicht über die wichtigen älteren Rekonstruktionen der Chronologie und Urkundenausfertigung der hier zu besprechenden Dokumente (Mendelssohn/Niese) bietet Täubler 1913, 167-169 und vgl. weiterhin Juster 1914, 132-159; Freber 1993, 56-63 (mit den Anmerkungen) und vgl. den neueren Kommentar von Pucci Ben Zeev 1998, passim zu den einzelnen Dokumenten, jeweils mit umfangreichen Angaben zu der älteren Literatur.

${ }^{9}$ Im Folgenden wird begrifflich zwischen „Dokument“ und „Dokumentenreferat“" unterschieden. Der Begriff „Dokument“ benennt das orginale Schriftstück bzw. dessen wortgetreue Abschrift. Der Begriff „Dokumentenreferat" benennt dagegen die zusammenfassende Wiedergabe des Textes des orginalen Dokumentes, wobei aber die Diktion des zugrunde liegenden Orginaltextes im Text des Referates einen Niederschlag finden konnte (= stichpunktartige Wiedergabe des Orginaltextes mit wörtlichen Zitaten).

${ }^{10}$ Freber 1993, 52 spricht beispielsweise von „Unzulänglichkeiten in den Titulaturangaben Caesars“ und von der offensichtlichen „Korruptheit der Texte“ im Dokumentenexkurs des Josephus. Die Konjekturen

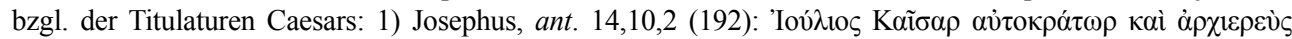

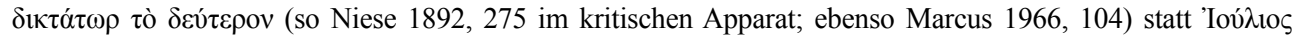

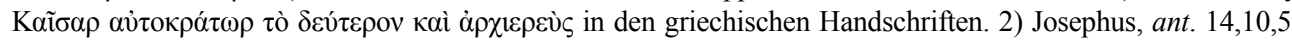

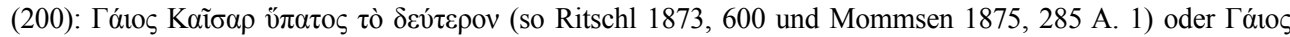

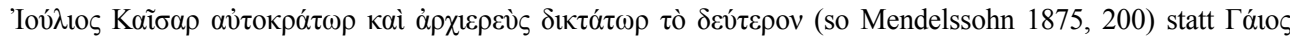

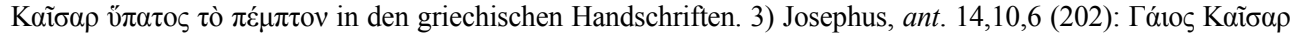

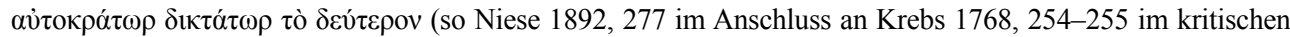

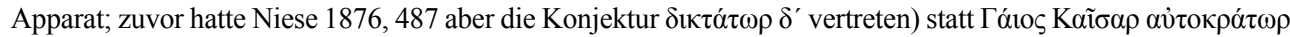

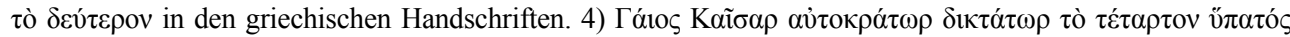

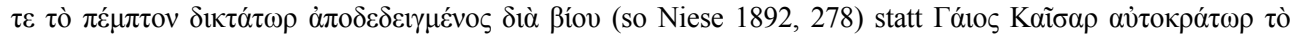

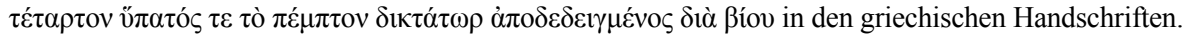


der hier eingenommenen Perspektive, dann können die Dokumente in eine chronologische Reihenfolge gebracht werden, die einen schlüssigen historischen und politischen Sinn ergeben. Erst aus der rückwärtigen Sicht des Josephus (und auch der des heutigen Interpreten) waren die Titulaturen bzw. Datierungen seiner Vorlagen verwirrend. Dies führte dazu, dass Josephus die Texte, weil er die Dokumente - quasi als lose Blattsammlung - ungeordnet vorliegen hatte und weil er die Datierungen seiner Vorlagen nicht verstand, in einer heillosen chronologischen Verwirrung präsentierte. ${ }^{11}$ Dies war aber in Hinsicht auf die apologetische Darstellungsabsicht des Josephus ein zu vernachlässigender Aspekt, da es ihm hier nicht um eine historisch exakte Anordnung der Dokumente in ihrer korrekten Reihenfolge ging, sondern vornehmlich um den Nachweis, dass die Römer in der Vergangenheit die Juden mehrfach mit besonderen Privilegien ausgezeichnet hatten. Für diesen Zweck war die von ihm gewählte Art der Präsentation der Dokumente vollkommen ausreichend.

Mit der Kernthese dieser Abhandlung ist nun zugleich ein neues Indiz für die zuletzt von Miriam Pucci Ben Zeev (1998) ausführlich entwickelte Deutung gewonnen, dass die mittel- oder unmittelbaren Vorlagen des Josephus auch für den Teil der mit Caesar verbundenen Dokumente authentische Aktenstücke waren. ${ }^{12}$ Denn die Texte wurden in Hinsicht auf die Titulaturen Caesars ausschließlich im Kontext ihrer Abfassungszeit geschrieben und genügten in späterer Zeit nicht mehr den Erfordernissen einer eindeutigen Zeitbestimmung, weshalb sie Josephus aus historischer Unkenntnis in der falschen Abfolge präsentierte. Darin erkennt der Autor dieses Beitrages nun ein gewichtiges Indiz für die historische Authentizität der von Josephus im Zusammenhang mit Caesar zitierten und referierten Schriftstücke.

Am Ende des Aufsatzes und vor dem Literaturverzeichnis findet der Leser zur schnellen Orientierung eine tabellarische Übersicht über die im Folgenden rekonstruierte chronologische Abfolge der Dokumente.

${ }^{11}$ Pucci Ben Zeev 1995, 211-215, 215 [Fazit] führt den Nachweis, dass die Behauptung des Josephus, die Dokumente könnten auch auf Publikationen auf Bronzetafeln in Rom und in den Städten des Ostens des Imperium Romanum nachgelesen werden (Josephus, ant. 14,188; 14,266 und 12,416; 14,96-198; b. Jud. 6,106-110), sich mit der in den Inschriften dokumentierten Praxis gut verbinden lässt. Dies bedeutet aber nicht, dass Josephus die Dokumente auch mittels eigener Autopsie der Bronzetafeln gelesen und exzerpiert hätte (so auch Pucci Ben Zeev 1996a, 21-30, 30 [Fazit]), denn er zitiert offensichtlich auch solche Dokumente, die weder in Rom noch im Osten des Imperium Romanum öffentlich publiziert waren. Josephus selbst hatte bei der Abfassung seines Dokumentenexkurses m.E. in ungeordneter Reihenfolge - quasi als lose Blattsammlung - griechische und lateinische Abschriften und/oder Referate der Dokumente unterschiedlicher Herkunft zur Hand und ordnete diese thematisch, wobei er in Hinsicht auf die chronologische Abfolge der Dokumente - an der er nur am Rande interessiert war - oft danebengegriffen hat. Besonders auffällig ist das Dokument Josephus, ant. 14,10,8 (213-216), das er unter die Dokumente aus der Zeit Caesars einordnet, obwohl es wohl in die Zeit nach dessen Ermordung gehört und ein Dokument des C. Iulius Caesar [Octavianus] ist, vgl. das

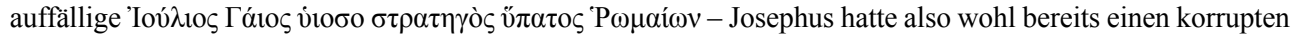
griechischen Text vorliegen und wusste mit dem v́ıбo [ein Überbleibsel von Gaii Iulii Caesaris filius] nichts anzufangen und verband ihn deshalb wegen des 'Iov́ $\lambda$ ıo den Kommentar und die Besprechung des Dokumentes bei Pucci Ben Zeev 1998, 107-118.

${ }_{12} \mathrm{Zu}$ der an den Aufsatz von H.R. Moehring (1975, 133-157; vgl. auch Baumann 1983, 69-87) von neuem sich anschließenden Diskussion über die Authentizität der bei Josephus zitierten Dokumente, vgl. die Literaturangaben bei Freber 1993, 52-54; Pucci Ben Zeev 1994a, 31 A. 2; 1995, 211 A. 2 und 1998, 6-10. Die Auseinandersetzung mit den Dokumenten des Josephus vom 15. bis zum 19. Jh. skizziert Bickermann $1955,11-15$. 


\title{
Die Rekonstruktion der chronologischen Abfolge der von Flavius Josephus referierten und ganz oder teilweise zitierten Dokumente ${ }^{13}$
}

\author{
Die Texte des Josephus werden im Folgenden in der Reihenfolge präsentiert und bespro- \\ chen, die der Autor des Beitrages als historische Abfolge der Texte vorschlagen möchte. \\ Am Anfang steht ein Dokumentenreferat, das Josephus als zweiten Text seines Exkurses \\ präsentiert.
}

Josephus, ant. 14,10,3 (196-198): [196] Die Verordnungen, Zugeständnisse und Beschlüsse [i.e. des Senates] zur Zeit des Imperator und Konsuln Gaius Caesar beinhalten folgendes: dass seine [i.e. des Hyrkanus II.] Kinder über die Juden herrschen sollen und [dass sie] den Nießbrauch an den ihnen gegebenen Orten haben sollen und dass der Hohepriester selbst und Ethnarch sich der Unrechtleidenden unter den Juden annehmen soll. [197] An des Alexanders Sohn Hyrkanus, den Hohepriester der Juden, soll man Gesandte schicken, die mit ihm über die amicitia et societas [mit dem Volk und Senat Roms] verhandeln werden. Bronzene Tafeln, die dies beinhalten, sollen auf dem Kapitol und in Tyrus und in Sidon und in Askalon (und) in Tempeln aufgestellt werden und in lateinischer und griechischer Ausfertigung graviert werden. [198] Dass weiterhin dafür Sorge zu tragen ist, dass dieses senatus consultum an die städtischen Schatzmeister und politischen Führer der einzelnen Städte [übersandt werde und auch] an unsere Freunde gelange ${ }^{14}$ damit den Gesandten die [übliche] gastliche Aufnahme zuteil werde und dass die [diesbezüglichen] edicta überall bekannt gemacht werden." (die Übersetzung in Anlehnung an diejenige von Heinrich Clementz). ${ }^{15}$

13 Die Datumsangaben (z.B. Schlacht bei Pharsalos 02.08.48 v.Chr.) in diesem Beitrag sind bis zum Jahr 45 v.Chr. stets solche des vorjulianischen Kalenders. Diese Darstellungsweise ist sinnvoll erstens, weil die Umrechnungsregeln vorjulianischer Datumsangaben in solche des julianischen Kalenders umstritten sind, und zweitens, weil die Quellen selbst bei den Datumsangaben für die Zeit vor 45 v.Chr. stets die vorjulianischen Daten angeben (vgl. Judeich 1885, 51-55 und Heinen 1966, 4 A. 3). Die absolute und relative Chronologie wird mit dieser Vorgehensweise also eindeutig wiedergeben, zumal der konkrete Bezugsrahmen etwa für die Amtszeiten der Konsuln in den Jahren 48 bis 45 v.Chr. der vorjulianische Kalender war.

${ }^{14}$ Gelegentlich werden die letzten zwei Anordnungen des senatus consultum in der Sache mit der Abfertigung einer jüdischen Gesandtschaft in Rom in Verbindung gebracht, wobei der Senatsbeschluss anordnete, dass den jüdischen Gesandten $\xi \xi \dot{v} v 1 \alpha$ gegeben werden und sie in die formula amicorum eingetragen werden sollen (z.B. in neuerer Zeit Baumann 1983, 99; Ward - Eilers 2012, 416 und zuvor bereits Roth 1914, 59-60). Eine solche Interpretation macht einen Eingriff in den Text notwendig. Eine solche Deutung ist offensichtlich vom Willen getragen, den Senatsbeschluss mit der bei Josephus, ant. 14,10,1 (185) erwähnten Gesandtschaft des Hyrkanus II. zu verbinden. Der Text, wie er überliefert ist, besagt lediglich, dass den abzusendenden

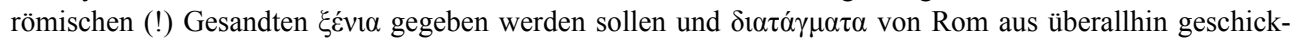
te werden sollen. Das kann auch so verstanden werden, dass den römischen Gesandten vor der Reise von Organen des römischen Gemeinwesens (wohl die Quästoren) die für die Gesandtschaftsreise notwendigen Utensilien, wie es in der politischen Praxis üblich war, bereitgestellt werden sollen (vgl. Premerstein 1925, 1134). Weiterhin ist eine gastliche Bewirtung römischer Gesandte durch fremde Gemeinwesen zwar m.W. in den Inschriften nicht belegt, aber zumindest im Zusammenhang der legatio libera ist in der literarischen Überlieferung nachgewiesen, dass Senatoren, die sich im Rahmen einer solchen legatio libera bei fremden Gemeinwesen aufhielten, gewöhnlich von Freunden Roms gastlich bewirtet wurden (vgl. z.B. Cicero, Verr . 2,4,11,25). Deshalb kann sich der Hinweis im Text auf die Freunde und die gastliche Bewirtung der römischen Gesandten im Referat des von Josephus referierten senatus consultum auch auf diesen Kontext beziehen. Der Wortlaut bei Josephus ist demnach auch ohne Eingriffe in den Text verständlich und fügt sich in die bekannte politische Praxis Roms.

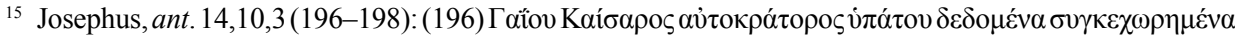

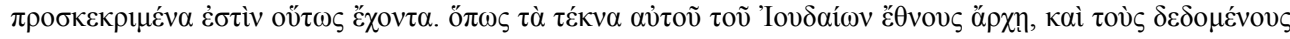

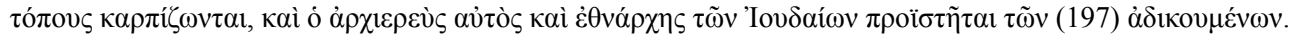


Die gedrängte Ausdrucksweise des Josephus gibt zu erkennen, dass es sich bei dem Text nicht um die wörtliche Wiedergabe einer Urkunde handelt, sondern um eine den Wortlaut der Vorlage aufnehmende, sprachlich unebene und stichpunktartige Inhaltswiedergabe des zugrunde liegenden Dokumentes. ${ }^{16}$ Dieser sprachlichen Charakteristik entspricht ebenso der Wortlaut, mit dem Josephus das Referat einleitet: Гaiiov Kaí $\alpha \rho \rho \varsigma$

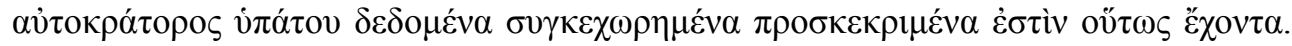

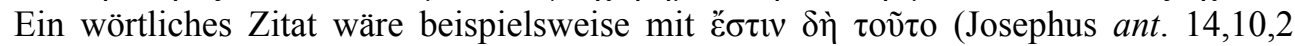
[192]) oder $\tilde{\eta} v ~ \delta \grave{\varepsilon} \tau$ coเoṽov (Josephus ant. 14,10,9 [218]) eingeleitet worden. Es trifft daher nicht den Sachverhalt, wenn man die einleitenden Worte des Josephus vom frag-

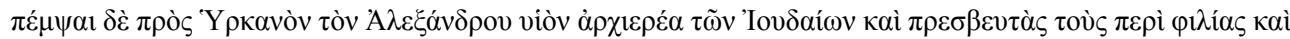

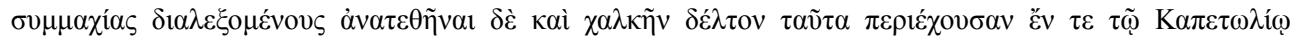

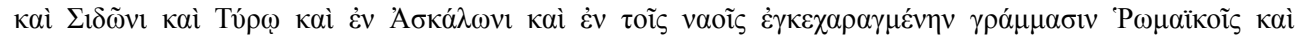

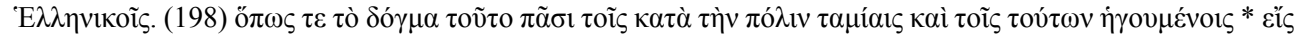

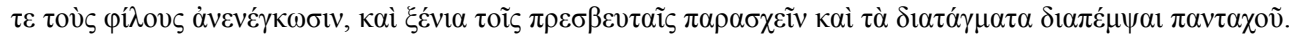
Der griechische Text nach der Ausgabe von Benedikt Niese im Jahr 1892. In der Edition des Josephus von Siwart

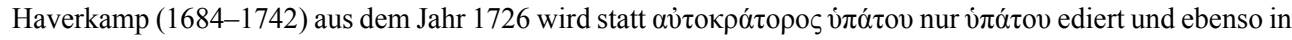
der griechisch-lateinischen Ausgabe von Karl Wilhelm Dindorf(1802-1883) aus dem Jahr 1865. Mendelssohn

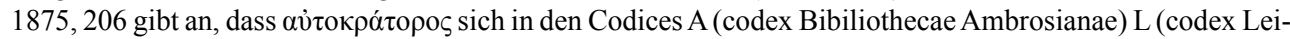
densis) F (codex Laurentianus) P (codex Palatinus) findet, weshalb Niese auch ả̉ hat. Der interpres Latinus (= Lateinische Übersetzung des Josephus Textes) gibt dagegen dictatoris, was wohl illustriert, dass man sich bereits im Mittelalter über den Text Gedanken machte und ihn irritiert durch seinen Ort im Dokumentenexkurs des Josephus (nach einem Dokument in dem Caesar als imperator pontifex maximus dictator II benannt wird) in seiner chronologischen Implikation nicht verstand und den Text deshalb ändern wollte; vgl. im Zusammenhang der Interpretationsarbeit am Text des Josephus in der Zeit der Aufklärung weiterhin auch die phantasievolle Textherstellung im Jahr 1768 bei Johann Tobias Krebs (1718-1782) 1768, 226-232. Zum Text und mit den bibliographischen Angaben zu der älteren Literatur, vgl. den Kommentar und die Interpretation des Wortlautes bei Pucci Ben Zeev 1996b, 77-79; 1996c, 199-201; 1998, 54-67; Freber 1993, 57 A. 289 (die differierenden Deutungen in der älteren Forschung) und von den älteren Beiträgen insbes. Momigliano 1934/1967, 15 [197-198], 19 [201] und Juster 1914, 138-139. Seit Pucci Ben Zeev, vgl. insbesondere noch Ward - Eilers 2012, 414-427, die im Text des Josephus Fragmente eines Senatsbeschlusses aus dem Jahr $44 \mathrm{v}$.Chr. erkennen möchten (dies war mit anderen Argumenten bereits die Meinung von Niese 1876, 486-487 und vgl. auch die Rekonstruktion von Täubler 1913, 169, 171-175, die der von Ward - Eilers im Grundgedanken verwandt ist) und Seeman 2013, 325, der das Dokument nach dem Vorbild der älteren Forschung zumindest in die Zeit nach dem Brief Caesars an die Sidonier (Josephus, ant. 14,10,2 (190-195)) datiert, was nach der herrschenden Meinung [dazu weiter unten im Text] auf das Ende des Jahres 47 v.Chr. (dies war die Meinung von Judeich 1885, 138-139) oder in das Jahr 46 v.Chr. (dies war die Meinung von Mendelssohn 1875, 205-211; Saulnier 1981, 172, 196) oder in das Jahr 44 v.Chr. (dies war die Meinung Nieses 1876, 486-487) führt. Zu der Frage, was unter dem Titel des Ethnarchen zu verstehen ist, vgl. nun Eckhardt 2013, 351-356 (der Titel hat nur Judäa zum gedanklichen Objekt und beinhaltet keineswegs eine Zuständigkeit des Hyrkanus II. in Hinsicht auf alle Juden im Imperium Romanum, wie es in Anlehnung an die Deutung von Adolf Büchler (1896, 96-98) in der älteren Forschungsliteratur als Interpretation vertreten wurde. Diese ältere Deutung wird aber von Sharon 2010, 482-483 vertreten (mit weiterer Literatur)).

${ }^{16}$ Roth 1914, 56 spricht vom durchaus fragmentarischen Charakter des Textes, der syntaktische Unebenheiten aufweist. Pucci Ben Zeev 1998, 62-63 spricht in Hinsicht auf den Text von einem „document“ und denkt dabei wohl an fragmentarische wörtliche Zitate des Josephus (oder seiner Quelle) aus dem zugrunde liegenden „document.“ Die stakkatorartige Aneinanderreihung der Beschlussinhalte im Text des Josephus legt den Gedanken nahe, dass ein ursprünglich ausführlicherer Text von Josephus (oder seiner Quelle) lediglich auf die wesentlichen Beschlussinhalte reduziert wird, wobei einzelne Merkmale in der Diktion (ö $\pi \omega \varsigma$... ö $\pi \omega \varsigma$ ) der Textvorlage durchaus einen Niederschlag im Text des Referates gefunden haben können (beachte

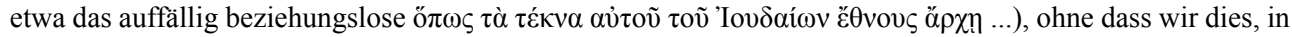
Ermangelung der Orginalurkunde, im Detail verifizieren können. 
mentarischen Text des vermeintlichen Orginaldokuments trennt. ${ }^{17}$ Vielmehr bildet der Text eine Einheit und ist ein Dokumentenreferat und kein Dokument. Deshalb ist die Ti-

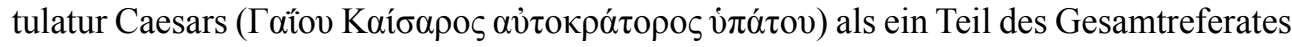
einzuschätzen, in dem das der Inhaltsangabe zugrunde liegende Dokument von Josephus zeitlich eingeordnet wird. ${ }^{18}$

Bei dem Dokument handelt es sich um einen Senatsbeschluss, ${ }^{19}$ wie aus der Benennung des Schriftsücks als $\delta$ ó $\gamma \mu \alpha$ sowie aus den spezifischen Inhalten des Textes erkennbar ist. ${ }^{20}$ Die Bezugnahme auf $\delta 1 \alpha \tau \alpha ́ \gamma \mu \alpha \tau \alpha$ (=edicta/formulae) am Ende des Referates ${ }^{21}$ die (von einem römischen Magistraten) überall hin geschickt werden sollen, zeigt, dass in dem Senatsbeschluss ausdrücklich vorgesehen ist, seine Inhalte teilweise oder insgesamt (von einem Magistrat Roms) mit mehreren Edikten an verschiedene Adressaten allgemein bekannt zu machen. ${ }^{22}$ Es wird im senatus consultum weiterhin angeordnet, am Ende Bronzetafeln des Senatsbeschlusses selbst auf dem Kapitol in Rom und in Tempeln in Sidon, Tyros und Ascalon zu publizieren, wobei die Exemplare von Sidon, Tyros und Ascalon bilingual (griechisch und lateinisch) sein sollen. ${ }^{23}$

17 So z.B. Pucci Ben Zeev 1998, 54-55 (mit dem Literaturnachweisen der unterschiedlichen älteren Deutungen); Ward - Eilers 2012, 415, 416-417 und vgl. auch Roth 1914, 55: „Die ganz allgemein gehaltene Überschrift wird man bei der Untersuchung außer acht lassen müssen, da sie von der exzerpierenden Hand des Josephus stammen kann“, ebenso bereits Judeich 1885, 125-126. Seeman 2013, 325-326 zitiert in seiner Darstellung das „Document 2“ ganz ohne die einleitenden Worte des Josephus und gibt so implizit zu verstehen, dass er sie als spätere Zutat ohne Wert für die historische Auswertung des Textes einschätzt.

18 Wichtig für die Bewertung der Überlieferung bei Josephus in Hinsicht auf ihre Herkunft ist der Hinweis von Ward - Eilers 2012, 416-417, dass die Diktion in der Einleitung des Dokumentenreferates eine lateinische Vorlage in der Diktion mechanisch übersetzt (data, concessa, adiuncta sunt). Josephus (oder seiner Quelle) lag in diesem Fall also bereits eine lateinische Zusammenfassung (!) des senatus consultum vor, die er (oder seine Quelle) nur noch wörtlich ins griechische übersetzte.

19 Mason 1974, 39 für $\delta o ́ \gamma \mu \alpha=$ senatus consultum, ebenso z.B. Pucci Ben Zeev 1998, 60-61, 62. Mit dem Begriff $\delta o ́ \gamma \mu \alpha$ kann auch ein edictum benannt werden (Mason 1974, 39); aber im Fall des referierten Textes bei Josephus handelt es sich um Beschlussgegenstände, die nach der Inschriftendokumentation Gegenstände von Senatsverhandlungen waren (die Anordnung der Aushandlung der amicitia et societas, die Publikationsanordnung und insbesondere die Anordnung von edicta zur Bekanntmachung der Inhalte des senatus consultum, vgl. beispielsweise den Senatsbeschluss über die Bacchanalen: ILS 18, Z. 2-3).

20 Diese Deutung des Textes z.B. auch bei: Roth 1914, 56 mit A. 1; Pucci Ben Zeev 1998, 62; Ward Eilers 2012, 415; Seeman 2013, 325.

${ }^{21}$ Vgl. Mason 1974, 36, 126-131, insbes. 127. Ausdrücklich bei Plutarch, Marc. 24; P.Oxy. 9, 1201 Z. 11

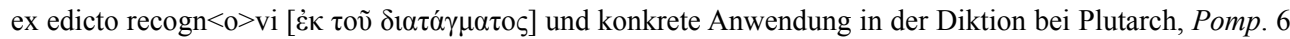
(vgl. die weiteren Belege Sherk 1969, 195 und bei H. Stephanus, Thesaurus Graecae Linguae 3 [1835] 1338

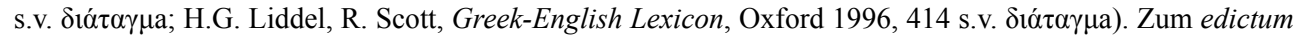
als Bezeichnung magistratischer Dokumente mit öffentlichem und verbindlichem Rechtsinhalt, vgl. die reichen Quellennachweise bei O. Hey, in: Thesaurus Linguae Latinae 6, 63-74, insb. 64-66, 68-71 s.v. edico/ edictum. Zum magistratischen edictum als einer der mit Dokumenten verbundenen Rechtsquellen neben der lex, dem senatus consultum, dem foedus und der pactio, vgl. beispielsweise: Cicero, Caec. 51 (weitere Quellen bei O. Hey, in: Thesaurus Linguae Latinae 6, 69: s.v. edico/edictum).

22 Parallelen zu dieser Praxis Roms in der Inschriftendokumentation bei Pucci Ben Zeev 1998, 59-60. Eine Parallele bietet etwa auch das senatus consultum bzgl. Stratonikeia, in dem angeordnet wird, dass seine Inhalte zumindest zum Teil in Briefen den betroffenen Gemeinwesen bekannt gemacht werden sollen (Sherk 1969, Nr. 18 Z. 107-109).

${ }^{23}$ Diese Anordnung verbindet sich mit der üblichen Praxis Roms, wie sie in den Inschriften und auch in der literarischen Überlieferung begegnet, vgl. Pucci Ben Zeev 1995, 211-215 mit den Nachweisen der Paral- 
Einem Teil der älteren Forschung folgend, vermutet Miriam Pucci Ben Zeev (1998), dass das Referat des Josephus einen Senatsbeschluss aus dem Jahre 47 v.Chr. wiedergibt. ${ }^{24}$ Josephus bzw. seine Quelle fassen demnach einen Beschluss zusammen, den die von Hyrkanus II. nach Rom geschickte Gesandtschaft (Josephus, ant. 14,10,1 (185-186)) unter Vorsitz Caesars vom Senat erhielt, als Caesar nach der Schlacht bei Zela (02.08.47) sich kurzfristig im Rom aufhielt, bevor er sich auf den Kriegszug nach Afrika begab.

Josephus, ant. 14,10,1 [185]: „Caesar hatte sich nach Rom begeben und er bereitete sich vor, [von Italien] nach Afrika überzusetzen, wo er Scipio und Cato bekriegen wollte, als Hyrkanus zu ihm schickte und ihn um Bestätigung der amicitia et societas bitten ließ.“25

Dieser Deutung stehen allerdings einige Einwände entgegen: Erstens, dass Caesar

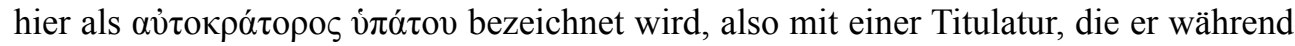
des Bürgerkrieges nur im Jahr 48 v.Chr. führte. ${ }^{26}$ Denn im Jahr 47 v.Chr. war Caesar nur dictator, aber nicht consul. In den Jahren 46, 45 und 44 v.Chr. war er zugleich consul und dictator. ${ }^{27}$ Zweitens ist eine solche Senatssitzung unter Vorsitz Caesars im Jahr 47 v.Chr. nicht überliefert, sondern Josephus, ant. 14,8,5 (145-148) berichtet vielmehr für das

lelen (vgl. auch Avram 2009, 211-232 mit dem Vorschlag zwischen der Publikation [die bronzene Tafel] und publizistischen Ausfertigungen [z.B. Kopien auf Marmorstelen] zu unterscheiden).

${ }^{24}$ Pucci Ben Zeev 1998, 63 (erwogener Deutungsvorschlag), 66-67 (schließlich vertretene Deutung); vgl. in neuerer Zeit Seeman 2013, 325-326, der, ohne sich genau festzulegen, das zugrundeliegende Dokument zumindest in das Jahr 47 v.Chr. oder später datiert. VanderKam 2004, 379 denkt wegen der Erwähnung des Konsulats Caesars an die Jahre 46-44 v.Chr. Von den älteren Beiträgen, die das senatus consultum in das Jahr 47 v.Chr. datieren, vgl. z.B.: Viereck 1888, 97-99, 101; Roth 1914, 54-60; Momigliano 1934/1967, 15 16 [197-198], 19-20 [200-201]; Smallwood 1976, 42 A. 65; Baumann 1983, 96-99. Eine chronologische Variante dieser Deutung bietet Mendelssohn 1875, 205-211, der im Text bei Josephus, ant. 14,10,3-4 (196-199) insgesamt Fragmente eines die Anordnungen Caesars bestätigenden senatus consultum über die amicitia et societas des Hyrkanus II. mit Rom erkennt und den Senatsbeschluss in das Jahr 46 v.Chr. datiert (ihm schließt sich an: Schürer 1890, 281 A. 23). Eine Instruktion an den Senat erkennen Judeich 1885, 126-127 und Juster 1914, 138-139 im Text des Josephus; Grätz 1905, 663 spricht von einer „Veröffentlichungsanzeige“; Täubler 1913, 174, 176 spricht von einem „Beschlussprotokoll“, in dem Caesar im Jahr 47 v.Chr. Hyrkanus II. anweist, Gesandte nach Rom zu schicken - er folgt also der Konjektur von Judeich 1885, 127-128 ('Y pкavòv statt $\pi \rho \grave{\varsigma}$ 'Y $\rho \kappa \alpha v o ̀ v)$, er ordnet den Vorgang aber chronologisch anders als Judeich ein.

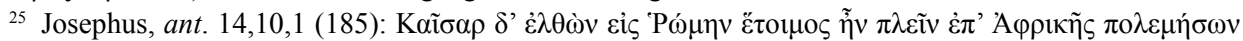

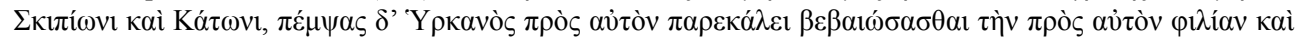
$\sigma v \mu \mu \alpha \chi i \alpha v$.

${ }^{26}$ In Briefen des Jahres 49 v.Chr. benennt sich Caesar selbst als imperator (Cicero, Att. 9,19 (16); 10,9 (8) B) und wird von Cicero als imperator benannt (Cicero, Att. 9,12 (11) A). Im Jahr 48 v.Chr. wird Caesar in Inschriften aus der Zeit nach der Schlacht bei Pharsalos als imperator consul II pontifex maximus benannt, vgl. die Zusammenstellung der Inschriftentexte bei Freber 1993, 189-194: IGR 4, 305 [48 v.Chr. Pergamon]; I.Delos Nr. 1587 [48 v.Chr. Delos]; IGR 4, 928 [48 v.Chr. Chios]; Sylloge3, 760 [48 v.Chr. Ephesos]; SEG 15, 748 [Phokaia]; Raubitschek 1954, 65-66 [48 v.Chr. Athen]; vgl. auch Sueton, Caes. 68,3, wo Caesar nach der Niederlage bei Dyrrhachium im Jahr 48 v.Chr. von seinen Soldaten mit imperator apostrophiert wird. Demnach war Caesars Titulatur 49 v.Chr. imperator pontifex maximus, während der Diktatur des Jahres 49 v.Chr. imperator dictator pontifex maximus und im Jahr 48 v.Chr. imperator consul II pontifex maximus. Auch imperator consul - wie bei Josephus - war für das Jahr 48 v.Chr. in seiner chronologischen Implikation eindeutig, denn während seines ersten Konsulats (59 v.Chr.) war Caesar nur Konsul und nicht gleichzeitig auch imperator. Die Ordinalia Angabe nach consul war also in der konkreten Situation des Jahres 48 v.Chr. für Zwecke der chronologischen Bestimmung entbehrlich.

${ }^{27}$ Holmes 1923, 564-567. Die Ehreninschriften mit einer Titulatur Caesars, vgl. die Inschriften und Nachweise bei Freber 1993, 189-194; Raubitschek 1954, 65-75 und Robert 1955, 257-260. 
Jahr 47 v.Chr. von einem Empfang einer Gesandtschaft des Hyrkanus II. durch den Senat unter Vorsitz des Prätors Lucius Valerius am Ende des Jahres (13.12.47 v.Chr.). ${ }^{28}$ Drittens bereitet Schwierigkeiten bei einer solchen Deutung weiterhin die Tatsache, dass der Text bei Josephus die Aushandlung der amicitia et societas Roms mit Hyrkanus II. als einen Gegenstand zukünftiger Verhandlungen zwischen römischen Gesandten und

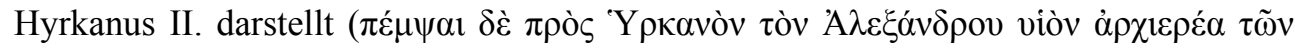

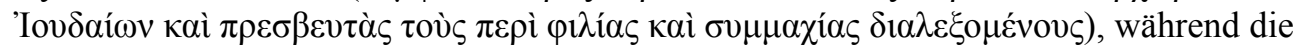
für das Jahr 47 v.Chr. von Josephus erwähnte Gesandtschaft des Hykanus II. die Freundschaft und Bundesgenossenschaft in Rom (von Caesar und vom Senat) bestätigen lassen will und deren Aushandlung bzw. Bestätigung in Rom unmittelbar erfolgen soll, d.h. also nicht erst Gegenstand zukünftiger Verhandlungen außerhalb Roms sein soll. Man müsste bei einer solchen Deutung also annehmen, dass die Gesandtschaft des Hyrkanus II. ihr Ziel im Jahr 47 v.Chr. nicht erreichte, ${ }^{29}$ sondern entweder eine (sonst nicht belegte) Gesandtschaft Roms an Hyrkanus II. mit dem Auftrag der Vereinbarung der amicitia et so-

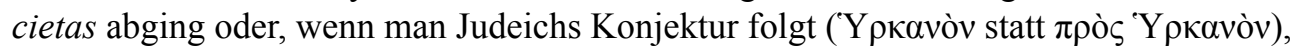
eine erneute Gesandtschaft des Hyrkanus II. zu diesem Zweck später abgesandt wurde. ${ }^{30}$ Im Gegenteil berichtet aber Josephus, ant. 14,8,5 (145-148), dass bereits am Ende des Jahres 47 v.Chr. die amicitia et societas Roms mit Hyrkanus II. bestätigt wird (13.12.47 v.Chr.). Viertens widerspricht einer solchen Interpretation, dass Caesar als imperator, pontifex maximus und dictator II am Ende des Jahres 47 v.Chr. (dazu weiter unten), die von Josephus im referierten senatus consultum vorgesehenen politischen Inhalte, also auch die Vereinbarung der amicitia et societas des Hyrkanus II. mit Rom, in einem

${ }^{28} \mathrm{Zu}$ der heute üblichen Interpretation, das Dokument sei von Josephus irrtümlich in die Zeit des Hyrkanus II. versetzt worden und gehöre tatsächlich in die Zeit Hyrkanus I., vgl. später die Ausführungen oben im Text.

${ }^{29}$ Dies ist tatsächlich die Voraussetzung der Deutungen, die den Text des Josephus für einen Senatsbeschluss halten und das senatus consultum in das Jahr 47 v.Chr. verlegen. Dissimulierend Pucci Ben Zeev 1998, 65: „Hyrkanus sent to him, with the request that he should confirm the friendship and alliance with him, as we learn from Ant. XIV, 185. Whether they obtained their request, however, is doubtful." Täubler 1913, 176 erkennt im Text des Josephus ein „Beschlussprotokoll“ [also eine Anordnung Caesars] vom Juli des Jahres 47 v.Chr., in dem Hyrkanus II. nach den Edikten Caesars angewiesen wird, Gesandte nach Rom

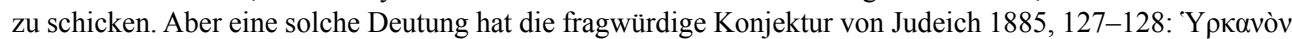

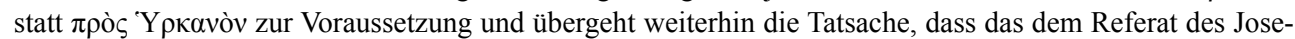
phus zugrundeliegende Dokument, wie gezeigt, sich in der Diktion und im Kontext seiner Anordnungen als senatus consultum zu erkennen gibt.

${ }^{30}$ Ein Ausweg aus diesem argumentativen Dilemma wäre es, wenn man annähme, dass das senatus consultum im Jahr 47 v.Chr. vor der Ankunft der von Josephus, ant. 14,10,1 (185) erwähnten Gesandtschaft

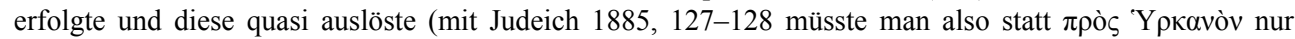
'Ү९каvòv lesen). Allerdings müsste man bei einer solchen Deutung eine sehr dichte und unglaubwürdige Ereignisfolge in der auf Caesars Entscheidung folgenden Zeit rechnen, wobei zwischen dem Senatsbeschluss und der Ankunft der Gesandtschaft des Hyrkanus II. in Rom nur wenige Monate verflossen wären. Die zwingende Voraussetzung einer solchen Interpretation wäre es allerdings, dass die chronologische Angabe im Dokumentenreferat (Caesar imperator consul) des Josephus historisch wertlos ist; denn im Jahr 47 v.Chr. war Caesar nicht imperator consul. Judeich, Caesar 138 bietet eine Variante einer solchen Deutung, wenn er meint, dass der Text bei Josephus ein Edikt Caesars sei, im dem die Gesandtschaft des Hyrkanus II. angekündigt würde (Judeich 1885, 136, 138-139). Es liegt auf der Hand, dass solche Kombinationen artifiziell sind und einer Interpretation, die den tatsächlich überlieferten Text erklären kann, bei der historischen Rekonstruktion aus methodischen Gründen der Vorrang gebührt. 
Brief an Sidon als verbindliches Recht (die Hinterlegung des entsprechenden Ediktes im aerarium ist bereits erfolgt $)^{31}$ kommuniziert. ${ }^{32}$ Den Gesandten des Hyrkanus II. ging es am Ende des Jahres 47 v.Chr. also lediglich darum, die vom Magistrat im Felde (Caesar imperator II pontifex maximus) in der vorangegangenen Zeit bereits gewährten rechtlichen Inhalte, vermittelt von Caesar, auch förmlich durch den Senat in Rom bestätigen zu lassen (Josephus, ant. 14,10,2 (192-195)).

Es bietet sich wegen der beschriebenen Merkmale der Inhaltsangabe bei Josephus, ant. 14,10,3 (196-198) eine andere Deutung des Befundes an, die auch die Titulatur Caesars im Text bei Josephus, ant. 14,10,3 (196) (imperator consul) berücksichtigt, von der man auf der Grundlage der unter anderem von Pucci Ben Zeev vertretenen Deutung annehmen muss, dass sie, als eine Zutat des Josephus, falsch ist. Denn im Jahr 47 v. Chr. nach dem Sieg über Aegypten war Caesar nicht Konsul.

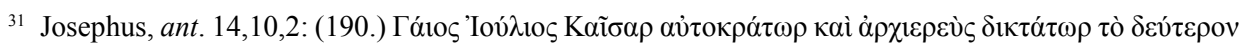

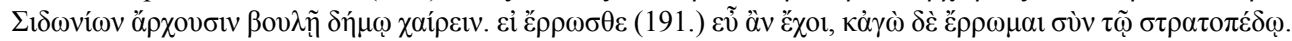

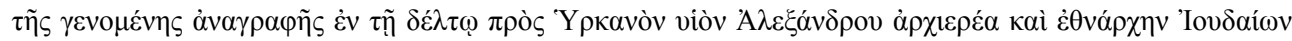

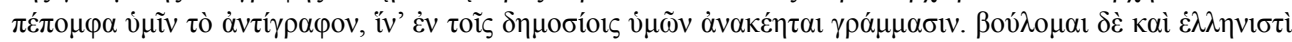

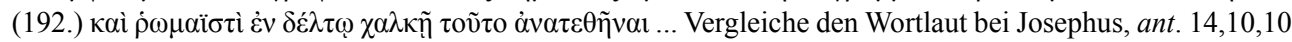

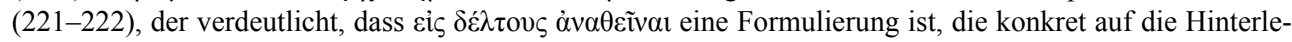

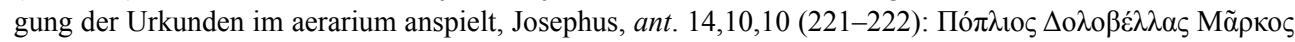

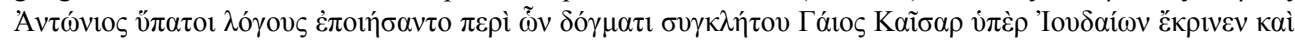

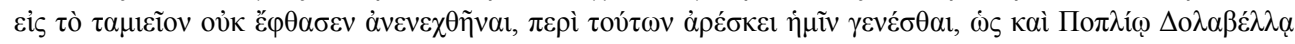

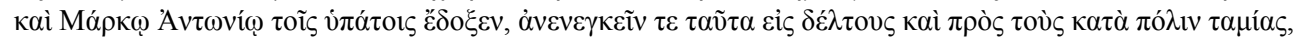

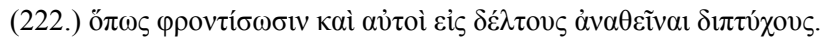

32 Roth 1914, 56-60 meint, die im Edikt Caesars bei Josephus, ant. 14,10,2 (194-195) in der Mitte des Jahres 47 v.Chr. gewährte persönliche Status eines socius bzw. eines amicus für Hyrkanus II. und seine Kinder sei zu unterscheiden von der amicitia et societas, die die Gesandten Hyrkanus II. am Ende des Jahres 47 v.Chr. erbitten (ihm folgt weitgehend z.B. Baumann 1983, 96-99; dissimulierend sind die Ausführungen bei Pucci Ben Zeev 1998, 65). Diese sei tatsächlich nicht gewährt worden und mit ihrer Aushandlung sei eine römische Gesandtschaft beauftragt worden, die der Senat dann im besagten senatus consultum (Josephus, ant. 14,10,3 (196-198)) am Ende des Jahres 47 v.Chr. beschloss. Eine solche Deutung kann Roth nur vertreten, weil er das Dokument bei Josephus, ant. 14,8,5 (145-148) weitgehend mit den Argumenten von Ritschl und Mendelssohn in der Darstellung des Josephus zum Jahr 47 v.Chr. für falsch platziert hält und in die Herrschaft des Hyrkanus I. in das Jahr 127 v.Chr. verlegt (Roth 1914, 40-47; Ritschl 1873, insbes. 596-605; dagegen Mommsen 1875, 281-291 und die Erwiderungen: Mendelssohn - Ritschl 1875, 419-435 und Mendelssohn 1877, insbes. 253). Denn in diesem Dokument wird bereits am Ende des Jahres 47 v.Chr. in der Tat die amicitia et societas Roms mit den Juden erneuert. Zu der an Ritschl und Mendelssohn anknüpfenden Deutung, die komplett die politische Botschaft des Senatsbeschlusses bei Josephus, ant. 14,8,5 (145-148) verkennt, vergleiche die Ausführungen weiter unten im Text (auch Pucci Ben Zeev 1998, 22, 359, 396 fußt auf dieser heute allgemein vertretenen Überzeugung). Ferner kann man auf der Grundlage der in den „Forschungen" Teil III, VI und VII (Zack 2013, 100-106; Zack 2015a, 27-83; Zack 2015b, 115-178) entwickelten Deutung zur amicitia et societas nun gegen die Deutung von Roth geltend machen, dass zumindest der Status des socius das Verhältnis der amicitia et societas in Verbindung mit den hospitium zur Voraussetzung hat - Hyrkanus II. befand sich also in der Mitte des Jahres 47 v.Chr. bereits nach dem Edikt Caesars im Verhältnis der amicitia et societas zu Rom und wollte dies mit der Gesandtschaft nach Rom am Ende des Jahres $47 \mathrm{v} . C h r$. auch noch förmlich bestätigen lassen (ganz so wie es Josephus, ant. 14,10,1 (185) auch formuliert). Weiterhin werden die Juden in den gleichzeitigen Diaspora-Dokumenten im 10. Kapitel des 14. Buches der antiquitates Judaicae des Josephus durchweg als socii Roms benannt (so richtig Freber 1993, 66 A. 327 mit den Quellennachweisen), so dass sie sich also damals tatsächlich schon im Verhältnis der amicitia et societas mit Rom befinden. 
Während der Schlacht von Pharsalos befinden sich Truppen des Volkes der Juden unter den Streitkräften des Cn. Pompeius Magnus (Appian, b. c. 2,71 (294)), so dass im Kontext der wechselnden politischen und militärischen Konstellationen im Jahr 48 v.Chr. der Beschluss des Senates in Rom einen politischen und militärtaktischen Sinn erst nach der Schlacht bei Pharsalos ergibt, als der Zusammenhalt der Koalition des Pompeius zumindest gefährdet ist und nach der Flucht des Pompeius aus Griechenland zu befürchten steht, dass Caesar gegen Pompeius in Aegypten Krieg führen müsse. ${ }^{33}$ Deshalb wird nach der Schlacht bei Pharsalos in Rom noch im Jahr 48 v.Chr. vom Senat ein Beschluss über die Juden gefasst. Dieser Beschluss wird unmittelbar von einem Magistrat in Rom durch Edikte den Gemeinwesen der betroffenen Region bekannt gemacht, einerseits, um mit den politischen Versprechungen Hyrkanus II. im drohenden Krieg gegen Pompeius in Aegypten für die Sache Caesars zu gewinnen, ${ }^{34}$ und andererseits, um den für die Verhandlung mit Hyrkanus II. abgeschickten Gesandten Roms freies Geleit und gastliche Aufnahme in den Städten der von ihnen zu besuchenden Region zu sichern, die sich zum Zeitpunkt des senatus consultum unter der militärischen und politischen Kontrolle der Pompeianer befindet. ${ }^{35}$ Der von Caesar kontrollierte Senat und die Magistrate in Rom reklamieren also nach dem Sieg bei Pharsalos mit den Edikten politisch für sich, dass sie auch im Einflussbereich des Bürgerkriegsgegners der rechtmäßige Vertreter der römischen Herrschaft seien, weshalb ihren Gesandten auf der Reise zu Hyrkanus II. auch Gastfreundschaft bei den Freunden Roms in den Städten des griechischen Ostens zukäme. ${ }^{36}$

${ }_{33}$ Zur strategischen Lage nach dem Sieg bei Pharsalos, vgl. Freber 1993, 9-11. Zur bewusst moderaten Politik Caesars gegenüber den griechischen Anhängern des Pompeius im Osten des Imperium Romanum nach dem Sieg bei Pharsalos, vgl. Freber 1993, 12-30. Diese Politik zielte letztlich darauf ab, die ehemaligen Parteigänger des Pompeius durch beneficia eng an Caesar zu binden und damit Pompeius schließlich die Ressourcen für militärische Aktionen gegen Caesar zu entziehen. In den Kontext dieser politischen und militärischen Strategie Caesars gehört auch die Initiative des römischen Senats (von Caesar politisch kontrolliert) gegenüber Hyrkanus II.

${ }^{34}$ Eine politisch-militärische Folge der Initiative des Senats war es nun in der auf Pompeius Ermordung folgenden Zeit, dass Hyrkanus II. und insbesondere Antipater Mithridates von Pergamon bei der Zuführung militärischer Hilfe für Caesar diplomatisch gegenüber den Machthabern der von Mithridates zu querenden Region unterstützten und ihm außerdem wichtige miltärische Hilfestellung bei der Kriegführung in Aegypten leisteten (Josephus, ant. 14,8,1-2 (127-135); b. Iud. 1,9,3-4 (187-192)).

${ }^{35}$ Die pompeianische Allianz im griechischen Osten vor der Schlacht bei Pharsalos, vgl. Freber 1993, 4 A. 11 mit den Quellennachweisen.

${ }^{36}$ Bereits im Jahr 49 v.Chr. hatte Caesar vergeblich versucht mit Gewalt durch die Entsendung von Legionen unter Führung des Aristobulos II., die Kontrolle über die strategisch wichtige Region Judäa zu gewinnen (Cassius Dio 41,18,1; Josephus, b. Iud. 1,9,1 (183); ant. 14,7,4 (123-124)). Der Plan scheiterte aber an der zeitigen Ermordung des Arstobulos II. durch Anhänger des Pompeius. Mit der erneuten und nun diplomatischen Initiative im Jahr 48 v.Chr. versuchte es Caesar auf diplomatischen Wege und schließlich erfolgreich, sein militärtaktisches und strategisches Ziel zu erreichen. Ob die im nach Pharsalos vom Senat beschlossene Gesandtschaft Rom wirklich verlassen hat, kann man wegen der potentiellen Lebensgefährdung der Gesandten mit Recht bezweifeln. Am Ende wurden die Vereinbarungen, wie die Dokumente bei Josephus zeigen, von Caesar und seinem consilium mit den Gesandten des Hyrkanus II. ausgehandelt. Politisch bedeutsam war das senatus consultum und die ihm folgenden Schreiben an die Gemeinwesen der Region nach Pharsalos vor allem wegen der allgemein kommunizierten politischen Botschaft an Hyrkanus II., der erkennen musste, dass eine Parteinahme für Caesar ihm dauerhaft eine Verbesserung seiner Position gegenüber Rom bringen würde. 
Der von Josephus referierte Senatsbeschluss gehört also in das Jahr 48 v.Chr., in die Zeit nach der Schlacht bei Pharsalos. Da Caesar sich zu dieser Zeit außerhalb Roms aufhielt, besagt Josephus' einleitender Text des Dokumentenreferates, dass das von ihm referierte senatus consultum über die Vergünstigungen für Hyrkanus II. erging, als Caesar

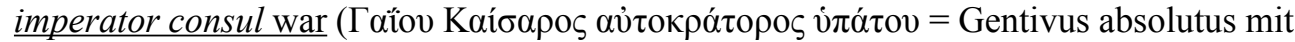
einer Zeitbestimmung). Einer solchen Auffassung des av̉ die oben dargestellte Ansicht, dass der gesamte Text bei Josephus, ant. 14,10,3 (196198) eine stichwortartige Zusammenfassung eines zugrunde liegenden Schriftstückes darstellt. Josephus übernahm demnach die Titulatur Caesars, wie er sie im Dokument fand, in die Einleitung des Referats. Die Benennung Caesars als imperator consul war im Jahr 48 v.Chr. in seiner chronologischen Implikation eindeutig. Denn während seines ersten Konsulats (59 v.Chr.) war Caesar nur consul, aber nicht zugleich auch imperator. Die Iterationsziffer nach consul war also in der konkreten Situation des Jahres 48 v.Chr. zumindest für Zwecke der chronologischen Bestimmung entbehrlich.

Diese Rekonstruktion der Ereignisabfolge kann durch einen inhaltlichen Vergleich des Dokumentenreferates mit dem Text des Ediktes Caesars (imperator II pontifex maximus) für Hyrkanus II. und dessen Kinder in der Sache allgemein bestätigt werden (Josephus, ant. 14,10,2 (192-195)). Das Edikt fällt seinem Inhalt nach in die Zeit nach Caesars Sieg in Aegypten (Einnahme Alexandrias 27.03.47 v.Chr.) ${ }^{37}$ und wurde in späterer Zeit (Ende 47 v.Chr., dazu weiter unten) an den Brief des imperator II dictator II Caesar an Sidon zur Kenntnisnahme beigefügt. Der Text des Ediktes vollzieht in der Zeit nach dem Krieg in Aegypten die ehedem im Senatsbeschluss und in den folgenden Edikten

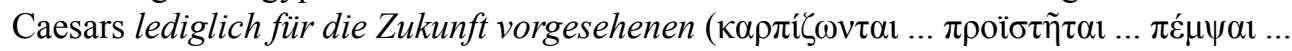

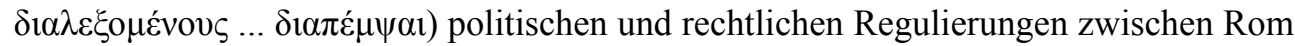
und Hyrkanus II. und dessen Kindern. Das Edikt Caesars hat dem Inhalt nach den Senatsbeschluss zur Voraussetzung. Der Senatsbeschluss geht dem Edikt also dem Inhalt nach zeitlich voraus.

Josephus, ant. 14,10,2 (190-195): ,[190] Gaius Iulius Caesar, Imperator und Pontifex maximus, zum zweiten Mal Diktator grüßt den Magistrat, den Senat und das Volk der Sidonier. Wenn es euch gut geht, bin ich zufrieden; ich und mein Heer sind gleichfalls wohlauf. [191] Ich schicke euch die Abschrift des auf einer Tafel niedergelegten Schriftstückes, das Hyrkanus, den Sohn des Alexander, Hohepriester und Ethnarchen der Juden betrifft, damit es in eurem Archiv hinterlegt werde. Ich will aber auch, dass es in griechischer und lateinischer Sprache auf einer bronzenen Tafel aufgestellt werde. [192] Es ist dieses: Iulius Caesar, zum zweiten Mal Imperator und Pontifex maximus, verordnete mit einem consilium: Weil der Jude Hyrkanus, Sohn des Alexander, sowohl jetzt als auch früher, im Frieden wie im Krieg, stets Treue und Eifer für unsere Angelegenheiten gezeigt hat, was ihm auch schon viele unserer Imperatoren bezeugten, [193] weil er ferner jüngst im Alexandrinischen Kriege uns mit tausendfünfhundert Mann als socius beistand und weil er bei einer von mir veranlassten Sendung an Mithridates mit Tapferkeit alle Übrigen in der Schlachtordnung übertroffen hat, [194] in Erwägung dessen ernenne ich Hyrkanus, den Sohn Alexanders, und dessen Kinder zu Ethnarchen der Juden, gestatte ihnen, das jüdische Hohepriestertum ihrem Gebrauche gemäß für immer beizubehalten, und befehle, dass er selbst und seine Söhne zu unsern socii und auch zu den mannweise gezählten amici gerechnet werden sollen. [195] Alles, was nach ihren Gesetzen an hohepriesterlichen Privilegien besteht, soll, das ordne ich an, ihm und seinen Söhnen verbleiben. Wenn über jüdische Einrichtungen

${ }^{37}$ Die Ereignisse nach der Ermordung des Pompeius und während Caesars Aufenthalt in Aegypten, vgl. die Übersicht bei Freber 1993, 31-47. 
unter den Juden ein Streit ausbrechen sollte, gefällt es mir, dass sie darüber die Entscheidung haben. Ich verbiete, dass [in Judäa] überwintert werde, oder dass man Geld [von den Juden] eintreibe.“ (die Übersetzung mit Modifikationen nach derjenigen von Heinrich Clementz) ${ }^{38}$

Caesars Titulatur in diesem Edikt bereitet eine Schwierigkeit, die in der Vergangenheit dazu geführt hat, dass die modernen Interpreten seit Benedikt Niese (1849-1910) meinten, den Text korrigieren zu müssen. ${ }^{39}$ Caesar benennt sich im Jahr 47 v.Chr. als imperator II und pontifex maximus, aber nicht als dictator II, obwohl er schon im Herbst 48 v.Chr. in Rom zum dictator II für ein ganzes Jahr gewählt worden war. ${ }^{40}$ Die ,korrek-

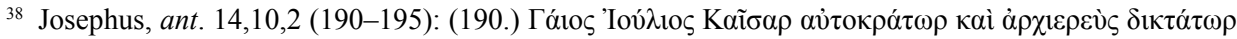

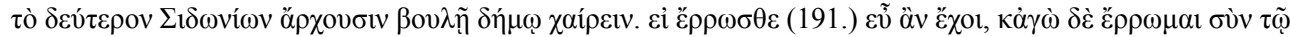

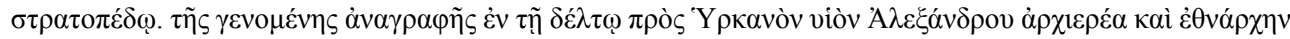

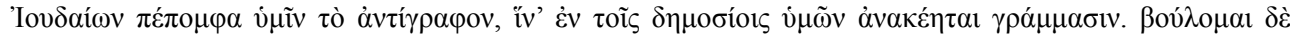

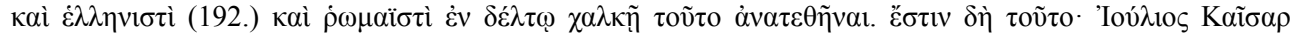

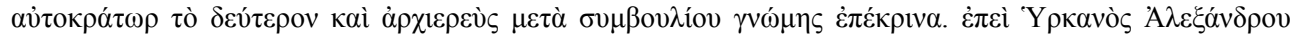

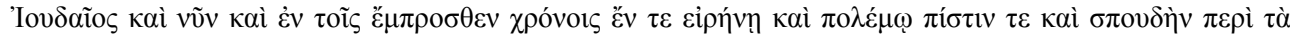

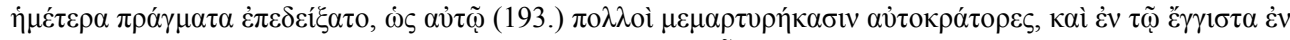

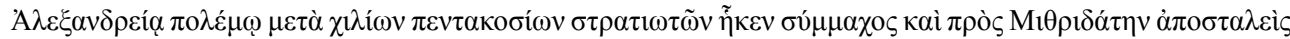

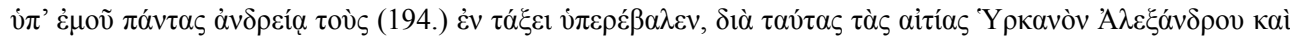

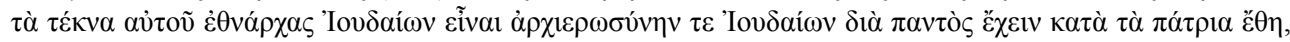

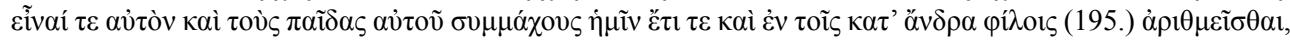

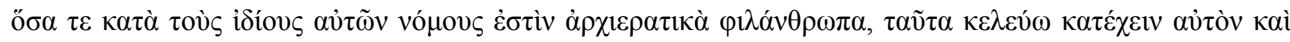

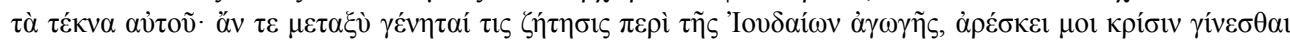

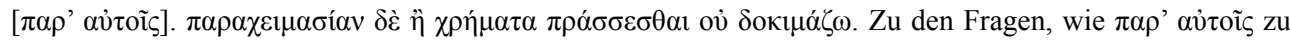
deuten ist und was unter dem Titel des Ethnarchen zu verstehen ist, vgl. nun Eckhardt, Ethnos 351-356 (der Titel hat nur Judäa zum sachlichen Objekt und beinhaltet keineswegs eine Zuständigkeit des Hyrkanus II. in Hinsicht auf alle Juden im Imperium Romanum. Die entgegengesetzte Position nimmt Sharon 2010, 482-483 [mit weiterer Literatur] ein.). Zum Text und mit den bibliographischen Angaben zu der älteren Literatur, vgl. den Kommentar und die Interpretation bei Pucci Ben Zeev 1998, 31-53 und Pucci Ben Zeev 1996b, 73-76; 1996c, 197-199; Seeman 2013, 323-325; Pucci Ben Zeev 1998, 52-53 datiert nach dem Vorbild der älteren Forschung (z.B. Momigliano 1934/1967, 13-14 [195-196], 18 [200]; Juster 1914, 139; ebenso neuerdings auch Seeman 2013,323) das Schreiben Caesars an Sidon in die Zeit von dessen Aufenthalt in Syrien (anders aber noch in: Pucci Ben Zeev 1996b, 74). Im Weiteren wird oben im Text dagegen die Auffassung vertreten, dass das Schreiben erst nach Caesars Rückkehr nach Italien an Sidon geschickt wurde. Für eine solche chronologische Einordnung des Dokuments sprechen: 1.) Wie noch im Folgenden zu zeigen sein wird, die Titulatur Caesars in Brief an Sidon, die sich in auffälliger Weise von der in dem an den Brief angehängten Dekret für Hyrkanus II. und seine Kinder unterscheidet (vgl. auch die Tituatur im Dokumentenreferat bei Josephus, ant. 14,10,6 (202-210)), 2.) Der Brief an Sidon hat zur Voraussetzung, dass das dem Brief angehängte Dekret

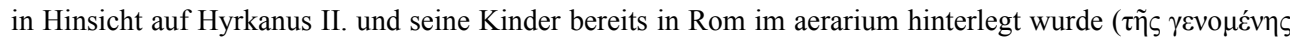
$\dot{\alpha} v \alpha \gamma \rho \alpha \varphi \tilde{\eta} \varsigma$ غ̇v $\tau \tilde{n} \delta \delta \dot{\lambda} \tau(\omega)$, was im Kontext der innerrömischen Ratifikationsvorgänge von außenpolitischen Handlungen dessen Bestätigung zumindest durch den Senat in Rom zur Voraussetzung hat, dass der Brief Caesars aus Gründen der politischen Praxis Roms und den damit verbundenen Zeitverzögerungen auf jeden Fall einige Zeit nach dem Dekret Caesars für Hyrkanus II. und seine Kinder geschrieben worden sein muss.

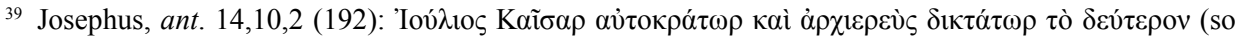

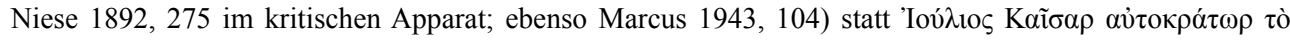

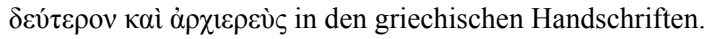

${ }^{40}$ Vgl. Holmes 1923, 564-567 (auch Josephus, ant. 14,11,1 (270), b. Iud. 1,11,1 (218) belegen indirekt, dass Caesar im Herbst 48 v.Chr. zum zweiten Mal zum Diktator gewählt worden war).

Die einschlägigen literarischen Quellenbelege führen zu der Einsicht, dass die zweite Diktatur Caesars bereits im Herbst des Jahres 47 v.Chr. endete: Andersen 1938, 23-25; vgl. Raubitschek 1954, 69-71 mit den Inschriften [Samos, Thespiai], die verdeutlichen, dass Caesar am Anfang des Jahres 46 v.Chr. nur consul III war, ohne noch dictator II zu sein [Rautischek 1954, 69 (Samos), 69 (Samos). 71 (Thespiai)], vgl. auch CIL 
te" Titulatur Caesars wäre zu dieser Zeit also mutmaßlich imperator dictator II pontifex maximus. Warum benennt sich Caesar in diesem Schriftstück sowie im Dokumentenreferat bei Josephus, ant. 14,10,6 (202-210) nicht als dictator II? Ein römischer Diktator musste sich bei seiner Ernennung auf ager Romanus aufhalten, um das Amt annehmen (quasi „ergreifen“) zu können. ${ }^{41}$ Solchen ager Romanus gab es nur in Italien. ${ }^{42}$

Zum Jahr 210 v.Chr. berichtet Livius über Auseinandersetzungen zwischen dem Senat und dem Konsul M. Valerius Laevinus wegen der Ernennung eines Diktators comitiorum habendorum causa. Livius 27,5,14-19:43

Als der Konsul dies vorlas, beeindruckte es den Senat so, dass er meinte, der Konsul dürfe nicht die Wahlen abwarten, sondern müsse einen Diktator comitiorum habendorum causa ernennen und sogleich in seine provincia zurückkehren. Die Debatte darüber ging weiter, weil der Konsul sagte, er werde in Sizilien M. Valerius Messala, der jetzt das Kommando über die Flotte habe, zum Diktator ernennen, die Senatoren aber erklärten, außerhalb des ager Romanus - und der sei auf Italien beschränkt - könne ein Diktator nicht ernannt werden. Als der tribunus plebis M. Lucretius den Senatoren diese Frage vorlegte, beschloss der Senat, der Konsul solle, bevor er die Stadt verlasse, das Volk befragen, wer nach seinem Willen zum Diktator ernannt werden solle, und er solle den zum Diktator ernennen, den das Volk bestimmte und wenn der Konsul das nicht wolle, solle der Prätor das Volk befragen, wenn auch der nicht wolle, dann sollten die Tribunen die Sache vor die

1,2967 = AE 1967, 107 Vibo Valentia und ILS 6375 (Caesar und Lepidus werden nur als Konsuln benannt, so dass die Datierung in das Jahr 46 v.Chr. führt und zwar in die Zeit vor der Ernennung Caesars zum Diktator)] und weiterhin Cicero, Phil. 2,62 und vgl. Cicero, Att. 11,7,1; Livius, per. 112; Cassius Dio 42,20,3. 42,21,1-2; Plutarch, Antonius 8,4-5; Plutarch, Caesar 51,1; Cassius Dio 42,35,5-6; 42,55,4. Die zweite Diktatur wird weiterhin in den fasti Capitolini ausdrücklich unter dem Jahr 47 v.Chr. geführt [Degrassi 1954, 78] - zuerst werden C. Iulius C.f. C. $n$. Caesar II dictator und M. Antonius M.f. M. n. magister equitum [eine entsprechende Datierung findet sich auch in AE 1972, 14] genannt und dann werden erst die Konsuln des Jahres Q. Fufius Q. f. C. n. Calenus und P. Vatinius P. f. genannt (vgl. auch ILS 6375, wo auf die Datierung C. Iulio Caesare dict. iter. M. Antonio mag. eq. gleich die Datierung [C. Caes]are M. Lepido cos. folgt). Die Münze (Crawford 1974, Nr. 467; vgl. auch die entsprechenden Titulaturen in den Inschriften aus dem Jahr 46 v.Chr. (ILS 70 und IGR 4, 929)), die Caesar im Jahr 46 v.Chr. als dict. iter. und cos. tert. benennt, ist demnach nicht als tatsächlich gegebene Titulatur Caesars am Anfang des Jahres 46 v.Chr. (vor der Schlacht bei Thapsos am 06.04.46 v.Chr.) zu verstehen, sondern einerseits als aktuelle Titulatur (cos. tert.) und andererseits als Erinnerung an die bereits geendete erste und zweite Diktatur Caesars - so bereits Andersen 1938, 23-25; vgl. Raubitschek 1954, 70 - dementsprechend ist Holmes 1923, 564-567 und die dort zitierte ältere Literatur zu korrigieren. Die zweite Diktatur Caesars war, wie es die Quellen ausdrücklich überliefern [Plutarch, Caesar 51,1; Cassius Dio 42,30,3. 42,55,4], auf ein Jahr beschränkt [sie begann im Herbst 48 und endete im Herbst 47 v.Chr.] und sie ragte nicht in das Jahr 46 v.Chr. hinein. Dazu fügt es sich gut, dass Caesar bei seinem großen Triumphzug im Jahr 46 v.Chr. mit einer überaus großen Anzahl von teilnehmenden Liktoren ausdrücklich auch auf die vergangene erste und zweite Diktatur Bezug nahm (Cassius Dio 43,14,3).

${ }^{41}$ Zum Zeremoniell der Wahl und Ernennung des Diktators, vgl. Mommsen 1887, II: 145-153. Zu den speziellen Auspicien, die vom Diktator bei seinem Amtsantritt zu befolgen waren, vgl. Livius 3,27,1; vgl. Mommsen 1887, II: 174; Kunkel et al. 1995: 668-670 (Ernennung des Diktators), 678 (Amtsantritt des Diktators), 712-716 (Caesars Diktaturen). Exempla für die Ernennung von Diktatoren im 4. Jh. v.Chr. auf ager Romanus außerhalb Roms in Italien, vgl. Livius 7,21,9 (352 v.Chr.), 8,23,13 (327 v.Chr.), 9,38,13-14 (309 v.Chr.). Zur uneinheitlichen Überlieferung bezüglich der Frage, ob die Diktatorenernennung in Rom stattfinden musste bzw. auch auf ager Romanus außerhalb Roms (aber in Italien!) stattfinden konnte (in Rom, vgl. Livius 7,19,9-10; 22,57,8-9; 23,22,10-11), vgl. die Literatur und Quellen bei: Oakley 1998, 157 zu Livius 7,12,8.

${ }_{42}$ Zur Abgrenzung der bei Varro l.l. 5,33 genannten Bodentypen des ager Romanus, ager Gabinus, ager hosticus, ager peregrinus und ager incertus, vgl. Zack 2012, 61-128.

${ }^{43}$ Vgl. den Kommentar zu Livius 27,5,14-19 von Weissenborn - Müller, T. Livi ab urbe condita, Bd. 6, $15-17$. 
Plebs bringen. Als der Konsul erklärte, er werde das Volk nicht in einer Sache befragen, die in seine potestas falle, und er auch dem Prätor die Befragung untersagte, befragten die Tribunen die Plebs, und die Plebs entschied, Q. Fulvius, der zurzeit in Capua stand, solle zum Diktator ernannt werden. Doch an dem Tag, an dem dieses concilium plebis stattfinden sollte, ging der Konsul heimlich nach Sizilien weg. Allein gelassen, beschlossen die Senatoren, einen Brief an M. Claudius zu schicken, er solle der von seinem Kollegen im Stich gelassenen res publica zu Hilfe kommen und den, den der populus wolle, zum Diktator ernennen. So ernannte der Konsul M. Claudius Q. Fulvius zum Diktator und aufgrund desselben scitum plebis ernannte der Diktator Q. Fulvius den pontifex maximus P. Licinius Crassus zum magister equitum (Übersetzung mit Variationen und mit den lateinischen Fachbegriffen nach Hans Jürgen Hillen). ${ }^{44}$

Der zu ernennende Diktator musste sich demnach persönlich auf ager Romanus aufhalten. Andernfalls wäre die ablehnende Antwort des Senats bezüglich der Ernennung des M. Valerius Messala, der sich in Sizilien aufhielt, ohne ein gedankliches Objekt. Der Begriff ager Romanus bezeichnet in der Anschauung des Livius einen Boden-Typus, den es nur in Italien gab. ${ }^{45}$ Die den „Ernennungsakt“ abschließende Annahme des Amtes durch die zum Diktator gewählte Person konnte in Ausnahmefällen außerhalb Roms erfolgen, aber nur in Italien, weil es den für diese Zeremonie notwendigen ager Romanus nur in Italien gab. Dieser Befund wird durch eine andere Erzählung des Livius zum Jahre 208 v.Chr. ergänzt (27,29,1-5), indem diese Schilderung zeigt, dass in Ausnahmefällen die Ernennung des Diktators durch den Konsul auch außerhalb Roms auf ager Romanus

44 Livius 27,5,14-19: haec recitata a consule ita mouere senatum ut non exspectanda comitia consuli censeret, sed dictatore comitiorum habendorum causa dicto extemplo in prouinciam redeundum. illa disceptatio tenebat quod consul in Sicilia se M. Ualerium Messallam qui tum classi praeesset dictatorem dicturum esse aiebat, patres extra Romanum agrum - eum autem Italia terminari - negabant dictatorem dici posse. M. Lucretius tribunus plebis cum de ea re consuleret, ita decreuit senatus ut consul priusquam ab urbe discederet populum rogaret quem dictatorem dici placeret, eumque quem populus iussisset diceret dictatorem; si consul noluisset, praetor populum rogaret; si ne is quidem uellet, tum tribuni ad plebem ferrent. cum consul se populum rogaturum negasset quod suae potestatis esset, praetoremque uetuisset rogare, tribuni plebem rogarunt, plebesque sciuit ut Q. Fuluius, qui tum ad Capuam erat, dictator diceretur. sed quo die id plebis concilium futurum erat, consul clam nocte in Siciliam abiit; destitutique patres litteras ad M. Claudium mittendas censuerunt ut desertae ab collega rei publicae subueniret diceretque quem populus iussisset dictatorem. ita a M. Claudio consule Q. Fuluius dictator dictus, et ex eodem plebis scito ab Q. Fuluio dictatore P. Licinius Crassus pontifex maximus magister equitum dictus.

45 Es wird von Livius erst für die Zeit des 2. Punischen Krieges berichtet, dass es den ager Romanus nur in Italien geben konnte, und eine sachliche Notwendigkeit für diese rechtliche Einschränkung war erst gegeben, als Rom mit der Einrichtung der Provinzen Sizilien und Sardinien Besitz außerhalb Italiens gewann. Demnach wird die Formulierung der vorauszusetzenden gesetzlichen Regel wohl in die Zeit nach dem 1. Punischen Krieg und vor den Beginn des 2. Punischen Krieges gehören. Eine in der angewendeten Pragmatik verwandte und auch zeitlich parallele historische Entwicklung gab es im Bereich der Prozesse um Grundstücke: Während in einer ersten Phase der Entwicklung der Prätor den Prozess auf dem umstrittenen Grundstück führte, wurde zu einen späteren Zeitpunkt der historischen Entwicklung (3. Jh. v.Chr., als Rom in ganz Italien Besitz und Hegemonie besaß) dazu übergegangen, dass die Prozessparteien symbolisch ein Stück Erde vom umstrittenen Grundstück zum Gerichtsort brachten, vgl. Gellius, n.a. 20,10 (vgl. Gaius, inst. 4,17 und Cicero, Mur. 12,26), zur Stelle, vgl. Kaser 1956, 225-227 mit Literaturangaben. Am Ende der Entwicklung führte man den Prozess nicht mehr um den Gegenstand selbst (fundus/ager) in der alten Form des Legisaktionprozesses, sondern um den (ungegenständlichen) Besitz (possessio - usus) mit Hilfe des prätorischen interdictum, vgl. Aelius Gallus in: Huschke - Seckel - Kübler 1988, I: frg. 12 (= Festus 260.262 L. s.v. possessio); zur Entwicklungsgeschichte des prätorischen interdictum, vgl. Kaser 1956, 243-271. Zum Fragment des C. Aelius Gallus, vgl. Kaser 1956, 243-253, 258-271. 
vorgenommen werden konnte: ${ }^{46}$ Der Konsul M. Claudius Marcellus war im Krieg gegen Hannibal gefallen und der andere Konsul T. Quinctius Crispinus schwer verletzt worden. Crispinus ließ das Heer, das unter dem Oberbefehl seines gefallenen Kollegen gestanden hatte, durch den Militärtribun M. Marcellus nach Venusia führen und begab sich selbst schwer verletzt nach Capua. Er teilte dem Senat in einem Brief die bedrohliche militärische Lage mit und gab an, dass er wegen seiner Verletzung nicht zur Abhaltung der Wahlen nach Rom kommen könne. Deshalb bat er den Senat um die Entsendung einer Gesandtschaft zu ihm nach Capua, mit der er die Lage besprechen könne. Der Senat schickte Q. Fabius zum Heer nach Venusia und Sex. Iulius Caesar, L. Licinius Pollio und L. Cincius Alimentus als Gesandte zu Crispinus nach Capua. Sie erhielten vom Senat den Auftrag, dem Konsul mitzuteilen: ut si ad comitia ipse uenire Romam non posset dictatorem in agro Romano diceret comitiorum causa (Livius 27,29,577). Es gab also in der Anschauung des Livius bzw. seiner Quelle ager Romanus in Capua, auf dem Crispinus einen Diktator hat ernennen können. ${ }^{48}$

Im Kontext, der in der vorliegenden Abhandlung diskutierten Texte des Josephus, bedeutet der rekonstruierte Sachverhalt der zeremoniellen Voraussetzungen für die Diktatorenernennung, dass die Amtseinsetzung Caesars in der Zeit vom Herbst 48 v.Chr. bis zum Spätsommer 47 v.Chr. zeremoniell noch nicht abgeschlossen war. Denn Caesar hielt sich noch im griechischen Osten auf und die den Ernennungsakt abschließende Annahme (,Ergreifung“) des Diktatoramtes durch Caesar auf ager Romanus stand noch aus. Die konkreten Amtsbefugnisse eines Diktators reklamierte Caesar zwar schon während seines Aufenthaltes in Aegypten für sich, ${ }^{49}$ den Titel aber konnte er zumindest in öffentlichen Schriftstücken nicht benutzen, ohne sich damit in seiner Funktion als pontifex maximus in Konflikt mit der traditionellen Ordnung des Zeremoniells einer Diktatoreneinsetzung zu begeben.

Ein schwacher historiographischer Reflex dieser heiklen Situation kann auch der Schilderung bei Cassius Dio 42,21,1 f. entnommen werden, der die zeremonielle Schwierigkeit bei der Bestellung Caesars zum Diktator im Herbst 48 v.Chr. dadurch andeutet, dass Caesar in Aegypten die Wahl zum Diktatur sofort annahm, obgleich er sich außerhalb Italiens aufhielt, Cassius Dio 42,21,1-2: „(1) Auf diese Weise wurden also die genannten Bestimmungen beschlossen und in Geltung gesetzt. Caesar übernahm, wiewohl

46 Vgl. den Kommentar von Weissenborn - Müller, T. Livi ab urbe condita, Bd. 6, 84-85.

47 Übersetzung: „Wenn er zu den Wahlen nicht selbst nach Rom kommen könne, solle er auf ager Romanus einen Diktator comitiorum causa ernennen“ (Übersetzung mit Variationen nach Hans Jürgen Hillen).

48211 v.Chr. wurde Capua, das 216 v.Chr. zu Hannibal abgefallen war (Livius 23,6-10; Diodor 26,13; Zonaras 9,2), nach seiner Kapitulation vom römischen Senat bestraft und als Gemeinwesen aufgelöst (Livius 26,16; Cicero, leg. agr. 1,19. 2,88; Velleius Paterculus 2,44) und ager omnis et tecta publica populi Romani facta (Livius 26,16,8), vgl. im Detail Ungern-Sternberg 1975, passim.

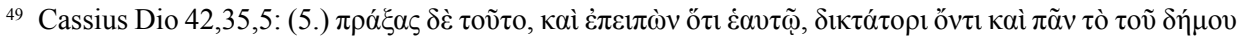

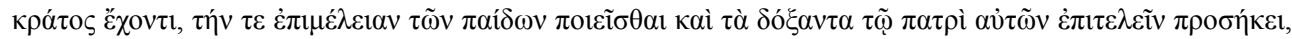

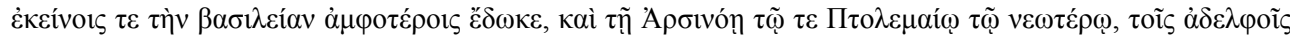

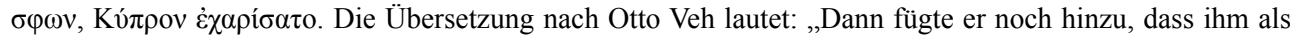
Diktator, der alle Gewalt des Volkes besitze, zustehe, sich um die Kinder zu kümmern, und die Bestimmungen ihres Vaters auszuführen. Und so verlieh er beiden das Königtum, während er Arsinoe und dem jüngeren Ptolemaios, ihren Geschwistern, die Insel Zypern zukommen ließ.“Als Quelle für die Darstellung des Cassius Dio wird man an Livius denken, vgl. Radicke 2004, 24-27. 
er außerhalb Italiens weilte, sofort die Diktatur und bestellte Antonius, ohne dass dieser auch nur Prätor gewesen war, zu seinem magister equitum; und auch der Konsul schlug seinen Namen vor, wiewohl die Auguren sich dem aufs nachdrücklichste widersetzten und erklärten, dass niemand länger als sechs Monate das Amt des magister equitum versehen dürfe. (2) Sie ernteten aber nur viel Spott dafür, dass nach ihrem Entscheid der Diktator selbst im Widerspruch zu aller väterlichen Überlieferung für ein Jahr gewählt werden könne, während sie sich wegen des magister equitum so kleinlich zeigten." (Die

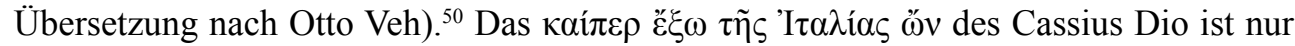
unter der Voraussetzung verständlich, dass Caesars Aufenthalt außerhalb Italiens dem vollständigen Antritt seiner Diktatur in irgendeiner Weise entgegenstand. ${ }^{51}$

Caesar beanspruchte also, wie die Texte des Josephus illustrieren, während seines Aufenthaltes im Osten nicht den Titel sondern lediglich die Amtsgewalt eines Diktators für sich, und es gelang ihm auf diese Weise vor allem, mit der Einsetzung seines politischen Gefährten M. Antonius als magister equitum die politischen Entscheidungen in Rom effektiv zu kontrollieren. ${ }^{52}$ Nur darin bestand augenblicklich der konkrete politische Nutzen der Diktatur für Caesar; denn den militärischen Oberbefehl im Krieg gegen die Allianz der Bürgerkriegsgegner konnte er auch aufgrund einer anderen Ermächtigung beanspruchen, die ihm zuvor schon vom Senat im Jahr 49 v.Chr. verliehen worden war. ${ }^{53}$

Caesar konnte also, vor seiner Rückkehr nach Italien, den Titel des Diktators aus Gründen des traditionellen Zeremoniells vorerst nicht offiziell benutzen. Einen Nieder-

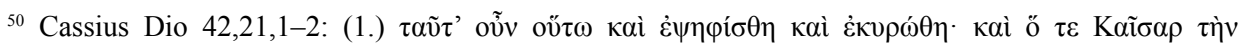

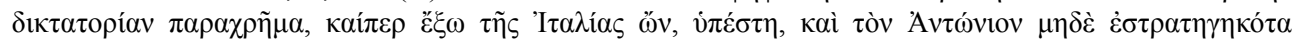

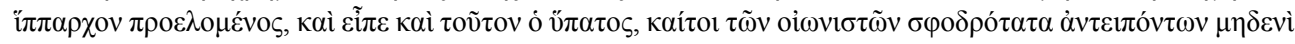

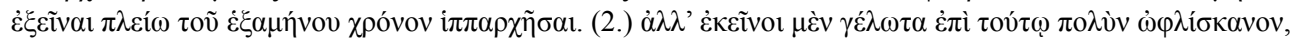

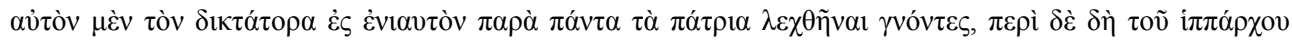
$\dot{\alpha} \kappa \rho 1 ß о \lambda о \gamma о u ́ \mu \varepsilon v o l$.

${ }^{51}$ Im Fall der ersten Diktatur Caesars im Jahr 49 v.Chr. erwähnt Cassius Dio, dass M. Aemilius Lepidus in seiner Eigenschaft als Prätor vom Volk Caesar, der sich noch außerhalb Italiens in Massilia aufhielt (Caesar, b.c. 2,21,5), zum Diktator wählen ließ und ihn entgegen dem Herkommen auch sofort als solchen

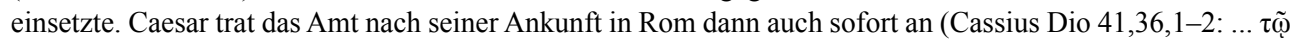

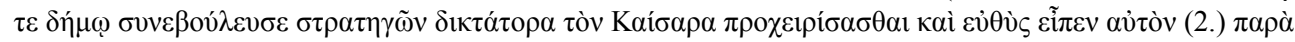

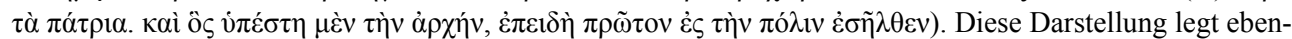
falls den Gedanken nahe, dass zwischen der Wahl zum Diktator, der Ernennung und dem Antritt des Amtes traditionell ein zusätzlicher zeremonieller Schritt der Amtseinsetzung notwendig war, nämlich, wenn man sich an die weitere Überlieferung hält, die Einsetzung des Diktators auf ager Romanus, den es nur in Italien gab. Auffällig ist auch der Status des dictator designatus im Fall der vierten Diktatur Caesars (Ps. Caesar, b. Hisp. 2,1, vgl. Sherk 1969, Nr. 26, col. b. Z. 7), was ebenfalls zu dem Gedanken führt, dass auf die Wahl zum Diktator noch eine zusätzliche zereremonielle Handlung (Ernennung durch den Konsuln und Annahme der Ernennung durch den gewählten Diktator auf ager Romanus) hinzutreten musste, um die Amtseinsetzung zum Diktator perfekt zu machen.

${ }_{52}$ M. Antonius als magister equitum in Rom, vgl; Cicero, Phil. 2,61-63; Att. 11,7,1; Plutarch, Ant. 8-9; Cassius Dio 42,21. 45,28; Plinius, n.h. 8,55; Degrassi 1954, 78.

${ }^{53}$ Im Kontext der Gesetzgebung im Jahr 49 v.Chr. während Caesars Aufenthalt in Rom, Cassius Dio

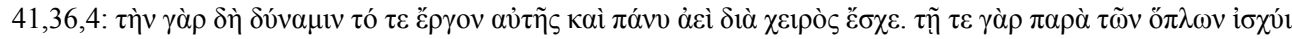

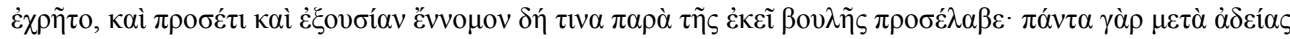

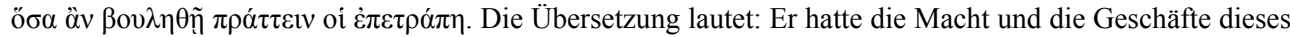
Amtes (der Diktatur) unausgesetzt in seiner Hand. Denn er bediente sich der Waffengewalt und erhielt vom Senat eine Art gesetzliche Vollmacht übertragen, wonach er straflos ganz nach Gutdünken verfahren könne. Die Quelle des Cassius Dio ist an dieser Stelle wahrscheinlich Livius, vgl. Radicke 2004, 24-27, 332. 
schlag dieser Situation findet sich neben dem Dokument bei Josephus, ant. 14,102 (192195) auch im Referat einer Entscheidung Caesars bei Josephus, ant. 14,10,6 (202-210). ${ }^{54}$ Der zuletzt genannte Text wurde von Josephus unter Missachtung der Chronologie der Dokumente an ein Zitat aus einem Edikt Caesars in seiner Eigenschaft als ű $\pi \alpha \tau \varsigma$ ऽò $\pi \varepsilon \dot{\mu} \mu \pi \tau$ ov aus dem Jahr 44 v.Chr. wohl deshalb angehängt (Josephus, ant. 14,10,5 (200201)), weil er im Zusammenhang dokumentieren wollte, was die rechtliche Situation Judäas in Hinsicht auf die innerjüdische Besitzverteilung und die diversen Steuer- und Abgabenerhebungen (innerjüdisch und im Verhältnis zu Rom) nach 44 v.Chr. war.

Josephus, ant. 14,10,6 (202-210): ,,[202] Gaius Cäsar, zum zweiten Mal Imperator, ${ }^{55}$ ordnete an: Für die Stadt Jerusalem sollen sie [i.E. die Juden] mit Ausnahme von Joppe jährlich eine Abgabe entrichten, es sei denn, dass es das siebente so genannte Sabbatjahr ist, weil sie in diesem weder Baumfrüchte ernten noch Felder bebauen. [203] In Sidon soll alle zwei Jahre der vierte Teil der Feldfrüchte als Abgabe geliefert werden, und außerdem sind dem Hyrkanus und dessen Kindern die Zehnten ebenso zu entrichten, wie sie deren Vorfahren entrichtet worden sind. [204] Kein Magistrat oder Promagistrat, Praetor oder Legat soll im Gebiete der Juden Hilfstruppen und Soldaten ausheben und von den Juden Geld eintreiben, sei es zur Überwinterung, sei es mit einer anderen Benennung; dieselben sollen vielmehr von allen Dienstleitungen verschont bleiben. [205] Alles, was sie später haben, kaufen, besitzen oder bewohnen, sollen sie besitzen. Die Stadt Joppe, welche die Juden schon früher, als sie mit den Römern amicitia schlossen, besessen haben, soll ihnen wie früher gehören; [206] auch sollen Alexanders Sohn Hyrkanus und dessen Söhne als Eigentümer dieser Stadt von den Ackerbauern derselben als Zoll für das aus der Umgegend und dem Hafen jährlich nach Sidon ausgeführte Getreide sechsundzwanzigtausendfünfundsiebzig Modii erhalten, mit Ausnahme des Sabbatjahres, in welchem weder das Feld bebaut noch Baumfrüchte geerntet werden. [207] Die Dörfer in der großen Ebene, welche dem Hyrkanus und dessen Vorfahren ebendort gehörten, sollen Hyrkanus und die Juden gemäß Senatsbeschluss unter demselben Recht wie auch früher besitzen. [208] Ferner sollen

${ }^{54}$ Auch die Ehreninschriften, in denen Caesar lediglich als Imperator bzw. Imperator und Pontifex benannt wird, könnten auf diese Weise eine Erklärung finden, indem sie vielleicht in das Jahr 47 v.Chr. vor Caesars Rückkehr nach Italien gehören, vgl. die Inschriften und Nachweise bei Freber 1993, 189-194: IG 12,5, 557 (Karthaia auf Keos); Raubitschek 1954, 66 (Demetrias in Thessalien); IGR 4, 303 (Pergamon); IGR 4, 307 (Pergamon); IG 7 Nr. 62 (Megara).

55 Benedikt Niese (1892, 277 im Apparat) konjiziert nach dem Vorbild von Johann Tobias Krebs (1768,

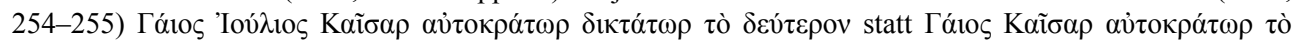
$\delta \varepsilon v ́ \tau \varepsilon \rho o v$, wie es die griechischen Handschriften geben (entsprechend auch die Konjektur für Josephus, ant. 14,10,2 (192); vgl. Niese 1892, 275). Dem wird man entgegenhalten dürfen, dass ein entsprechendes

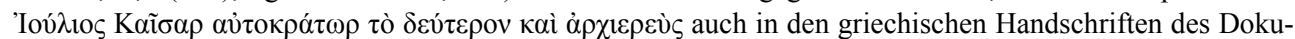
ments bei Josephus, ant. 14,10,3 (192) begegnet (anders dagegen Pucci Ben Zeev 1998, 84, die der Konjektur von Niese und Krebs folgt). Mit der Zeit des Bürgerkrieges scheint Caesar die Zählung seiner Imperatorenakklamationen also neu bekommen zu haben, denn er war bereits 61 v.Chr. in Spanien und 55 v.Chr. in Gallien von den Soldaten als Imperator ausgerufen worden (Combès 1966, 455-456). Im Jahr 46 v.Chr. dagegen

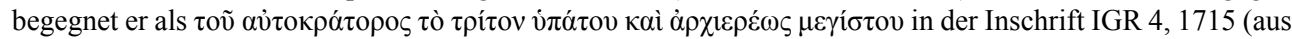

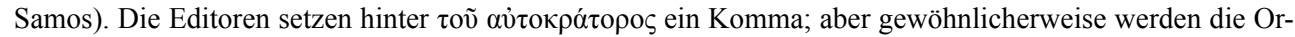

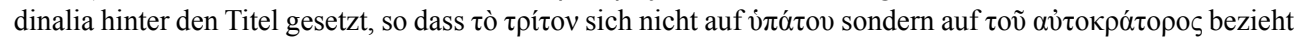
(ebenso die noch nicht publizierte Inschrift, ebenfalls aus Samos, bei Raubitschek 1954, 69). Wir haben damit unabhängig von den Josephus-Texten erstens einen Beleg dafür, dass Caesar in der Zeit des Bürgerkrieges die Zählung seiner Imperatoren-Ausrufungen von neuem begann und zweitens haben wir einen Nachweis darüber, dass die Imperatorenakklamationen in der Zeit des Bürgerkrieges dem Anschein nach zwar in den Inschriften gewöhnlich nicht mit den Ordinalia angegeben wurden (so Pucci Ben Zeev 1998, 84 mit der Literatur dazu; vgl. Combès 1966, 109), dies aber keine durchweg geübte Praxis war. Damit haben die Ordinalia Angaben hinter dem Imperatoren-Titel, wie sie in den hier besprochenen Texten des Josephus begegnen, eine Parallele in der Inschriftendokumentation. 
die Rechtsbeziehungen, welche von jeher zwischen den Juden und ihren Hohepriestern bestanden, sowie die Gunstbezeugungen, die ihnen vom römischen Volke und Senate gemacht worden sind, in Gültigkeit bleiben. [209] Dieselben Rechte sollen sie auch in Lydda genießen. Alle Plätze, ländlichen Weiler und Dörfer, die früher den dem römischen Volke befreundeten Königen von Syrien und Phönizien gehörten und deren Nutznießung sie durch Schenkung derselben erhalten haben, sollen gemäß Senatsbeschluss Eigentum des Ethnarchen Hyrkanus und der Juden sein. [210] Dem Hyrkanus, seinen Söhnen und den von ihm geschickten Gesandten steht das Recht zu, bei den Gladiatorenspielen und Tierkämpfen ihren Zuschauerplatz unter den Senatoren zu nehmen, ${ }^{*}$ und wenn sie sich vom Diktator oder vom Reiteroberst das Wort erbitten, so sollen sie in den Senat eingeführt werden und in zehn Tagen nach dem Senatsbeschluss Antwort erhalten." ${ }^{\text {"56 }}$

Caesar benennt sich, wie im oben zitierten Edikt für Hyrkanus II. und seine Kinder, nur als imperator II, da er zum Zeitpunkt der referierten Anordnungen nach dem Krieg in Aegypten $^{57}$ und vor seiner Rückkehr nach Italien ${ }^{58}$ noch nicht (abschließend) zum Diktator ernannt ist. Gleichwohl hat er, wie der Text des Dokumentes zeigt, im Auge, dass er nach seiner Rückkehr nach Italien, den zur Bestätigung der amicitia et societas mit Rom durch den Senat nach Rom entsendeten Gesandten des Hyrkanus II. dann in seiner

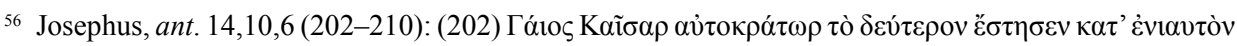

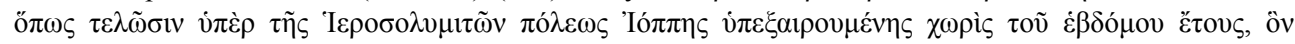

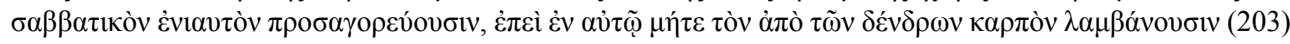

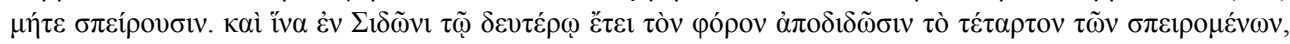

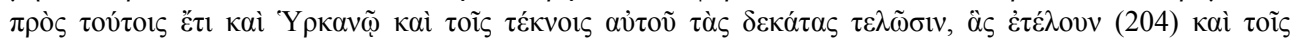

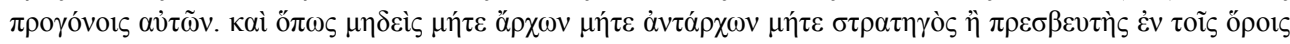

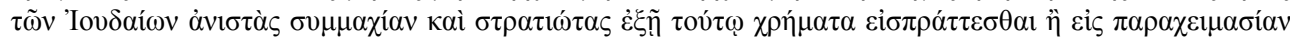

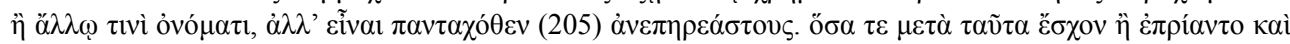

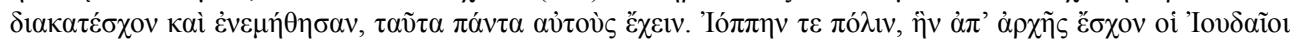

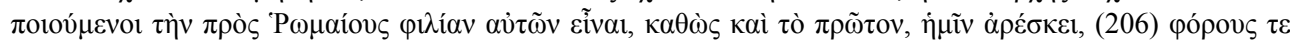

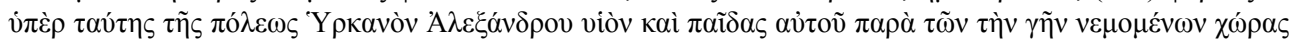

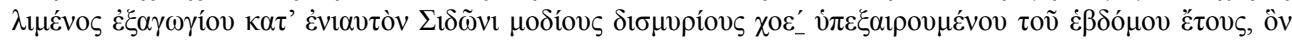

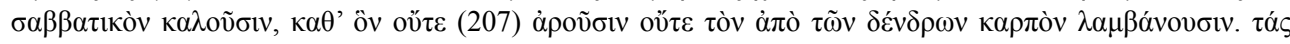

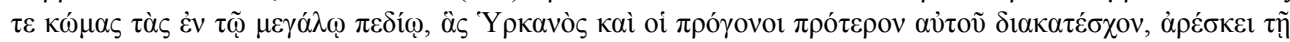

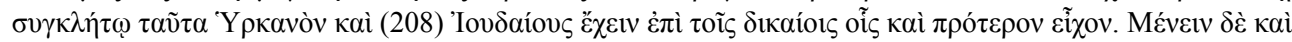

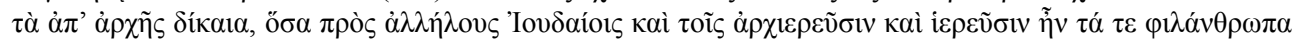

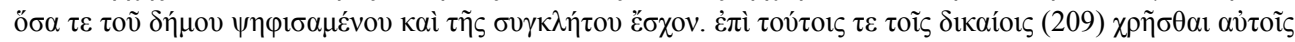

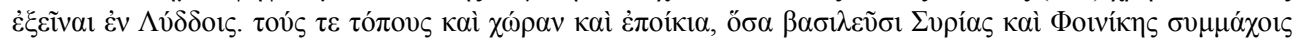

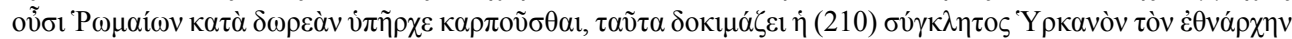

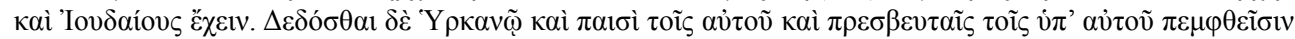

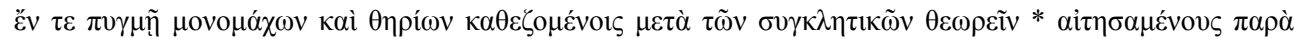

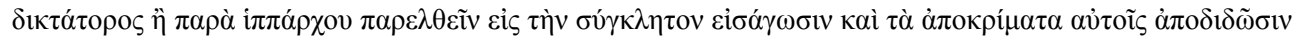

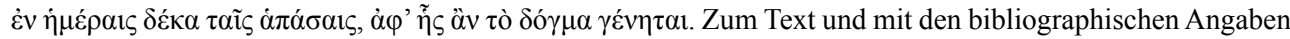
zu der älteren Literatur, vgl. den Kommentar und die Interpretation des Wortlautes bei Pucci Ben Zeev 1998, 80-101 (und zum Verständnis des Inhalts des schwierigen Textes, vgl. auch Schalit 1969, 753-759, 777-781 und Roth 1914, 65-72) und Pucci Ben Zeev (1996b, 82-85; 1996c, 203-205), die den Text vermutungsweise mit dem Jahr 47 v.Chr. verbindet (ebenso dissimulierend Seeman 2013, 329-331 und aus viel früherer Zeit Juster 1914, 140, 141, 158 A. 1, der den Teil Josephus, ant. 14,10,6 (205-210), mit dem Senatsbeschluss des Jahres 44 v.Chr. verbindet (ebenso VanderKam 2004, 38). Momigliano 1934/1967, 14-15 [196-197], 19 [201] verbindet den Text mit einem Senatsbeschluss am Ende des Jahres 47 v.Chr.). Ein nützliches Referat der differierenden älteren Deutungen mit den Literaturangaben gibt auch Freber 1993, 58-59 A. 294, 297-299; vgl. derselbe, ebenda 69-75 zu den steuerrechtlichen und territorialen Regulierungen des Dokumentes.

57 Einnahme Alexandrias 27.03.47 v.Chr., vgl. Judeich 1885, 51-52.

58 Nach der Schlacht bei Zela, 09.08.47 v.Chr., vgl. Judeich 1885, 51-52. 
Eigenschaft als (dann auch förmlich ernannter) Diktator im Senat das Wort erteilen könne. Für den Fall, dass er verhindert sei, lässt er die Möglichkeit offen, dass sein magister equitum den jüdischen Gesandten im Senat das Wort erteilen könne. ${ }^{59}$

Der Text des Josephus ist das Referat über Anordnungen Caesars, ${ }^{60}$ die nach dem Sieg in Aegypten und vor dessen Rückkehr nach Italien erfolgten. Er gehört in denselben zeitlichen Kontext wie das Dokument bei Josephus, ant. 14,10,2 (192-196), wie die Identität der Imperator-Titulatur (imperator II) verdeutlicht. Ob die Anordnungen Caesars gleichzeitig mit dem Dekret bei Josephus, ant. 14,10,2 (192-196), oder früher oder später, erfolgten ist nicht zu entscheiden. Erwägenswert ist es, dass Caesar bei einer Gelegenheit die Verhältnisse in Judäa regelte und dies auch in nur einem Dokument festgehalten wurde, von denen wir nur Ausschnitte in ant. 14,10,2 (192-195) und 14,10,6 (202-210) von Josephus mitgeteilt bekommen, weil ihm bei der Abfassung des Exkurses nur Dokumente vorlagen, in denen die Inhalte der gesamten Anordnungen Caesars mit Rücksicht auf die konkreten Informationsinteressen der Dokumentenempfänger lediglich selektiv kommuniziert wurden.

Das Referat der Anordnungen Caesars besteht aus zwei Teilen. Im ersten Teil trifft Caesar selbst Anordnungen (Josephus, ant. 14,10,6 (202-206)) und im zweiten Teil (Josephus, ant. 14,10,6 (207-209)) trifft er Anordnungen, die sich ausdrücklich auf vorherige Entscheidungen des Senates in Rom stützen, die Hyrkanus II. den vor Zeiten gültigen Besitzstand in Judäa bestätigten. ${ }^{61}$ Die modernen Deutungen, die im zweiten Teil des Textes das Referat eines Senatsbeschlusses aus dem Jahr 47, 46 oder 44 v.Chr. erkennen möchten (Niese/Mendelssohn/Viereck), ${ }^{62}$ zerreißen das von Josephus als Einheit dar-

59 Eine Parallele zu diesem Dokument bietet nach Ansicht des Autors dieses Beitrages das foedus Roms mit Lykien 48/47 v.Chr., vgl. Mitchell 2005, 165-258 und nun auch SEG 55, 1452 (p. 472-479); AE 2005, 1487 und Kantor 2014, 135-136. Kantors Bevorzugung der Textrekonstruktion des Präskripts des foedus durch Mitchell [dictator III] entgegen dem Zeugnis der Inschrift aus Thespiae (Raubitschek 1954, 70-71) kann der Autor dieses Beitrages sich nicht anschließen. SEG 55, 1452, Z. 62 deutet vielmehr darauf hin, dass Caesar auch im Präskript des foedus als imperator bezeichnet wurde. Es verhielt sich also im Fall der dritten Diktatur Caesars wohl so, wie im Fall seiner zweiten Diktatur: Es gab in Rom bereits einen magister equitum, bevor Caesar abschließend nach seiner Rückkehr aus Afrika nach Italien offiziell auch den Titel des Diktators annehmen konnte, was aber erst nach der Beeidung und der Urkundenausfertigung des foedus mit Lykien geschah, weshalb Caesar im Präskript des foedus wahrscheinlich imperator III genannt wurde.

${ }^{60}$ Der Text nimmt zwar am Ende auf vorherige Senatsbeschlüsse Bezug, er ist aber kein Auszug aus einem Senatsbeschluss (so aber vermutungsweise Pucci Ben Zeev 1998, 93-97; Seeman 2013, 329), sondern ein Dekret Caesars, das erfolgte, als er nach dem Sieg in Aegypten die Verhältnisse in Judäa ordnete.

${ }^{61}$ Weiterhin hat Caesar bei der Bezugnahme auf die Senatsbeschlüsse der Vergangenheit auch solche Beschlüsse im Auge, die schon im 2. Jh. v.Chr. erfolgt waren, wie der Bezug insbesondere auf die syrischen Könige (und phönikische socii) der Vergangenheit verdeutlicht (Josephus, ant. 14,10,6 (209)), die es zur Zeit der Anordnungen Caesars schon einige Zeit nicht mehr gab (ohne die Einsicht dieses historischen Rückbezuges auf die Situation am Ende des 2. Jh. v.Chr., Pucci Ben Zeev 1998, 92).

62 Mendelssohn 1875, 197-205; Niese 1876, 486-487; Viereck 1888, 99-101; vgl. auch z.B. die Deutung bei Roth 1914, 80-81, der in Josephus, ant. 14,10,5-7 (200-210) Fragmente eines senatus consultum des Jahres 44 v.Chr. erkennt, wobei Josephus, ant. 14,10,5-6 (200-204) das anlässlich der Senatssitzung gehaltene Referat, der bereits im Jahr 47 v.Chr. von Caesar ergangenen Anordnungen, sei und wobei Josephus, ant. 14,10,7 (211-212) einen Teil Rede Caesars im Senat referiere, während Josephus, ant. 14,10,6 (205-210) den Inhalt des Senatsbeschlusses des Jahres 44 v.Chr. wiedergebe. Grätz 1905, 664 legt den Text in das Jahr 47 v.Chr. Einen Überblick über die chronologischen Deutungen des Dokuments in der älteren Literatur bietet auch Freber 1993, 58 A. 294. 
gebotene Referat in zwei unterschiedlich alte Teile, wozu keine Veranlassung besteht. ${ }^{63}$ Denn die Bezugnahme auf mehrere Senatsbeschlüsse der Vergangenheit im zweiten Teil des Referates (Josephus, ant. 14,10,6 (207-209)) muss sich nicht auf den angeblichen Senatsbeschluss über die amicitia et societas mit Hyrkanus II. vom Ende des Jahres 47 v.Chr. (oder 46 v.Chr.) oder einen Senatsbeschluss im Jahr 44 v.Chr. (Mendelssohn/ Niese/Viereck) beziehen, sondern kann grundsätzlich auch an die Entscheidungen des Senates im Jahr 48 v.Chr. anknüpfen, die bei Josephus, ant. 14,10,3 (196-198) nur sehr summarisch mitgeteilt werden. Der Text bei Josephus, ant. 14,10,3 (196-197): ö $\pi \omega \varsigma$

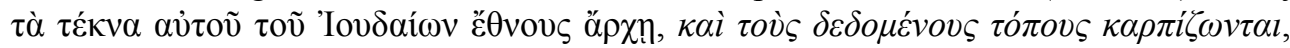

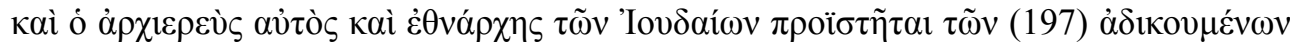
lässt sich mit Josephus, ant. 14,10,6 (207-210) in der inhaltlichen Aussage zumindest

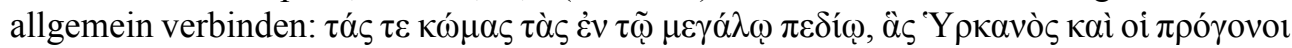

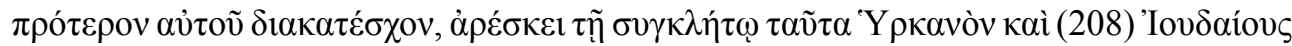

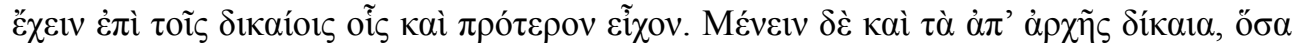

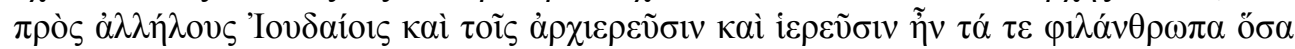

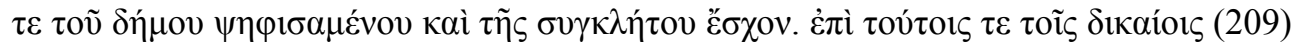

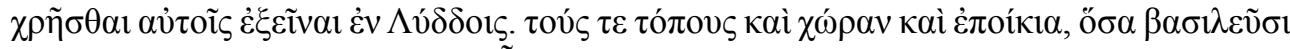

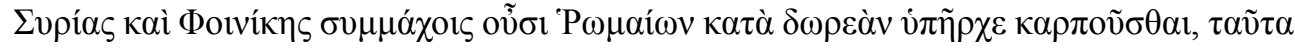

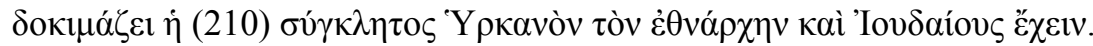

Der Inhalt des Senatsbeschlusses aus dem Jahr 48 v.Chr. lässt sich also in den Grundzügen rekonstruieren, wenn man Josephus, ant. 14,10,2 (192-195), 14,10,3 (196-198) und 14,10,6 (207-209) zusammennimmt.

In einen Brief teilt Caesar seine jüngst getroffenen Entscheidungen in Hinsicht auf den Besitzstand des Hyrkanus II. dem Senat mit und fordert die Konsuln außerdem auf, seine Anordnungen auf dem Kapitol zu publizieren.

Josephus, ant. 14,8,5 (143-144): [143] „Als Antipater so geredet hatte, bestätigte Caesar den Hyrkanus als Hohepriester, gab dem Antipater die Machtbefugnis, die er selbst wünschte, jede gewünschte Machtbefugnis und ernannte ihn zum Epitropos von ganz Judäa. [144] Auch erlaubte er dem Hyrkanus, die Mauern seiner Vaterstadt, die noch von Pompejus her zerstört dalagen, wieder aufzubauen, weil dieser darum bat und schrieb nach Rom an die Konsuln, sie sollten dies auf dem Kapitol publizieren. ${ }^{“ 64}$ (Übersetzung mit Modifikationen nach derjenigen von Heinrich Clementz).

Es kam anders, als es Caesar ursprünglich in Aussicht gestellt hatte. Die nur mündlich erteilte Erlaubnis zum Wiederaufbau der Mauern Jerusalems, ${ }^{65}$ deren Anordnung über den Senatsbeschluss des Jahres 48 v.Chr. hinausging, wurde im Jahr 47 v.Chr. vom Senat nicht bestätigt. Dies geht vor allem daraus hervor, dass diese Anordnung erst im Jahr 44 v.Chr. - also nach der bereits erfolgten Bestätigung der amicitia et societas Roms

${ }^{63}$ Mendelssohn 1875, 197-205; Viereck 1888, 99-100; Schürer, Theologische Literaturzeitung 1 Heft 15, 1875, 394; Schürer 1890, 281 A. 23; vgl. auch die Literaturnachweise bei Pucci Ben Zeev 1998, 93-94 und ihre Deutung 93-96, 97 [Fazit].

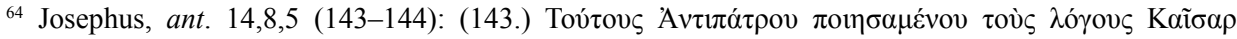

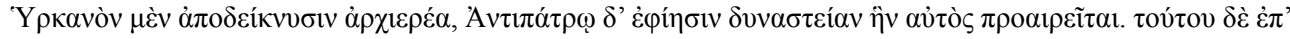

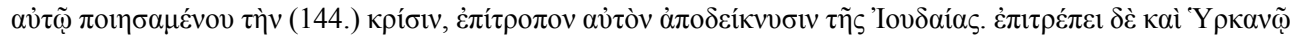

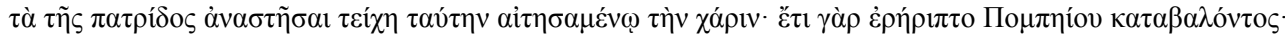

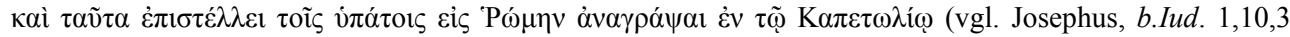
(199-200)).

${ }^{65}$ In den Edikten Caesars findet sich keine entsprechende Anordnung Caesars in Hinsicht auf Jerusalem! 
mit den Juden am 13.12.47 v.Chr. (Josephus, ant. 14,8,5 (145-148)) - von Caesar mit einem Edikt in ihrer Gültigkeit bestätigt wurde (Josephus, ant. 14,10,5 (200-201)). ${ }^{66}$ Zudem gab es vor dem Ende des Jahres 47 v.Chr. keine Konsuln, die vor der Rückkehr Caesars nach Italien die Bestätigung der mündlichen Anordnung Caesars hätten beantragen und schließlich auf dem Kapitol hätten publizieren können. ${ }^{67}$ Solche Konsuln wurden nach dem Ende der zweiten Diktatur Caesars erst am Ende des Jahres gewählt, und sie hatten ihr Amt nur für kurze Zeit. ${ }^{68}$

Die Gesandten des Hyrkanus II. erreichen zunächst von Caesar, dass er einen Teil der durch den Senatsbeschluss von 48 v.Chr. angeordneten und von ihm in einem Edikt schließlich festgehaltenen Vereinbarungen in einem Brief dem Volk und den Magistraten von Sidon als politischen Willen Roms mitteilt (Josephus ant. 14,10,2 [190-195]). ${ }^{6}$ Der Brief Caesars an Sidon gehört demnach nicht, wie es bisher stets angenommen wird, ${ }^{70}$ in die Zeit nach Caesars Sieg in Aegypten, sondern in die Zeit nach Caesars Rückkehr nach Italien an das Ende des Jahres 47 v.Chr., weshalb er sich in dem Brief auch als imperator pontifex maximus dictator II benennen kann, was er aus Gründen des Zeremoniells, wie gezeigt, vor dem Ende des Jahres 47 v.Chr. unterlassen hatte. ${ }^{71}$

Die über den Beschluss des Senates im Jahr 48 v.Chr. hinausgehende mündliche Anordnung Caesars über den Wiederaufbau der Mauern Jerusalems war dagegen nicht, wie ehedem von Caesar gefordert, vom Senat und Volk ratifiziert und auf dem Kapitol publiziert worden, auch weil eine solche Handlung einer Senatssitzung unter Vorsitz des zuständigen Magistraten (also Caesars als dictator oder M. Antonius als magister equitum) und einer gleichlautenden relatio bedurfte. Caesars zweite Diktatur war aber

${ }^{66}$ Eine Parallele für eine zeitverzögerte innerrömische Ratifikation (unter Beteiligung der Komitien) eines intergesellschaftlichen Vertrages Roms mit der Außenwelt in der Zeit Caesars bietet das foedus Roms mit Lykien, das wohl 47 v.Chr. ausgehandelt wurde und erst im Juli 46 v.Chr. (vor Caesars Rückkehr nach Italien) in Rom ratifiziert und als offiziell gebilligte und angeordnete Urkunde ausgefertigt wurde, vgl. Mitchell 2005, 165-258 und nun auch SEG 55, 1452 und AE 2005, 1487. Schiffe aus Lykien unterstützten Caesar bereits im Alexandrinischen Krieg: Caesar, b. Alex. 13,5. In späterer Zeit verweigern die Lykier und Rhodier dem C. Cassius die Waffenhilfe, weil sie Caesar gut behandelt hatte, weshalb C. Cassius gegen die Lykier zu Felde ziehen musste und Xanthos, Patara und Myra belagern musste: Cassius Dio 47,33,1-2; 47,34,1-6; 47,36,3-4.

67 Darauf machte bereits Mommsen 1875, 286 aufmerksam.

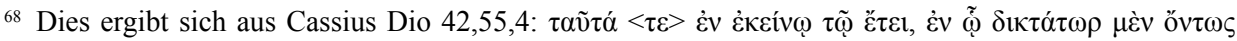

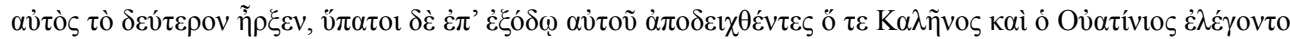
عĩvol ... Die Übersetzung nach Otto Veh lautet: „Dies waren seine Taten in jenem Jahr, in dem er tatsächlich allein als Diktator zum zweiten Male herrschte, obschon er zu Jahresende Calenus und Vatinus zu Konsuln ernannte, die dieses Amt bekleidet haben sollen." Die zweite Diktatur wird weiterhin in den fasti Capitolini ausdrücklich unter dem Jahr 47 v.Chr. geführt (Degrassi 1954, 78) - zuerst werden C. Iulius C.f. C. n. Caesar II dictator und M. Antonius M. f. M. n. magister equitum genannt und dann werden erst die Konsuln des Jahres Q. Fufius Q. f. C. n. Calenus und P. Vatinius P. f. genannt.

69 Josephus, ant. 14,10,2 (190-195), siehe das Zitat und die Übersetzung oben im Text.

70 Z.B. Grätz 1905, 664; Roth 1914, 52; Saulnier 1981, 171-172, 196; Pucci Ben Zeev 1998, 51-53.

71 Der Brief an Sidon hat zur Voraussetzung, dass das dem Brief angehängte Dekret in Hinsicht auf Hyrka-

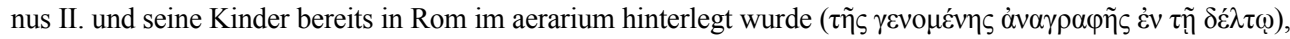
was im Kontext der innerrömischen Ratifikationsvorgänge von außenpolitischen Handlungen zumindest dessen Bestätigung durch den Senat in Rom zur Voraussetzung hat, so dass der Brief Caesars aus Gründen der politischen Praxis Roms und den damit verbundenen Zeitverzögerungen auf jeden Fall einige Zeit nach dem Dekret Caesars für Hyrkanus II. und seine Kinder geschrieben worden sein muss. Die Titulatur Caesars (er nennt sich nun dictator II) im Brief an Sidon führt auf die Zeit nach Caesars Rückkehr nach Italien. 
bereits beendet (Herbst 47 v.Chr.), als die Gesandten des Hyrkanus II. einen Empfang durch den Senat erhielten. Sie wurden vom Senat unter dem Vorsitz des Prätors Lucius Valerius empfangen (13.12.47 v.Chr. $\left.{ }^{72}\right)$.

Josephus ant. 14,8,5 [145-148]: „Der diesbezügliche Senatsbeschluss lautet so: [145] Der Prätor Lucius Valerius, Sohn des Lucius, beriet mit dem Senat an den Iden des Dezember (13. Dezember) im Tempel der Concordia. Bei der Niederschrift des senatus consultum waren zugegen: Lucius Coponius, Sohn des Lucius, aus der Collinischen Tribus, und Papirius aus der Quirinischen Tribus. [146] Weil die jüdischen Gesandten Alexander, Sohn des Jason, Numenius, Sohn des Antiochus, und Alexander, Sohn des Dorotheus, die viri boni und socii sind, darum gebeten haben, dass ihre von früher her mit den Römern bestehende gratia und amicitia erneuert werde, [147] und als Zeichen der societas einen goldenen Schild im Werte von fünfzigtausend Goldstücken überbrachten und weiterhin auch Briefe an die freien Städte und die Könige sich ausgebeten haben, um das Gebiet und die Häfen derselben in Sicherheit und unbehelligt besuchen zu können, [148] hat der Senat beschlossen, mit ihnen amicitia und gratia zu schließen, ihre Bitten zu bewilligen und den Schild anzunehmen. ${ }^{73}$ Das geschah im neunten Jahre der Regierung und des Hohepriestertums

${ }^{72}$ Der Senatsbeschluss erfolgte, wie der Urkundentext zeigt, am 13.12.47 v.Chr., was sich weder nach dem julianischen noch nach dem vorjulianischen Kalender Roms mit der Synchronisierung mit dem Monat Panemos verbinden lässt. Eugen Täubler hat dies plausibel damit erklärt, dass sich die Datumsangabe nicht auf den Urkundentext (Josephus, ant. 14,8,5 (145-148)), sondern auf den unmittelbar vor dem Dokumentenzitat erwähnten Brief Caesars nach Rom bezieht; Täubler 1913, 164 A. 3. 164-166 (ebenso Ritschl 1873, 600 A. 15 und Mommsen 1875, 285, der den Synchronismus ebenso mit dem Aufenthalt Caesars in Syrien verbindet).

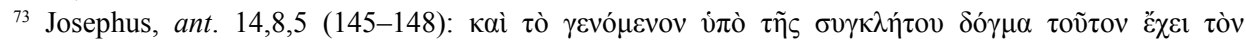

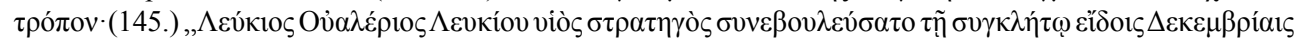

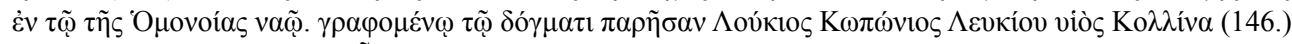

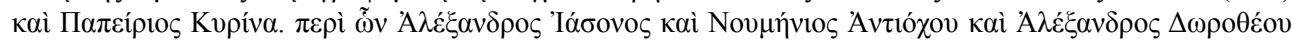

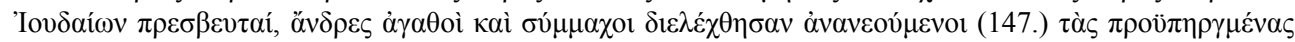

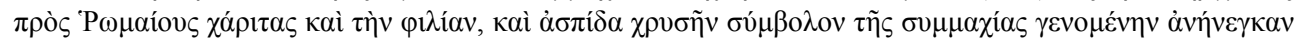

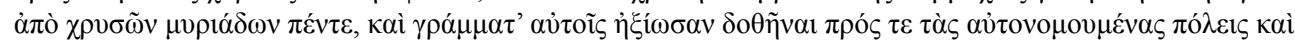

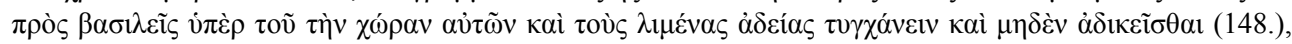

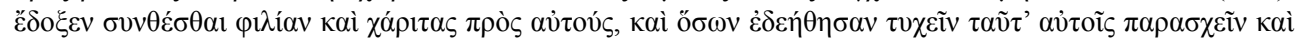

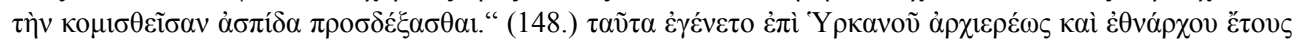
غ̇vót Unger 1894, 553-575 im Kontext seiner Darstellung, die zu erweisen sucht, dass das senatus consultum von Josephus am falschen Platz zitiert wurde, aber nicht in das Jahr 139 v.Chr. gehört (Ritschl/Mendelssohn), sondern in das Jahr 128 v.Chr. und im Jahr 127 v.Chr. im Tempelarchiv niedergelegt wurde und vgl. auch die Diskussion des Dokumentes und der Forschungsliteratur bei Juster 1914, 135-138. Von den älteren Beiträgen, vgl. Scaliger 1658, 157; Ritschl 1873, 596-605, und vgl. die gegenläufige Erwiderung von Theodor Mommsen (1875, 281-291, die aber von Ritschl - Mendelssohn 1875, 419-435 als keineswegs zwingend erwiesen wurde, vgl. weiterhin Mendelssohn 1875, 112-122; Mendelssohn 1877, 253-254 und vgl. aber auch die Erwiderung darauf im Jahr 1885 bei Judeich $(1885,130-135)$. Die Interpretation, wonach Josephus das senatus consultum am historisch falschen Ort zitiert, darf als die heute herrschende communis opinio gelten. Umstritten ist lediglich, ob das Dokument mit Simon Makkabäus (139 v.Chr.) oder mit Johannes Hyrkanus I. (128/127 v.Chr.) zu verbinden sei. Beispielsweise die Darstellung von Pucci Ben Zeev 1998, 399, 396, die das Dokument nicht gesondert bespricht, basiert durchgehend auf der Voraussetzung dieser Deutung; ebenso in neuerer Zeit Seeman 2013, 189-194. Von denen, die den Senatsbeschluss in das zweite Jh. v.Chr. verlegen, vgl. weiterhin z.B.: Viereck 1888, 103-106; Grätz 1905, 658-560; Roth 1914, 40-47; Momigliano 1934/1967, 30-35 [212-217]; Vermes et al. 1973, 195-197 (mit älterer Literatur); Smallwood 1976, 8 f. A. 15 (mit älterer Literatur); Fischer 1970, 96; Gauger 1977, 285 mit A. 240; Giovannini - Müller 1971, 163-164. Mit der Zeit Caesars wird das Dokument in älterer Zeit noch verbunden von z.B.: Mommsen 1875, 281-291; Niese 1876, 486-488; Judeich 1885, 129-135; Täubler 1913, 163-167 und Juster 1914, 135-138. 
des Hyrkanus, im Monate Panemos." ${ }^{\text {"74 }}$ (Die Übersetzung unter Zugrundelegung derjenigen von Heinrich Clementz).

Die Gesandten des Hyrkanus II. konnten in der Senatssitzung nur die Erneuerung der amicitia et societas mit Rom erreichen. Damit wurden in der politischen Konsequenz nur die schon im Jahr 48 v.Chr. für die Aushandlung der amicitia et societas vom Senat vorgesehenen politischen Inhalte in ihrer Gültigkeit bestätigt, die Caesar in zwei Edikten zuvor Hyrkanus II. bereits förmlich gewährt hatte (Josephus, ant. 14,10,3 (196-198); 14,10,6 (202-210)), die bereits im aerarium hinterlegt worden waren und die er auf Bitten der Gesandten des Hyrkanus II. in einem Brief an Sidon auszugsweise öffentlich kommuniziert hatte. ${ }^{75}$ Dies war das politische Ergebnis der Senatsverhandlung.

Die inhaltliche Differenz zwischen den das senatus consultum einleitenden Worten (Josephus, ant. 14,8,5 (143-145)) ${ }^{76}$ und dem Text des Senatsbeschlusses (Josephus, ant. 14,8,5 (145-148)) ist also kein Hinweis darauf, dass Josephus die Urkunde in einem falschen historischen Zusammenhang zitiert (Scaliger/Ritschl/Mendelssohn), sondern

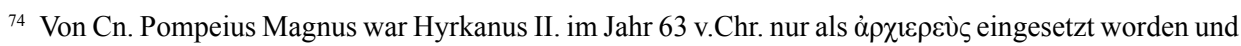
dessen Anspruch auf die Oberherrschaft über die Juden war nicht ausdrücklich unterbunden worden (Josephus, ant. 14,4,4 (73); 20,10,4 (244-245)). Das Tragen des Diadems (= Zeichen der Königswürde) wurde Hyrkanus II. von Pompeius aber untersagt (Josephus, ant. 20,10,4 (244). Die Bezeichnung von Hyrka-

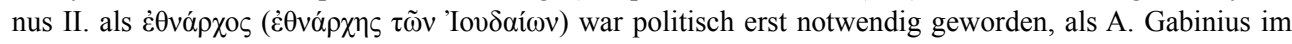
Jahr 56/55 v.Chr. die Ordnung Judäas nun grundsätzlich in eine ,,aristokratische“ Regierungsform überführte (Josephus, ant. 14,5,4 (91)) und damit den zwischenzeitlich von Hyrkanus II. erhobenen Anspruch auf die andauernde Oberherrschaft in Judäa (

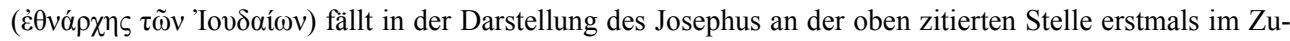
sammenhang mit der Rückschau auf die Ordnung des Gabinius im Jahr 56/55 v.Chr.). Von diesem Jahr an rechnet Josephus m.E. an der oben zitierten Stelle das Jahr 47 v.Chr. als das neunte Jahr des Hyrkanus II. als

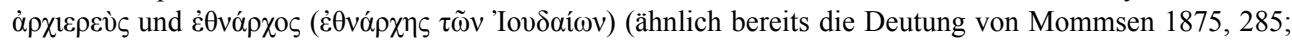
anders dagegen z.B. Pucci Ben Zeev 1998, 49 und Seeman 2013, 192). Die Bezeichnung der herrschaftli-

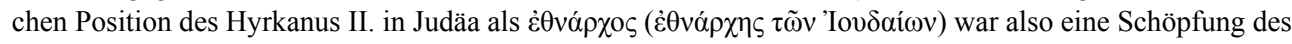
A. Gabinius und nicht schon des Cn. Pompeius Magnus (contra die traditionelle Deutung etwa bei Baumann 1983, 37-38; Sharon 2010, 479-481 mit der älteren Literatur in den Anmerkungen; kritisch aber dazu auch Eckhardt 2013, 237 mit. A. 373 und Sharon 2010, 479-481, der die erstmalige Verleihung des Titels Ethnarch an Hyrkanus II. aber mit Caesar verbindet, wobei er in diesem Zusammenhang das Zeugnis von Josephus ant. 14,5 [148] übersieht), der Hyrkanus II. zwar den Königstitel verwehrte, aber ihm in der Folgezeit zumindest die Möglichkeit beließ, (wie ein König) die politische und rechtliche Oberherrschaft über die Juden für sich zu beanspruchen, was A. Gabinius schließlich formal unterband, indem er Hyrkanus II. den neu kreierten

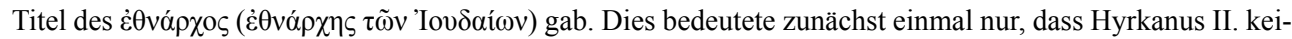

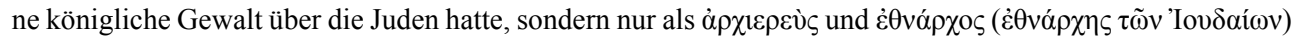
eine herausgehobene geistliche und (weitgehend undefinierte) weltliche Position unter den Juden einnahm. In den auf die Anordnungen von A. Gabinius folgenden Jahren ging es nun für Hyrkanus II. vor allem darum,

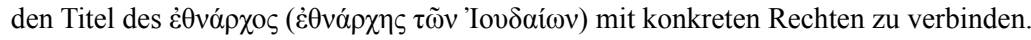

${ }^{75}$ Im Brief an Sidon (Josephus, ant. 14,10,2 (190-195)) werden nur diejenigen Inhalte der Anordnungen Caesars kommuniziert, die eine Bedeutung für Einwohner und Besucher (z.B. römische Statthalter) Sidons hatten. Die darüber hinausgehenden Anordnungen Caesars, die Sidon nicht betrafen, blieben dagegen unerwähnt, vgl. Josephus, ant. 14,10,6 (202-210).

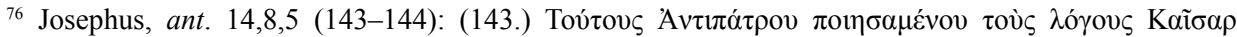

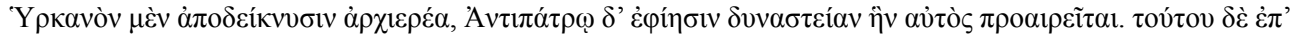

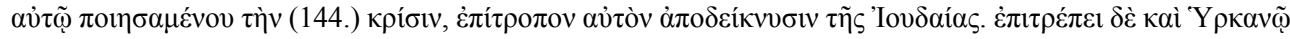

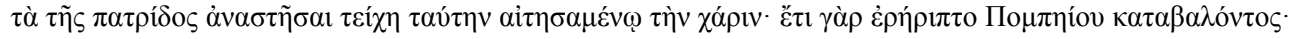

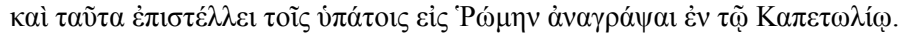


die inhaltliche Differenz ist vielmehr die politische Botschaft des Textes! Die jüngste mündliche Anordnung Caesars in Hinsicht auf den Wiederaufbau der Mauern Jerusalems, auf die das Dokumentenreferat einleitenden Worte des Josephus Bezug nehmen und die ihrem Inhalt nach über den Wortlaut des senatus consultum aus dem Jahr 48 v.Chr. (Josephus, ant. 14,10,3 (196-198)) hinausgingen, wurde am Ende des Jahres 47 v.Chr. vom Senat nicht bestätigt.

Die von Joseph Justus Scaliger (1540-1609) begründete und von Friedrich Ritschl (1806-1876) und Ludwig Mendelssohn (1852-1896) in den Jahren 1873 bis 1875 argumentativ entwickelte Deutung, wonach der Text des senatus consultum von Josephus am falschen historischen Ort in der Darstellung platziert worden sei, basiert in ihrem Kern lediglich auf der Beobachtung, dass der Inhalt des Senatsbeschlusses nicht mit den das Zitat einleitenden Worten des Josephus übereinstimmt, und erklärt dies damit, dass Josephus ein senatus consultum aus der Zeit des Hyrkanus I. versehentlich in die historische Darstellung der Zeit des Hyrkanus II. versetzt habe. Diese Interpretation darf als die heute herrschende communis opinio gelten. Die aus der Beobachtung heraus entwickelte Deutung ist keineswegs stichhaltig. Denn sie bezieht nicht in die Überlegungen mit ein, dass die fehlende Übereinstimmung zwischen den einleitenden Worten des Josephus mit dem Inhalt des in der Erzählung folgenden Senatsbeschlusses eine hinreichende Erklärung darin finden, dass die Anordnung Caesars in Hinsicht auf Jerusalem im Jahr 47 v.Chr. eben gerade vom Senat nicht bestätigt wurden. Mit dieser Erklärung erhalten auch die auf das Jahr 47 v.Chr. folgenden Gesandtschaften des Hyrkanus II. an Caesar und nach Rom einen diplomatischen Sinn. Die Fragen der Befestigung Jerusalems und der Herrschaft des Hyrkanus II. in Jerusalem waren im Jahr 47 v.Chr. nicht abschließend geklärt worden, und es bestand also noch Bedarf an einer weiteren Regulierung des Verhältnisse der Juden zu Rom. Weiterhin unterscheidet sich der Inhalt des senatus consultum bei Josephus deutlich vom dem des Senatsbeschlusses im Makkabäerbuches (1 Makk. 14,16-24; 15,15-24), mit dem nach der heute gängigen Deutung das senatus consultum bei Josephus in der Sache verbunden wird. Dagegen wiegt die Übereinstimmungen, nämlich die Gestalt und das Gewicht des von den jüdischen Gesandten mitgebrachten Geschenkes (goldener Schild), gering, da es auch im diplomatischen Verkehr Roms mit fremden Gemeinwesen standartisierte Formen des Geschenkes gab, die sich wiederholen konnten. ${ }^{77}$ Im Makkabäerbuch ist es der Konsul Lucius, der die Senatssitzung leitet und auf Beschluss des Senates einen Brief an die Könige und Länder absendet. Bei Josephus

Die Übersetzung unter Zugrundelegung derjenigen von Heinrich Clementz lautet, Josephus, ant. 14,8,5 (143-144): ,[143] Als Antipater so geredet hatte, bestätigte Caesar den Hyrkanus als Hohepriester, gab dem Antipater jede gewünschte Machtbefugnis und ernannte ihn zum Epitropos von ganz Judäa. [144] Auch erlaubte er dem Hyrkanus, die Mauern seiner Vaterstadt, die noch von Pompejus her zerstört dalagen, wieder aufzubauen, und schrieb nach Rom an die Konsuln, sie sollten dies auf dem Kapitol publizieren.“

${ }^{77}$ Lediglich das Gewicht der goldenen Schilde, die die Gesandten nach Rom brachten, entsprechen einander, wobei die Gewichtsangabe von 1000 Minen des im Makkabäerbuch erwähnten Schildes dem Gewicht des mit 50000 Goldmaßeinheiten von Josephus erwähnten Schildes entsprechen, sofern man für die Angabe des Josephus den Schekel als Gewichtseinheit (50 Schekel = 1 Mine) als Maßeinheit zurundelegt. Die Identität des von den Gesandten mitgebrachten Geschenkes entscheidet aber nicht über die Identität der Gesandtschaften; denn in der Praxis Roms gab es für unterschiedliche Klassen fremder in Rom empfangener Gesandtschaften ebenso standartisierte Quantitäten des Gastgeschenkes, die sich bei unterschiedlichen Gesandtschaften in der diplomatischen Praxis also grundsätzlich wiederholen konnten. 
dagegen leitet der Prätor Lucius Valerius die Senatsverhandlung. Im Makkabäerbuch ist Numenius der Leiter der Gesandtschaft nach Rom, während bei Josephus ein Gesandter mit Namen Numenius nur eines der Mitglieder der dreiköpfigen Gesandtschaft ist, der im Protokoll der Senatsitzung nicht an erster sondern an zweiter Stelle genannt wird. Der Brief des Senates im Makkabäerbuch $(1$ Makk. 15,19) weist die Könige und Länder an, weder Krieg mit den Juden zu führen noch kriegerische Aktionen gegen die Juden zu unterstützen und ihnen aus Judäa geflohene Verbrecher auszuliefern. Der Senatsbeschluss bei Josephus dagegen gibt den Gesandten lediglich Briefe mit, die es ihnen gestatten unbehelligt das Gebiete der Könige und Städte zu bereisen. Ein Kriegsverbot gegen die Juden wird im senatus consultum bei Josephus von den jüdischen Gesandten nicht erbeten und vom Senat also auch nicht formuliert. Die Unterschiede schließen es aus, dass der bei Josephus mitgeteilte Senatsbeschluss mit dem des Makkabäerbuches identisch ist und Josephus ihn versehentlich in die Erzählung über die Zeit Caesars eingefügt hat.

Wenn man im Sinne der älteren Deutungen (Niese/Mendelssohn) meinen möchte, es sei unglaubhaft, dass Hyrkanus II. ohne ausdrückliche Erlaubnis des Senates bereits im Jahr 47 v.Chr. mit dem Aufbau der Mauern Jerusalems begonnen habe (Josephus, ant. 14,9,1 (156); b.Iud. 1,10,4 (201)) und eine solche Erlaubnis erst im Jahr 44 v.Chr. erhielt, wird man dem entgegenhalten können, dass die mündlich erteilte Anordnung des politisch dominierenden Caesar 47 bis 44 v.Chr. Konflikte wegen des begonnenen Wiederaufbaus der Mauern Jerusalems mit dem römischen Senat politisch ausschlossen und mit einer endgültigen Bestätigung der Anordnung Caesars durchaus gewartet werden konnte, bis diese praktisch umzusetzen war (die praktische Voraussetzung war die länger andauernde Anwesenheit Caesars in Rom, was erst 45/44 v.Chr. gegeben war).

Vor dem Hintergrund der oben rekonstruierten politischen Sachlage erreichten die Gesandten des Hyrkanus II. von Caesar im Jahr 46 v.Chr., der nun nach dem Sieg bei Thapsos (06.04.46 v.Chr.) imperator dictator consul ist, nur noch eine detailliertere Ausformulierung und Auslegung einer Bestimmung, die Caesar nach dem Krieg in Aegypten im damaligen Edikt noch gedrängt formuliert hatte (Josephus, ant. 14,10,2 (194):

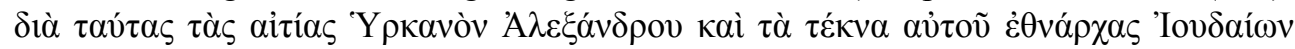

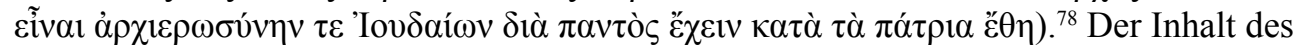

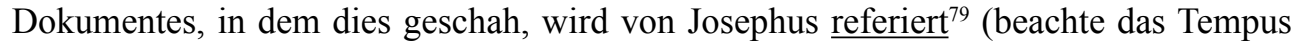

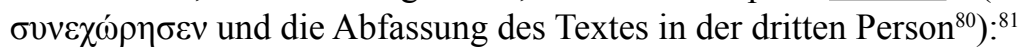

Josephus, ant. 14,10,4 (199): Gaius Caesar, Imperator, Diktator und Konsul, gewährt hiermit wegen der Tapferkeit und des Wohlwollens und der Philanthropie und in Übereinstimmung mit dem Senat

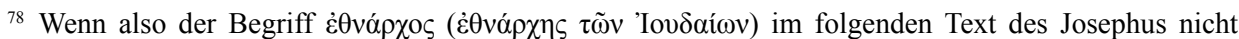
vorkommt, dann hat dies seine Ursache darin, dass gerade dieser Begriff in seiner Bedeutung konkretisiert werden sollte, contra Momigliano 1934/1967, 12 [194], der das „Dokument“ u.a. mit diesem Argument als seinem Inhalt nach älter als der angebliche Senatsbeschluss des Jahres 47 v.Chr. (Josephus, ant. 14,10,3 (196-198)) in das Jahr 48 v.Chr. datieren möchte (ihm folgen Vermes et al. 1973, 274 und Seeman 2013, 326-328; Saulnier 1981, 171-172, 196 das Dokument 49/48 v.Chr. datiert).

79 Pucci Ben Zeev 1996b, 80 denkt an ein senatus consultum als Vorlage (ebenso Seeman 2013, 326); aber bei genauer Betrachtung ist die Dokumentenvorlage des Josephus ein Edikt Caesars, in dem er (als Diktator) einen Aspekt eines vorherigen Senatsbeschlusses mit einer Verbalhandlung rechtlich vollzieht.

80 So z.B. auch Pucci Ben Zeev 1996b, 80; 1998, 72.

${ }^{81}$ Sprachlich lehnt sich der Text allerdings eng an den Wortlaut des zugrunde liegenden Dokumentes an, vgl. den Kommentar bei Pucci Ben Zeev 1998, 69-70. 
und dem Volkes der Römer, dass Hyrkanus, der Sohn Alexanders, und dessen Söhne Hohepriester und Priester für Jerusalem und das ganze Volk sein sollen mit denselben Rechten und Befugnissen, die auch ihre Vorgänger im Priestertum besessen haben. (Die Übersetzung mit Modifikationen nach derjenigen von Heinrich Clementz). ${ }^{82}$

Auffällig ist es, dass das Dokumentenreferat die Titel Caesars imperator dictator consul ohne die Ordinalia angibt. ${ }^{83}$ Im Jahr 49 v.Chr. war Casear imperator und kurzfristig imperator dictator, im Jahr 48 v.Chr. war er imperator consul, im Jahr 47 v.Chr. war er, wie gezeigt, zunächst imperator, dann nach dem Sieg über Aegypten imperator II und dann nach der Einsetzung als Diktator in Italien imperator [II] dictator II. Im Jahr 46 v.Chr. war er dagegen erstmals imperator dictator consul gleichzeitig. Das dem Referat des Josephus zugrunde liegende Dokument war im Jahr 46 v.Chr. auch ohne die Ordinalia in seiner chronologischen Aussage eindeutig. Erst aus rückwärtiger Sicht ist die Datierung mehrdeutig. ${ }^{84}$ Am Anfang des Jahres 46 v.Chr. aber konnte niemand wissen, dass Caesar nach der Schlacht bei Munda (17. März 45 v.Chr.) imperator und im Jahr 45/44 v.Chr. dictator $I V$., dictator $V$. und nochmals consul $I V$., consul $V$. und schließlich dictator perpetuus sein würde. Die Ordinalia waren demnach in der konkreten Situation am Anfang des Jahres 46 v.Chr. für die Zwecke einer eindeutigen Chronologie entbehrlich. Josephus übernahm in (historisch) oberflächlicher Manier das charakteristische Merkmal seiner Urkundenvorlage in dessen Referat, was, wie wir es schon bisher beobachten konnten, ein typisches Kennzeichen seiner Arbeitsweise ist. ${ }^{85}$

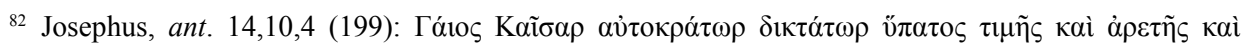

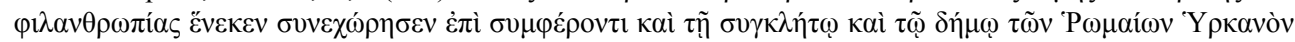

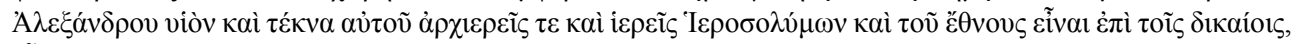

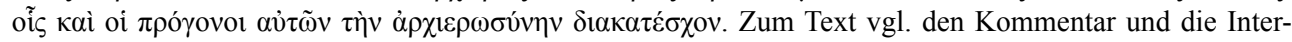
pretation bei Pucci Ben Zeev 1998, 68-73 mit dem Nachweis der älteren Literatur und Pucci Ben Zeev 1996b, 79-81; 1996c, 201-202 und in neuerer Zeit Seeman 2013, 326-328. In das Jahr 48 v.Chr. datieren Momigliano 1934/1967, 11-12 [193-194], 18 [200] und Smallwood 1976, 37 den Text des Josephus (für das Jahr 49/48 v.Chr. Saulnier 1981, 171-172, 196), was schwer möglich ist, da die förmliche Bestätigung Hyrkanus II. als Ethnarchos erst nach dem Sieg in Aegypten durch Caesar im Jahr 47 v.Chr. erfolgte - auf diese Anordnung Caesars aber nimmt der Text des Josephus doch offensichtlich Bezug und er hat sie also bereits zur sachlichen Voraussetzung, so dass der Text seinem Inhalt nach in die Zeit nach dem Krieg in Aegypten gehören muss. Weiterhin trug Caesar in der Zeit von Herbst 48 bis Herbst 47 v.Chr. nicht gleichzeitig die Titel des Konsuls und des Diktators, sondern war titularer Diktator erst nach seiner Rückkehr nach Italien. Erst im Jahr 46 v.Chr. ergab es sich erstmals, dass Caesar nach der Schlacht bei Thapsos (06.04.46 v.Chr.) titular dictator III und consul III gleichzeitig war.

${ }^{83} \mathrm{Zu}$ den an dieses Merkmal der Urkunde anknüpfenden diversen chronologischen Einordnungen des Dokumentes in der älteren Forschung (49/48 v.Chr. [Saulnier 1981, 171-172, 196], 48 v.Chr. [Momigliano 1934/1967, 12 [194]; Seeman 2013, 326-328], 47 v.Chr. [Viereck 1888, 99], 46 v.Chr. [Mendelssohn 1875, 208], 44 v.Chr. [Judeich 1885, 139]), vgl. Pucci Ben Zeev 1998, 71-73.

${ }^{84}$ Seeman 2013, 327 beispielsweise macht (aus der Sicht des modernen Lesers) darauf aufmerksam, dass Caesear die entsprechenden Titel 48, 46, 45 und 44 v.Chr. besaß.

${ }_{85}$ Viereck 1888, 99 und Roth 1914, 60-61 beispielsweise halten dagegen die einleitenden Worte zum Dokumentenreferat für eine Zutat des Josephus, dagegen aber Pucci Ben Zeev, 1996b, 79-80; $1998,70$.

Für die Datierung des Dokumentes in die Zeit nach dem Senatsbeschluss über die amicitia et societas Roms mit Hyrkanus II. (Josephus, ant. 14,8,5 (145-148)) spricht weiterhin der Inhalt des Textes, der zur Voraussetzung hat, dass sich Hyrkanus II. im Krieg im Jahr 47 v.Chr. in Aegypten bereits um Rom mit militäri-

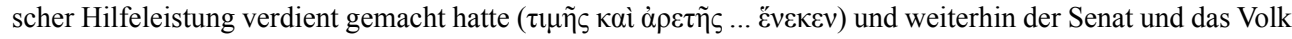
von Rom die amicitia et societas mit ihm und die damit verbundenen Privilegien in ihrer Verbindlichkeit im

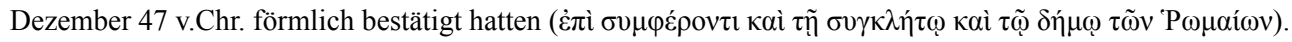


Die Situation im Jahr 46 v.Chr. war es demnach, dass die mündlich erteilte Anordnung Caesars über den Wiederaufbau der Mauern Jerusalems aus der Zeit nach dem Sieg in Aegypten und vor Caesars Rückkehr nach Italien, die über den Inhalt des Senatsbeschlusses aus dem Jahr 48 v.Chr. hinausging, vom Senat nicht bestätigt worden war und ein entsprechendes Dokument weder auf dem Kapitol publiziert noch im aerarium hinterlegt worden war.

An dieser Sachlage änderte sich bis zu einem Antrag Caesars während einer Senatssitzung am Anfang des Jahres 44 v.Chr. in seiner Eigenschaft als imperator IV consul $V$. und ernannter dictator auf Lebenszeit (was auf den Zeitraum zwischen dem 26. Januar und dem 15. Februar 44 v.Chr. führt ${ }^{86}$ offensichtlich nichts. Josephus zitiert aus dem Protokoll der Senatssitzung:

Josephus, ant. 14,10,7 (211-212): ,[211] Gaius Caesar, zum vierten Mal Imperator, zum fünften Mal Konsul, ernannter Diktator auf Lebenszeit, ${ }^{87}$ erklärte in Betreff der Rechte des jüdischen Hohepriesters und Ethnarchen Hyrkanus, des Sohnes des Alexander, Folgendes: [212] In Erwägung, dass die Imperatoren der Provinzen [in der Zeit] vor mir, vor dem Volk und dem Senat (von Rom) dem jüdischen Hohepriester Hyrkanus und den Juden das beste Zeugnis erteilt und das Volk und der Senat (von Rom) denselben ihren Dank erstattet haben, wollen auch wir bedacht und besorgt sein, dass dem Volk der Juden und dem Hyrkanus und seinen Söhnen von dem römischen Senat und Volk für ihre Loyalität und Verdienste uns gegenüber der gebührende Dank zuteil werde.“ (Die Übersetzung mit Modifikationen nach derjenigen von Heinrich Clementz). ${ }^{88}$

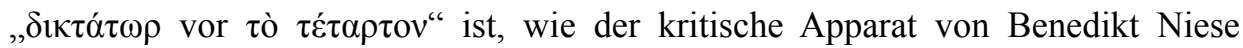
verdeutlicht, ${ }^{89}$ eine Einfügung von Niese in den Text - auch der interpres Latinus hat nur quater imperator. ${ }^{90}$ Nach Cassius Dio 43,49,1 war Caesar am Anfang des Jahres

${ }^{86}$ Pucci Ben Zeev 1998, 103, 105 (vgl. Seeman 2013, 328), die die Senatssitzung auf den 09. Februar 44 v.Chr. datiert und mit der bei Josephus, ant. 14,10,10 (219-222) erwähnten Senatssitzung verbinden möchte, deren senatus consultum bis zur Ermordung Caesars noch nicht im aerarium hinterlegt worden war (und also keine Rechtsgültigkeit erlangt hatte). Oben im Text wird die Meinung vertreten, dass der besagte Senatsbeschluss wohl erst in späterer Zeit erfolgte und sein Inhalt in Josephus, ant. 14,10,5 (200-201) referiert wird. Aber es ist zugegebenermaßen nicht ausgeschlossen, dass Josephus, ant. 14,10,5 (200-201) und 14,10,7 (211-212) in einen Sachzusammenhang gehören und sich also auf die Verhandlung und endliche Beschlussfassung einer Senatssitzung beziehen, die am 09. Februar 44 v.Chr. stattfand.

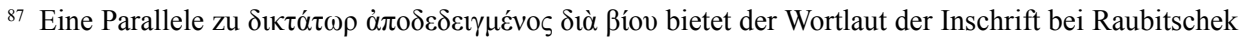
1954, 71 (Thespiai), die zugleich auch belegt, dass Caesar eine Zeit lang im Jahr 46 v.Chr. nur Konsul und Imperator war und im Verlaufe des Jahres auch zum dictator III. erwählt wurde (vgl. auch ILS 6375).

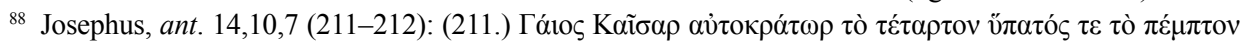

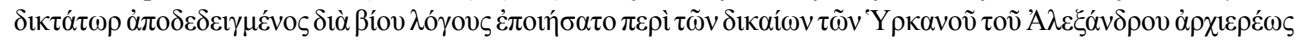

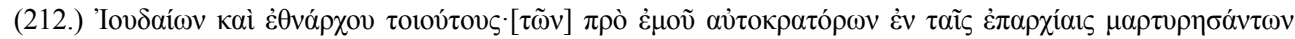

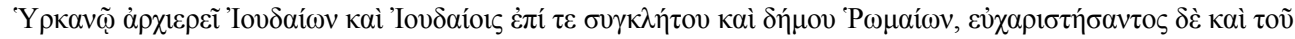

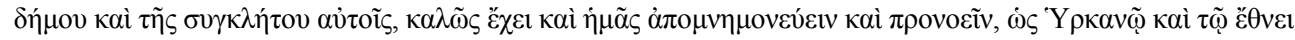

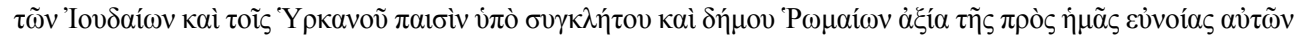

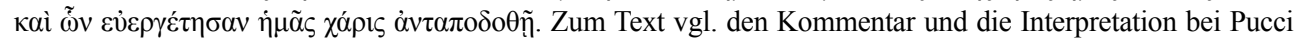
Ben Zeev 1998, 102-106 mit dem Nachweis der älteren Literatur und Pucci Ben Zeev 1996b, 85-86; 1996c, 205-206; 1996d, 251-253 und vgl. aus neuerer Zeit Seeman 2013, 331.

${ }^{89}$ Niese 1892, 278; ebenso bereits zuvor Krebs 1768, 282-283 (die von ihm zur Unterstützung seiner Konjektur herangezogenen Münzen mit C. Caesar Cos. Quinct. Imp. Sext. Dict. Perpetuo bzw. Caesar Augur Imp. Quinct. Cos. Quart. Dict. Quart. Parens Patriae gibt es m.W. nicht).

${ }^{90}$ In der Ausgabe von Karl Wilhelm Dindorf $(1865,554)$ ist $\delta$ i $\tau \dot{\alpha} \tau \omega \rho$ in typographisch eindeutiger

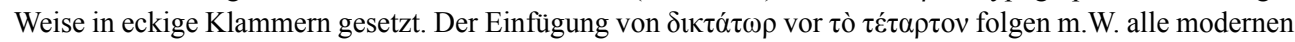


44 v.Chr. zum fünften Mal Diktator und plante eine sechste und siebte Diktatur (Cassius Dio 43,51,7). Erst später fasste Caesar, wenn man dem Verlauf der Darstellung von Cassius Dio folgt, den Plan einer Diktatur auf Lebenszeit (Cassius Dio 44,8,4), den er kurz vor seiner Ermordung dann auch verwirklichte. ${ }^{91}$ Vor dem Hintergrund dieser Schilde-

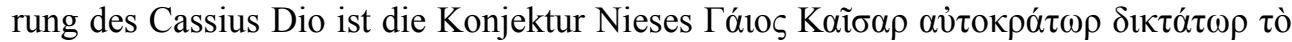

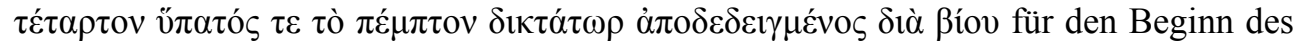

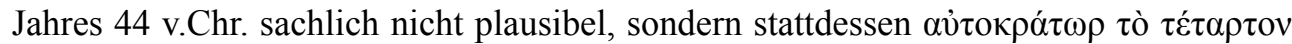

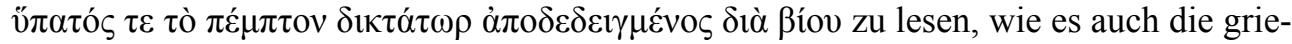
chischen Handschriften überliefern. ${ }^{92}$

Die weiter oben besprochenen Texte bei Josephus (Josephus, ant. 14,10,2 (192-195); 14,10,6 (202-210)), in denen Caesar als imperator II benannt wird, gehören in die Zeit nach dem Sieg über Aegypten und die später darauf folgende Überfahrt Caesars nach Syrien, wie der historische Teil der Darstellung des Josephus verdeutlicht (Josephus, ant. 14,10,3-5 (137-144)). Caesar hat demnach bei vier Gelegenheiten den Imperatortitel für sich in Anspruch genommen: Anlässlich der Siege im Gallischen Krieg (in der Zeit von 54 bis 48/47 v.Chr. imperator ohne Ordinalia), anlässlich des Sieges über Aegypten (27.03.47 v.Chr. Einnahme Alexandrias, imperator II), anlässlich des Sieges über Juba [und die Bürgerkriegsgegner] bei Thapsos (nach dem 06.04.46 v.Chr. imperator III.) und anlässlich des Sieges bei Munda (nach dem 17.03.45 v.Chr. imperator IV.). Nur im Fall des Sieges bei Munda ist die Imperatorenakklamation (ohne die Ordinalia) für Caesar ausdrücklich überliefert (Ps. Caesar, b. Hisp. 19,6),${ }^{93}$ und diese war, weil es seine letzte war, also die vierte Imperatorenakklamation (imperator IV.). Da Caesar im Jahr 46 v.Chr. Triumphe über Gallien, Aegypten, Pharnakes und Juba feierte, sind also die Imperatorenakklamationen II. und III. mit dem Sieg über Aegypten (imperator II) und mit dem Sieg bei Thapsos (imperator III.) zu verbinden. Dies wird zur Seite der im Jahr 46 v.Chr. aktuellen Imperatorenakklamationszählung durch zwei Inschriften bestätigt. Denn Caesar wird in ihnen im Jahr 46 v.Chr. als imperator III (also nach dem Sieg bei Thapsos) benannt. ${ }^{94}$ Wir haben damit zugleich, unabhängig von den Texten des Flavius Josephus,

Interpreten seit Nieses Ausgabe, z.B. Smallwood 1976, 42 A. 68 und Pucci Ben Zeev 1998, 102 (ohne die

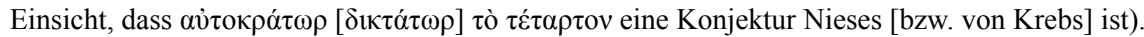

91 Als Quelle für die Darstellung des Cassius Dio wird man an Livius denken, vgl. Radicke 2004, $24-27$.

92 Der Text der vor kurzem von Fausto Zevi publizierten Fasten von Privernum zeigt, dass Caesar nicht zur gleichen Zeit dictator $I V$. und designierter dictator perpetuus war, so dass sich die von Benedikt Niese vorgeschlagene Konjektur auch deshalb verbietet (Zevi 2016, 287-309 insbes. der Text auf Seite 293, 295).

${ }_{93}$ Im bellum Africanum wird Caesar durchweg als Imperator (ohne Ordinalia) benannt, so dass er während des Krieges in Afrika also durchgängig den Titel Imperator trug (Ps. Caesar, b. Afr. 4,3. 35,4. 45,3. 54,5. 88,7).

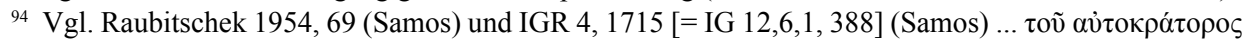

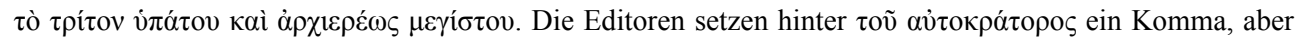
gewöhnlicherweise werden die Ordinalia hinter den Titel gesetzt, so dass $\tau$ ò $\tau \rho \dot{\tau} \tau o v$ sich nicht auf vi $\pi \dot{\tau} \tau o v$,

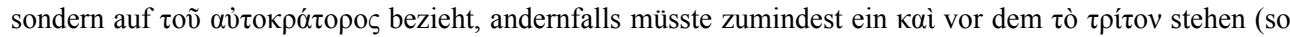
z.B. die entsprechende Diktion bei Syll.3 760). Die Datierung der Inschriften in das erste Viertel des Jahres 46 v.Chr. ergibt sich daraus, dass Caesar in ihnen nicht als Diktator benannt wird, wie es bis zur Schlacht bei Thapsos (06.04.46 v.Chr.) der Fall war (vgl. CIL 1, 2967 = AE 1967, 107 aus Vibo Valentia, wo ebenfalls der dictator III fehlt und Caesar nur als pontifex maximus imperator consul III benannt wird; vgl. auch ILS 6375). Denn erst nach der Schlacht wurde Caesar in Rom zum dictator III ernannt, wobei zugleich beschlossen wurde, dass er die Diktatur in den nächsten zehn Jahren innehaben sollte (Cassius Dio 43,14,4; vgl. Andersen 1938, 23-25; vgl. Raubitschek 1954, 70). 
zumindest zwei weitere Belege dafür, dass für Caesar in der Zeit des Bürgerkrieges seine Ausrufungen zum Imperator gelegentlich mit den Ordinalia angegeben wurden. ${ }^{95}$

Der Wortlaut des oben zitierten Antrags Caesars (Josephus, ant. 14,10,7 (211)) gibt den vom Senat empfangenen Gesandten des Hyrkanus II. nun zumindest die Zuversicht, dass Caesar vom Senat und von der Volksversammlung (!) die Bestätigung der ehedem erlassenen Anordnung erwirken wolle. Dies wurde von Caesar durchgesetzt; denn sein letztes Edikt, das kurz vor seinem Tod erlassen wird, bestätigt die Erlaubnis zum Wiederaufbau der Mauern Jerusalems und zudem werden die Regeln der zukünftigen Steuer- und Abgabenerhebung Roms in Judäa definiert. Josephus zitiert z.T. aus dem Text des Ediktes (Tem-

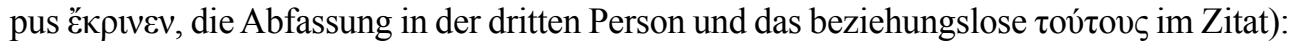

Josephus, ant. 14,10,5 (200-201): [200] Gaius Caesar, zum fünften Mal Konsul, verordnet hiermit, dass diesen [i.e. Hyrkanus II. und seinen Kindern] erlaubt sein soll, die Stadt Jerusalem besetzt zu halten und zu befestigen, ferner dass der jüdische Hohepriester und Ethnarch Hyrkanus, Alexanders Sohn, dieselbe [i.e. die Stadt Jerusalem] in Besitz nehmen darf, wie es ihm beliebt, [201] und dass man den Juden in jedem zweiten Jahre von den Getreide-Abgaben ein Kor erlässt und man sie weder zu Abgaben heranzieht noch sie dieselben Abgaben zahlen. (Die Übersetzung unter Zugrundelegung derjenigen von Heinrich Clementz). ${ }^{96}$

${ }_{95}$ Der Imperatoren-Titel wurde Caesar in der Zeit des Bürgerkrieges dem Anschein nach zwar in den Inschriften gewöhnlich ohne die Ordinalia angegeben (so Pucci Ben Zeev 1998, 84 mit der Literatur dazu; vgl. Combès 1966, 109; Freber 1993, 189-194), aber dies war offensichtlich keine durchweg geübte Praxis. Die modernen Deutungen, wonach Caesar den Imperatortitel quasi als Cognomen ohne die Ordinalia geführt habe, werden mit dieser Beobachtung zumindest relativiert (Deininger 1972, 990-991; Freber 1993, 29). Caesar hat den Imperatorentitel gelegentlich auch mit den Ordinalia geführt, wie insbesondere die Texte des Josephus zeigen. Das Fehlen der Ordinalia beim Imperatortitel in der Münzdokumentation und in der Mehrzahl der Inschriftendokumentation wird man nach meiner Ansicht am ehesten darauf zurückführen, dass die Ordinalia beim Imperatortitel zum (zeitgenössischen) Zweck der zeitlichen Bestimmung der Münzen und Inschriften entbehrlich waren (contra: Deininger 1972, 990-991 (mit der älteren Literatur)); denn die Angaben consul II oder consul III usw. waren für diesen Zweck vollkommen ausreichend (die Ehreninschriften mit einer Titulatur Caesars, vgl. die Sammlungen bei Raubitschek 1954, 65-75; Robert 1955, 257-260; Freber 1993, 189-194).

Pierre Assenmaker $(2012,111-142)$ vertritt neuerdings die m.E. zutreffende Meinung, dass der Titel imperator erst seit dem 1. Jh. v.Chr. in zweierlei Bedeutung verwendet wurde (siehe auch Zack 2001/2007, 152 A. 700 zum praenomen imperatoris) - als Titel des von den Soldaten akklamierten siegreichen Feldherren (mit Itarationsangabe) und als Titel des mit dem imperium ausgestatteten Feldherren, wobei die letztere Bedeutung die ältere Bedeutung des Titels gewesen sei (ohne Iterationsangabe; siehe zu dieser Unterscheidung neben Cassius Dio 43,44,2 auch Appian praef. 6 [23]); auch eine Durchsicht der Belegstellen zum Wort imperator bei Livius (z.B. mit Hilfe von: www.brepolis.net bestätigt diese zweite [und ältere] Wortbedeutung von imperator). Im Fall der im vorliegenden Aufsatz behandelten Texte des Josephus wird der Titel des Imperators allerdings als solcher gebraucht, der in der Hauptsache auf die Imperatorakklamtionen rekurriert, wobei die Iterationsziffern offensichtlich nur dann angeben wurden, wenn sie für die Zwecke der chronologischen Verortung notwendig waren.

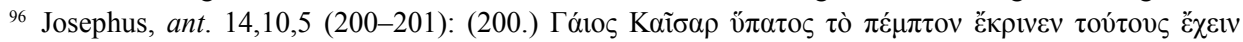

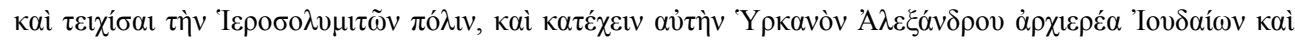

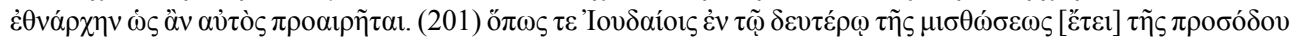

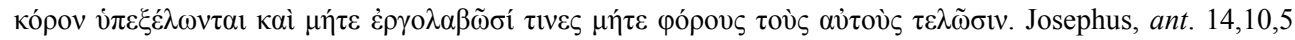

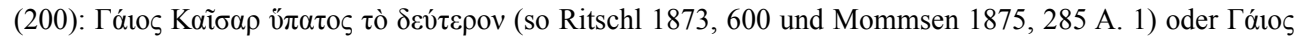

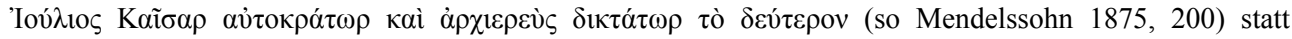
Га́ danken getragen, dass es unmöglich sei, dass Caesar die bereits 47 v.Chr. gewährte Erlaubnis zum Wiederaufbau der Mauern Jerusalems, der von Hyrkanus II. sofort begonnen wurde, erst im Jahr 44 v.Chr. mit einem Edikt bestätigte. Vergegenwärtigt man sich aber, dass es für Caesar im Jahr 47 v.Chr. keine Gelegenheit gab, diese über den Senatsbeschluss des Jahres 48 v.Chr. hinausgehende Anordnung in einem innerrömischen 
Das Edikt war von Caesar noch zu seinen Lebzeiten erlassen worden, es war aber, ebenso wie das zugehörige senatus consultum, ${ }^{97}$ wegen der zwischenzeitlichen Ermordung Caesars und den darauf folgenden Wirren in Rom nicht im aerarium hinterlegt worden. Deshalb erwirken die Konsuln des Jahres 44 v.Chr., M. Antonius und P. Cornelius Dolabella, nach der Ermordung Caesars am 11. April 44 v.Chr. einen Senatsbeschluss, demzufolge der dem letzten Edikt Caesars zugehörige Senatsbeschluss nun auch im aerarium hinterlegt wird und damit zugleich Rechtsgültigkeit erhält. Josephus übersetzt bzw. zitiert - den Orginaltext verkürzend (so übezeugend Pucci Ben Zeev 1994a, 32-33) $)^{98}$ - aus dem Text einer lateinischen oder griechischen Abschrift des Registrierungsexemplars, das für das aerarium auf lateinisch angefertigt worden war:

Josephus, ant. 14,10,10 (219-222): [219] Senatsbeschluss, als Abschrift entnommen aus dem aerarium und aus den öffentlichen Tafeln der Quästoren, unter den städtischen Quästoren Quintus Rutilius und Gajus Cornelius, <und zwar aus der zweiten Tafel die erste Columne>.99 Drei Tage vor den Iden des April (11. April) waren im Tempel der Concordia [220] bei der Niederschrift zugegen Lucius Calpurnius Piso aus der Menenischen Tribus, Servius Papinius Quintus aus der Lemonischen Tribus, Gajus Caninius Rebilius aus der Terentinischen Tribus, Publius Tidetius, Sohn des Lucius aus der Pollischen Tribus und Lucius Apulius, aus der Sergischen Tribus, Flavius, Sohnes des Lucius aus der Lemonischen Tribus, Publius Plautius, Sohnes des Publius aus der Papirischen Tribus, Marcus Sellius, Sohnes des Marcus aus der Maecischen Tribus, Lucius Erucius, Sohn des Lucius aus der Stellatinischen Tribus, Marcus Quintius Plancinus, Sohn des Marcus, aus der Pollischen Tribus und [221] Publius Serius.* Die Konsuln Publius Dolabella und Marcus Antonius hielten den Vortrag. Wegen der Entscheidungen, die Gaius Caesar in Übereinstimmung mit dem Senat wegen der Juden traf, die er aber [schließlich] nicht im aerarium hinterlegen konnte, gefällt es uns, wie es auch die Konsuln Publius Dolabella und Marcus Antonius beschlossen haben, dass diese auf Tafeln geschrieben werden und zu den städtischen Quästoren gebracht werden, damit diese dafür Sorge tragen, dass [die Beschlüsse] auf Tafeln in der Form von Diptychen geschrieben werden. [222] Dies

Ratifikationsprozess bestätigen zu lassen, dann ergab sich tatsächlich erst im Jahr 44 v.Chr. die praktische Möglichkeit für Caesar (der nach den Feldzügen in Afrika und Spanien nun wieder für längere Zeit in Rom weilte), die Bestätigung seiner Anordnung aus dem Jahr 47 v.Chr. von Senat und Volk Roms zu erreichen.

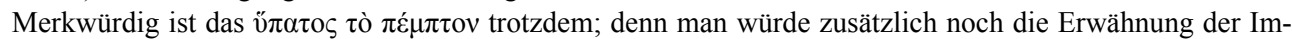
peratorentitel und Diktatortitel erwarten. Erließ Caesar das Edikt in seiner Eigenschaft Konsul und wurden deshalb die anderen Titel weggelassen? Kürzt Josephus die Titulatur seiner Vorlage? Für die Zwecke der chronologischen Bestimmung war $\tilde{\pi} \alpha \tau$ moderne Interpret halten müssen. Der Text der vor kurzem von Fausto Zevi publizierten Fasten von Privernum lässt die Deutung zu, dass Caesar im Jahr 44 v.Chr. eine Zeit lang nur consul $V$. war und nicht auch schon eingesetzter (= titularer) dictator perpetuus und es ist möglich, dass die merkwürdige Titulatur Caesars im Dokument so eine Erklärung fände (Zevi 2016, 287-309 insbes. der Text auf Seite 293, 295). Zum Text des Dokumentes vgl. den Kommentar und die Interpretation bei Pucci Ben Zeev 1998, 74-79 mit dem Nachweis der älteren Literatur und Pucci Ben Zeev 1996b, 81-82; Pucci Ben Zeev 1996c, 202-203 und aus neuerer Zeit Seeman 2013, 328.

${ }^{97}$ Ein magistratisches Edikt folgt auf einen vorherigen Senatsbeschluss, vgl. beispielsweise schon die Praxis in der ersten Hälfte des 2. Jh. v.Chr.: ILS 18, Z. $2-3$.

${ }_{98}^{98}$ Pucci Ben Zeev 1998, 121-136, 135-136 (zur Frage der Authentizität des Dokumentes) mit dem Nachweis der älteren Literatur und Pucci Ben Zeev 1994a, 31-40, 39-40 (Fazit).

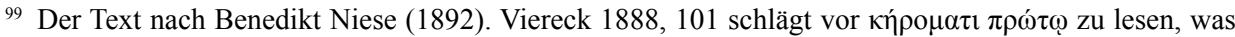
heute allgemein akzeptiert wird (Pucci Ben Zeev 1998, 124; Pucci Ben Zeev 1994a, 33-34) und womit der Text des Josephus in der Konsequenz zu erkennen gibt, dass er eine griechische oder lateinische Abschrift eines Dokumentes zur Vorlage hat, die im aerarium im Jahr 44 v.Chr. nach dem senatus consultum vom 11. April registriert worden war (Pucci Ben Zeev 1998, 124, 128-129, 130). 
[die Entscheidungen Caesars in Übereinstimmung mit dem Senat] geschah am fünften Tag vor den Iden des Februar (9. Februar 44 v.Chr.) im Tempel der Concordia. Anwesend waren als Gesandte des Hohepriesters Hyrkanus: Lysimachus, Sohn des Pausanias, Alexander, Sohn des Theodorus, Patroclus, Sohn des Chaerea, und Jonathas, Sohn des Onias. (Übersetzung in Anlehnung an diejenige von Miriam Pucci Ben Zeev). ${ }^{100}$

Die Hinterlegung des Senatsbeschlusses im aerarium (= Bestätigung seiner rechtlichen Gültigkeit), dessen Ergebnis Caesar vor seiner Ermordung bereits mit einen Edikt bekannt gegeben hatte (Josephus, ant. 14,10,5 (200-201)), war ein vorläufiger Erfolg für Hyrkanus II. Erstens war damit das Besetzungsrecht für Hyrkanus II. in Jerusalem gesichert. Zweitens bestätigte der Senat das im Jahr 47 v.Chr. von Caesar zwar schon versprochene, aber zwischenzeitlich vom Senat noch nicht gebilligte Befestigungsrecht für Jerusalem. Drittens erreichte Hyrkanus II. eine Erleichterung der Getreideabgaben seines Herrschaftsgebietes an Rom und viertens erreichte er das Ende von Verpachtungen und Abgaben der Juden zugunsten Roms in seinem Herrschaftsgebiet. Nimmt man diese Bestimmungen mit denen des Jahres 47 v.Chr. zusammen, dann hatte Hyrkanus II. in den Jahren 47 bis 44 v.Chr. nach innen und außen zumindest für den Moment eine umfassende und konkrete Regulierung seiner Herrschaftsrechte als Hohepriester und Ethnarch erreicht, wie er sie seit den Anordnungen des Pompeius und A. Gabinius gegenüber den Einwohnern seines Herrschaftsgebietes nur beanspruchen aber nicht als von Rom garantiertes Recht ausüben konnte. Die strukturellen Voraussetzungen für die endliche Wiedereinrichtung des von Pompeius abgeschafften Königtums in Judäa waren damit im Kern geschaffen, das aber in Zukunft nur noch ein Königtum vom Roms Gnaden sein konnte und an den rechtlichen Status des Ethnarchen anknüpfen musste und nicht an die Rechte des traditionellen jüdischen Königstums der Zeit vor Hyrkanus II. ${ }^{101}$

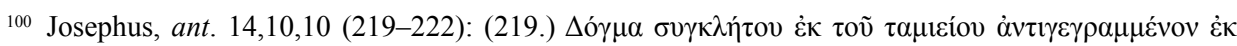

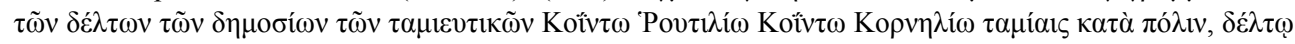

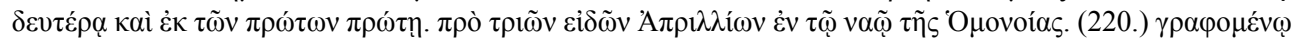

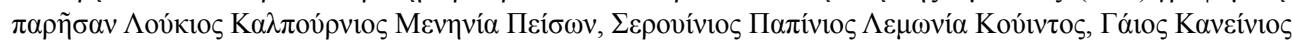

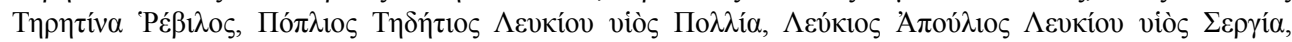

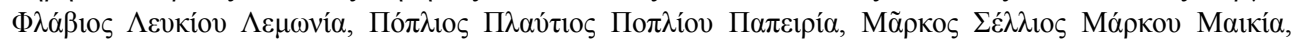

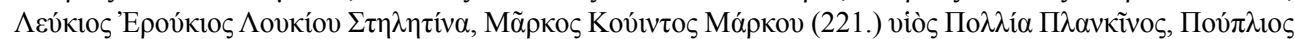

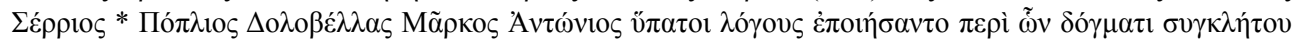

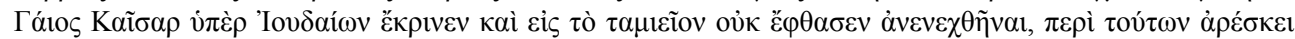

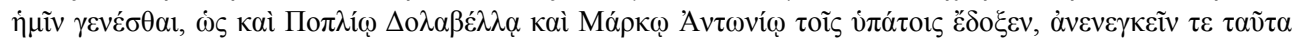

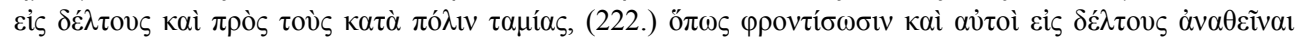

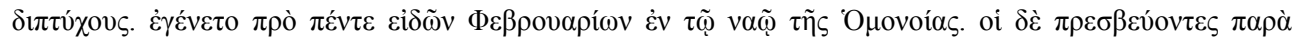

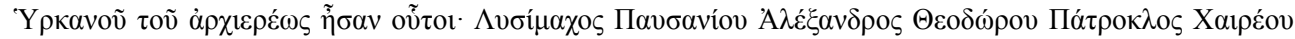

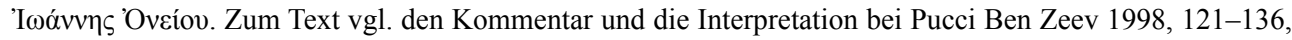
135-136 (zur Frage der Authentizität des Dokumentes) mit dem Nachweis der älteren Literatur und Pucci Ben Zeev 1994a, 31-40, 39-40 (Fazit); Seeman 2013, 343-345. In den Zusammenhang der nach Caesars Ermordung noch ausstehenden Bestätigung seiner acta bzgl. der Juden gehört wohl auch die Nachricht bei Sueton, Caes. 84,5, wonach Ausländer und insbesondere die Juden nach der Einäscherung Caesars noch viele Nächte den niedergebrannten Scheiterhaufen in Rom trauernd besuchten.

101 Zur rechtlichen Stellung Judäas im Imperium Romanum nach den Regulierungen der Jahre 47 bis 44 v.Chr., vgl. Schalit 1969, 148-155, 155: „Diese syrischen Städte und ebenso die Ethnarchie des Hyrkanos hielten also eine Zwischenstellung inne: Sie zählten zwar zu den Rom unterworfenen Gebieten, aber ihr Status wies eine staatsrechtliche Entwicklung in Richtung auf die von Tributen befreiten Städte auf.“ 


\section{Addenda}

I. Es gibt eine Inschrift, die man in Opposition zu der im Beitrag vertretenen Deutung so interpretieren könnte, dass Caesar im Jahr 48 v.Chr. als Konsul und Diktator II benannt worden wäre $(I G R$ 4, 929). Aber der Autor des Beitrages hält es vor dem Hintergrund der weiteren Inschriftendokumentation der Jahre 48-47 v.Chr. für möglich, dass die Inschrift in das Jahr 47 v.Chr. (2. Hälfte) oder sogar 46 v.Chr. (so Cagnat "forsitan") gehört, bzw. dass sie in den Kontext des Triumphes Caesars im Jahr 46 v.Chr. gehört, anlässlich dessen bei den Feierlichkeiten auf die ersten zwei Diktaturen Caesars ausdrücklich Bezug genommen wurde. Die These des Beitrages ist es, dass Caesar in öffentlichen Dokumenten vom Herbst 48 v.Chr. bis zum Spätsommer 47 v.Chr. aus zeremoniellen Gründen sich selbst (!) nicht als Diktator benannte. Bei der besagten Inschrift handelt es sich aber um eine Fremdbenennung Caesars, so dass - auch wenn sie in das Jahr 48 v.Chr. gehören sollte - sie nach der Ansicht des Autors kein zwingendes Argument gegen die im vorliegenden Beitrag vertretene Deutung darstellt.

II. Raubitschek, JRS 44, 1954, 71 (Thespiai) belegt zumindest für die dritte Diktatur Caesars, dass zwischen der Ernennung Caesars zum Diktator und seiner Einsetzung als Diktator ein Zeitraum verging. Das könnte man als zusätzlichen Beleg für die im Beitrag vertretene Unterscheidung von Wahl und Einsetzung (auf ager Romanus und erst dann Annahme des Titels) betrachten. 


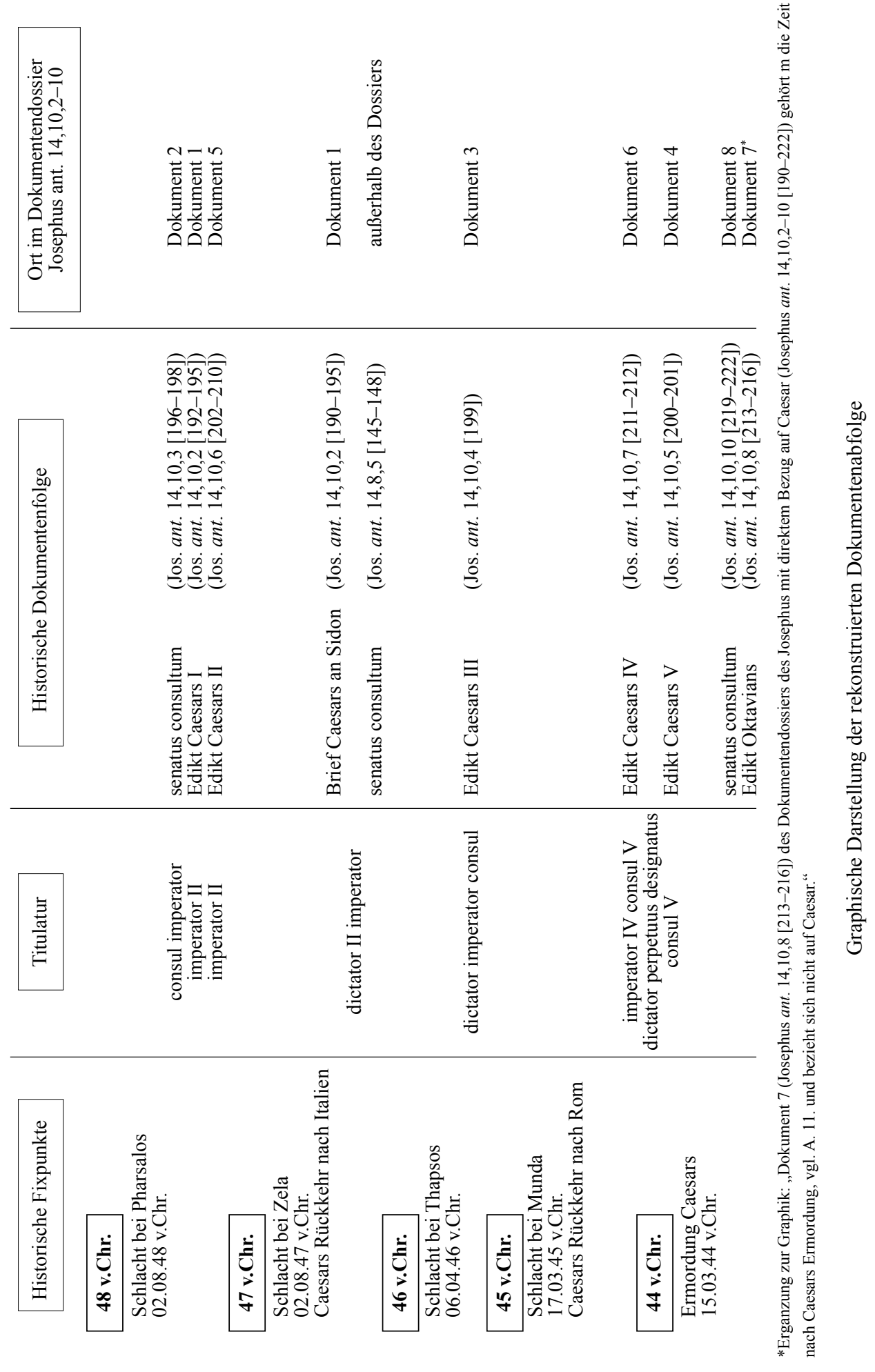




\section{LITERATURVERZEICHNIS}

Andersen, H.A. (1938), Cassius Dio und die Begründung des Prinzipates, Berlin.

Assenmaker, P. (2012), Nouvelles perspectives sur le titre d' imperator et l'appellatio imperatoria sous la République, $R B P h H$ 90: 111-142.

Avram, A. (2009), Le traité et sa publication : serment, tables de bronze et copies affichées sur des stèles, CCG 20: 211-232.

Baumann, U. (1983), Rom und die Juden. Die römisch-jüdischen Beziehungen von Pompeius bis zum Tode des Herodes (63 v.Chr.-4 v.Chr.), Frankfurt a.M.

Bickermann, E. (1955), Une question d' authenticité : Les privilèges juifs, in: Mélanges Isidore Levy, Brüssel: 11-34.

Broughton, T.R.S. (1951/1952), The Magistrates of the Roman Republic, 2 Bde., Chicago, Il.

Büchler, A. (1896), Die prieserlichen Zehnten und die römischen Steuern in den Erlassen Caesars, in: Festschrift zum achtzigsten Geburtstage Moritz Steinschneiders, Leipzig: 91-109.

Canali De Rossi, F. (2000), Le ambascerie Romane ad gentes in èta regia e repubblicana, Rom.

Combès, R. (1966), Imperator. Recherches sur l'emploi et la signification du titre d'imperator dans la Rome républicaine, Paris.

Crawford, M. (1974), Roman Republican Coinage, 2 Bde., Cambridge.

Degrassi, A. (Hg.) (1954), Fasti Capitolini, Turin.

Deininger, J. (1972), Von der Republik zur Monarchie: Die Ursprünge der Herrschertitulatur des Prinzipats, $A N R W$ I,1: 982-997.

Dindorf, W. (Hg.) (1865), Flavii Josephi, Opera, Bd. 1, Paris.

Eckhardt, B. (2013), Ethnos und Herrschaft. Politische Figurationen judäischer Identität von Antiochos III. bis Herodes I., Berlin.

Fischer, Th. (1970), Untersuchungen zum Partherkrieg Antiochos 'VII. im Rahmen der Seleukidengeschichte, Tübingen.

Freber, Ph.-St. G. (1993), Der hellenistische Osten und das Illyricum unter Caesar, Stuttgart.

Gauger, J.-D. (1977), Beiträge zur jüdischen Apologetik. Untersuchungen zur Authentizität von Urkunden bei Flavius Josephus und im I. Makkabäerbuch, Köln-Bonn.

Giovannini, A., Müller, H. (1971), Die Beziehungen zwischen Rom und den Juden im 2. Jh. v.Chr., MH 28: 156-171.

Grätz, H. (1905), Geschichte der Juden von den ältesten Zeiten bis auf die Gegenwart, Bd. 3, 5 Aufl., Leipzig.

Gruen, E.S. (2002), Diaspora: Jews amidst Greeks and Romans, Cambridge, Mass.

Haverkamp, S. (1726), Flavii Josephi opera omnia graece et latine..., Bd. 1-2, Amsterdam.

Heinen, H. (1966), Rom und Ägypten von 51 bis 47 v.Chr., Tübingen.

Holmes, T.R. (1923), The Roman Republic and the Founder of the Empire, Bd. 2, Oxford.

Huschke, Ph.E., Seckel, E., Kübler, B. (1988), Iurisprudentiae anteiustinianae reliquias in usum maxime academicum compositas a $\mathrm{Ph}$. Eduardo Huschke, editione sexta aucta et emendata ediderunt E. Seckel et B. Kübler, 2 Bde., Leipzig.

Judeich, W. (1885), Caesar im Orient. Kritische Übersicht der Ereignisse vom 9. August 48 v.Chr. bis Oktober 47, Leipzig.

Juster, J. (1914), Les Juifs dans l'Empire romain : leur condition juridique, economique et sociale, Bd. 1-2, Paris.

Kantor, G. (2014), Roman Treaty with Lycia (SEG LV 1452) and the Date of Caesar's Third Dictatorship, ZPE 190: 135-136.

Kaser, M. (1956), Eigentum und Besitz im älteren Römischen Recht, 2 Aufl., München.

Krebs, J.T. (1768), Decreta Romanorum pro Judeis facta e Josepho collecta et commentario historicocritico illustrata, Leipzig. 
Kunkel, W., Galsterer, H., Meier, Chr., Wittmann, R. (Hgg.) (1995), Staatsordnung und Staatspraxis der Römischen Republik. Zweiter Abschnitt: Die Magistratur, München.

Marcus, R. (1943), Josephus, Jewish antiquities 14-15, Cambridge, Mass. (ND 1998).

Marcus, R. (Hg./Übers.) (1966), Josephus, Jewish Antiquities, Books XII-XIV, Cambridge.

Mason, H.J. (1974), Greek Terms for Roman Institutions: A Lexicon and Analysis, Toronto.

Mendelssohn, L. (1875), Senati Consulta Romanorum quae sunt in Josephi Antiquitatibus, Acta Societatis Philologae Lipsiensis 5: 87-288 (mit der Rezension von E. Schürer (1876), Theologische Literaturzeitung 15, 390-396).

Mendelssohn, L. (1877), Zu den Urkunden bei Josephus, RhM 32: 249-258.

Mendelssohn, L., Ritschl, F. (1875), Nochmals der römische Senatsbeschluss bei Josephus ant. XIV, 8,5, RhM 30: 419-435.

Mitchell, S. (2005), The Treaty between Rome and Lycia of 46 BC (MS 2070), in: R. Pintaudi (Hg.), Papyri Graecae Schøyen I (Papyrologica Florentina XXXV), Florenz: 161-259.

Moehring, H.R. (1975), The Acta pro Judaeis in the Antiquitates of Flavius Josephus, in: J. Neusner (ed.), Christianity, Judaism and other Greco-Roman Cults: Studies for Morton Smith at Sixty, Leiden: $133-157$.

Momigliano, A. (1934/1967), Ricerche sull'organizzazione della Guidea sotto in dominio Romano (63 a.C.-70 d.C.), Bologna [ND Amsterdam 1967].

Mommsen, Th. (1875), Der Senatsbeschluss bei Josephus ant. 14,8,5, Hermes 9: 281-291.

Mommsen, Th. (1887), Römisches Staatsrecht, Bd. 1-2 (3 Aufl.), 3, Leipzig.

Niese, B. (1876), Bemerkungen über die Urkunden bei Josephus Archaeol. B. XIII. XIV. XVI., Hermes 11: 466-488.

Niese, B. (1892), Flavii Josephi opera edidit et apparatur critico instruxit, Bd. 3, Berlin.

Oakley, S.P. (1997-2005), A Commentary on Livy: Books VI-X [Bd. 1 (1997), 2 (1998), 3 (2005), 4 (2007)], Oxford.

Premerstein, A. von (1925), legatus, RE 12,1: 1133-1149.

Pucci Ben Zeev, M. (1994a), Publius Dolabella, Marcus Antonius and the Jews, Athenaeum 82: 31-40.

Pucci Ben Zeev, M. (1994b), Greek and Roman Documents from Republican Times in the Antiquities: What was Josephus' Source, SCI 13: 46-59.

Pucci Ben Zeev, M. (1995), Josephus, Bronze Tablets and Greek Inscriptions, AC 64: 211-215.

Pucci Ben Zeev, M. (1996a), Polybius, Josephus, and the Capitol in Rome, JSJ 27: 21-30.

Pucci Ben Zeev, M. (1996b), Caesar's Decrees in the Antiquities: Iosephus' Forgeries or Authentic Roman senatus consulta?, Athenaeum 84: 71-91.

Pucci Ben Zeev, M. (1996c), Ant. 14. 186-267: A Problem of Authenticity, in: Classical Studies in Honor of David Sohlberg, Jerusalem: 193-221.

Pucci Ben Zeev, M. (1996d), When was the Title dictator perpetuus given to Caesar?, AC 69: 251-253.

Pucci Ben Zeev, M. (1998), Jewish Rights in the Roman World: The Greek and Roman Documents Quoted by Josephus Flavius, Tübingen (dazu die Rezensionen: I. Shatzman, SCI 19, 2000, 308311; P. Cecarelli, Gnomon 73, 2001, 684-688; J. Sievers, JSJ 32, 2001, 337-340; M. Hadas-Lebel, REJ 160, 2001, 277-279).

Radicke, J. (2004), Lucans poetische Technik. Studien zum historischen Epos, Leiden-Boston.

Rajak, T. (1978), Jewish Rights in the Greek Cities under Roman Rule: A New Approach, in: W. Scott Green (Hg.), Approaches to Ancient Judaisms, Bd. 5: Studies in Judaism and its Greco-Roman Context, Grand Rapids: 19-35.

Rajak, T. (2001), The Jewish Dialogue with Greece and Rome: Studies in Cultural and Social Interaction, Leiden-Boston.

Raubitschek, A.E. (1954), Epigraphical Notes on Julius Caesar, JRS 44: 65-75.

Ritschl, F. (1873), Eine Berichtigung der republikanischen Consularfasten. Zugleich als Beitrag zur Geschichte der römisch-jüdischen internationalen Beziehungen, RhM 28: 586-614.

Ritschl, F. (1874), Römische Senatusconsulte bei Josephus, RhM 29: 337-344.

Robert, L. (1955), Inscriptions en l' honneur de César, in: L. Robert, Hellenica 10, Paris: 257-260. 
Roth, O. (1914), Rom und die Hasmonäer. Untersuchungen zu den jüdisch-römischen Urkunden im ersten Makkabäerbuche und in Josephus 'Jüdischen Altertümern XIV, Leipzig.

Saulnier, Chr. (1981), Lois Romaines sur les Juifs selon Flavius Joséphe, Revue Biblique 88: 161-198.

Scaliger, J. (1658), Animadversiones in chronologica Eusebii (apud Joannem Janssonium), Rom.

Schalit, A. (1969), König Herodes. Der Mann und sein Werk, Berlin.

Schuol, M. (2007), Augustus und die Juden. Rechtsstellung und Integrationspolitik der kleinasiatischen Diaspora, Frankfurt a.M.

Schürer, E. (1890), Geschichte des jüdischen Volkes im Zeitalter Jesu Christi, Bd. 1, 2 Aufl., Leipzig.

Seeman, Chr. (2013), Rome and Judea in Transition: Hasmonean Relations with the Roman Republic and the Evolution of the High Priesthood, New York.

Sharon, N. (2010), The Title Ethnarch in the Second Temple Period Judea, Journal for the Study of Judaism 41: 472-493.

Sherk, R.K. (1969), Roman Documents from the Greek East: Senatus Consulta and Epistulae to the Age of Augustus, Baltimore.

Smallwood, E.M. (1976), The Jews under Roman Rule: From Pompey to Diocletian, Leiden.

Täubler, E. (1913), Imperium Romanum. Studien zur Entwicklungsgeschichte des Römischen Reiches, Leipzig.

Unger, G. (1894), Zu Josephus, Sitzungsberichte der philosophisch-philologischen-historischen Classe der königlich bayrischen Akademie der Wissenschaften zu München: 551-604.

Ungern-Sternberg, J. von (1975), Capua im zweiten Punischen Krieg. Untersuchungen zur römischen Annalistik, München.

VanderKam, J.C. (2004), From Joshua to Caiaphas: High Priests after the Exile, Minneapolis-Assen.

Vermes, G., Millar, F., Schürer, E. (Hgg.) (1973), The History of the Jewish People in the Age of Jesus Christ (175 B.C.-A.D. 135), Bd. 1, Edinburgh.

Viereck, P., (1888), Sermo Graecus quo Senatus Populusque Romanus Magistratusque Populi Romani usque ad Tiberii Caesaris Aetatem in Scriptis Publicis usi sunt examinatur, Göttingen.

Ward, G., Eilers, C. (2012), An Embedded Fragment in Josephus' Caesarian Acta (AJ 14,196-212), Phoenix 56: 414-427.

Weissenborn, W., Müller, H.J. (Hgg./Komment.), T. Livi ab urbe condita libri, Bd. 4, Buch 21-23 (Berlin $\left.{ }^{9} 1900\right)$; Bd. 5, Buch 24-26 (Berlin $\left.{ }^{5} 1895 / 1911\right)$; Bd. 6, Buch 27-30 (Berlin $\left.{ }^{4} 1899-1910\right)$; Bd. 7 ,

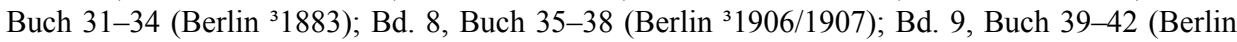
$\left.{ }^{3} 1909\right)$; Bd. 10, Buch 43-45; T. Livi Periochae et fragmenta. Iulii Obsequentis ab anno urbis conditae DV Prodigorum liber, Berlin ${ }^{2} 1880 / 1881$.

Zack, A. (2001/2007), Studien zum „Römischen Völkerrecht“. Kriegserklärung, Kriegsbeschluss, Beeidung und Ratifikation zwischenstaatlicher Verträge, internationale Freundschaft und Feindschaft während der römischen Republik bis zum Beginn des Prinzipats, 1 Aufl. (2001), 2 Aufl. (2007), Göttingen.

Zack, A. (2011), Forschungen über die rechtlichen Grundlagen der römischen Außenbeziehungen während der Republik bis zum Beginn des Prinzipats, I. Teil: Fragen an Sextus Pomponius: Quellenund sachkritische Untersuchungen zu Pomponius 37. lib. ad Muc. D. 49,15,5, Göttinger Forum für Altertumswissenschaft 14: 47-119 (http://gfa.gbv.de/dr,gfa,014,2011,a,06.pdf).

Zack, A. (2012), Forschungen über die rechtlichen Grundlagen der römischen Außenbeziehungen während der Republik bis zum Beginn des Prinzipats, II. Teil: Fragen an Varro de lingua Latina 5,33: die augurale Ordnung des Raumes, Göttinger Forum für Altertumswissenschaft 15: 61-128 (http:// gfa.gbv.de/dr,gfa,015,2012,a,02.pdf).

Zack, A. (2013), Forschungen über die rechtlichen Grundlagen der römischen Außenbeziehungen während der Republik bis zum Beginn des Prinzipats, III. Teil: Der personenrechtliche Status der amici, socii und amici et socii und die formula amicorum und formula sociorum, Göttinger Forum für Altertumswissenschaft 16: 63-103 (http://gfa.gbv.de/dr,gfa,016,2013,a,07.pdf).

Zack, A. (2014a), Forschungen über die rechtlichen Grundlagen der römischen Außenbeziehungen während der Republik bis zum Beginn des Prinzipats, IV. Teil: Der Unterschied zwischen den 
civitates foederatae und den civitates liberae. Der Personenstand einer Bürgerschaft und der Gemeindestatus, Göttinger Forum für Altertumswissenschaft 17: 131-180 (http://gfa.gbv.de/ dr,gfa,017,2014,a,07.pdf).

Zack, A. (2014b), Forschungen über die rechtlichen Grundlagen der römischen Außenbeziehungen während der Republik bis zum Beginn des Prinzipats, V. Teil: Das Ius Italicum und die kaiserzeitliche Befreiung des provinzialen Grundbesitzes von der Besteuerung: eine Kritik der Deutung von Friedrich Carl von Savigny, Göttinger Forum für Altertumswissenschaft 17: 247-308 (https://gfa. gbv.de/dr,gfa,017,2014,a,10.pdf).

Zack, A. (2015a), Forschungen über die rechtlichen Grundlagen der römischen Außenbeziehungen während der Republik bis zum Beginn des Prinzipats, VI. Teil: Die juristische Form und der rechtliche Gehalt der intergesellschaftlichen amicitia und amicitia et societas mit Rom. Erster Abschnitt: die Begrifflichkeit und die aus ihr zu erschließende Systematik der rechtlichen Formen, Göttinger Forum für Altertumswissenschaft 18: 27-83 (https://gfa.gbv.de/dr,gfa,018,2015,a,03.pdf).

Zack, A. (2015b), Forschungen über die rechtlichen Grundlagen der römischen Außenbeziehungen während der Republik bis zum Beginn des Prinzipats, VII. Teil: Die juristische Form und der rechtliche Gehalt der intergesellschaftlichen amicitia und amicitia et societas mit Rom. Zweiter Abschnitt: die „Urkundenhandlung“ der Dokumente, Göttinger Forum für Altertumswissenschaft 18: $115-178$.

Zevi, F. (2016), I fasti di Privernum, ZPE 197: 287-309. 